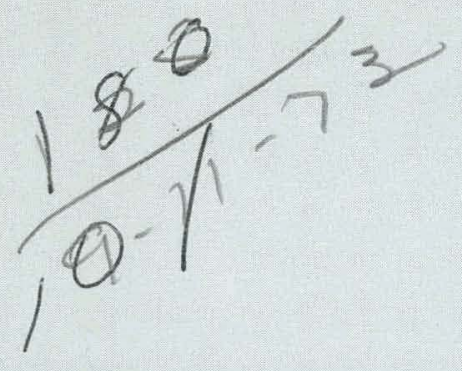

4h. 352

Y-1883

\title{
ULTRASONIC NONDESTRUCTIVE TESTING SYSTEM AUTOMATION
}

D. H. Gray

D. M. Darby

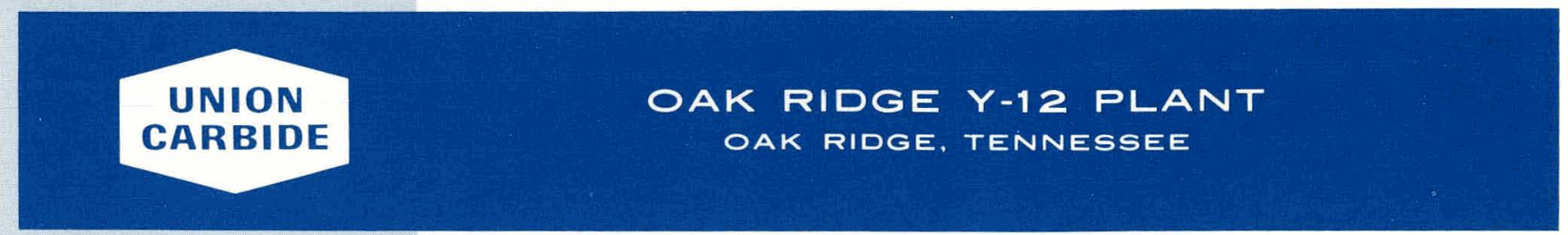

prepared for the U.S. ATOMIC ENERGY COMMISSION

under U.S. GOVERNMENT Contract W.7405 eng 26 


\section{DISCLAIMER}

This report was prepared as an account of work sponsored by an agency of the United States Government. Neither the United States Government nor any agency Thereof, nor any of their employees, makes any warranty, express or implied, or assumes any legal liability or responsibility for the accuracy, completeness, or usefulness of any information, apparatus, product, or process disclosed, or represents that its use would not infringe privately owned rights. Reference herein to any specific commercial product, process, or service by trade name, trademark, manufacturer, or otherwise does not necessarily constitute or imply its endorsement, recommendation, or favoring by the United States Government or any agency thereof. The views and opinions of authors expressed herein do not necessarily state or reflect those of the United States Government or any agency thereof. 


\section{DISCLAIMER}

Portions of this document may be illegible in electronic image products. Images are produced from the best available original document. 
Printed in the United States of America. Available from

National Technical Information Service

U.S. Department of Commerce

5285 Port Royal Road, Springfield, Virginia 22151

Price: Printed Copy \$5.45; Microfiche \$0.95

This report was prepared as an account of work sponsored by the United States Government. Neither the United States nor the United States Atomic Energy Commission, nor any of their employees, nor any of their contractors, subcontractors, or their employees, makes any warranty, express or implied, or assumes any legal liability or responsibility for the accuracy, completeness or usefulness of any information, apparatus, product or process disclosed, or represents that its use would not infringe privately owned rights.

Reference to a company or product name does not imply approval or recommendation of the product by Union Carbide Corporation or the U.S. Atomic Energy Commission to the exclusion of others that may meet specifications. 


\title{
ULTRASONIC NONDESTRUCTIVE TESTING SYSTEM AUTOMATION
}

\author{
D. H. Gray \\ D. M. Darby
}

Oak Ridge Y-12 Plant

P.O. Box Y, Oak Ridge, Tennessee 37830

Date Issued - September 10, 1973

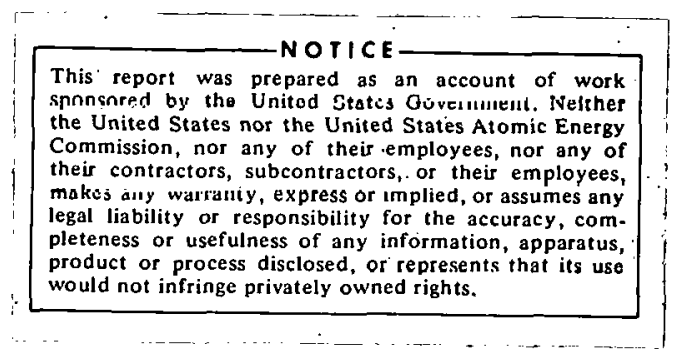

Prepared for the U.S. Atomic Energy Commission Under U.S. Government Contract W-7405eng-26

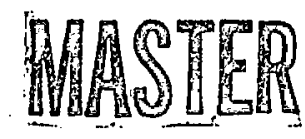




\section{ABSTRACT}

A commercial ultrasonic test facility has been interfaced to a medium-sized multiuser computer. The large volumes of data, formerly correlated to flaw size and flaw location manually, are now automatically accumulated and analyzed, and the results are plotted within a matter of minutes. The control system is capable of positioning the ultrasonic transducer with four degrees of motion-three linear and one angular. The data handling system offers the flexibility to allow implementation of nearly any future test requirements.

The system is now operational and is in daily use in a development laboratory. Surfaces of revolution and flat plates have been inspected with good results. Fourier transforms of ultrasonic waveforms are handled routinely. The multiuser computer configuration gives the user the impression of having a dedicated computer at his disposal. 


\section{CONTENTS}

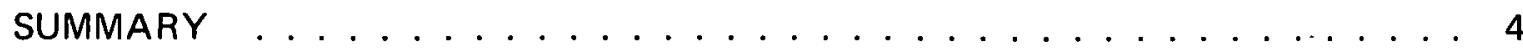

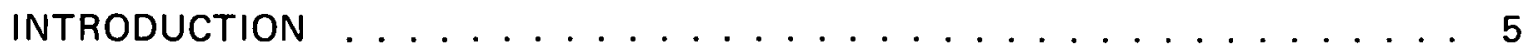

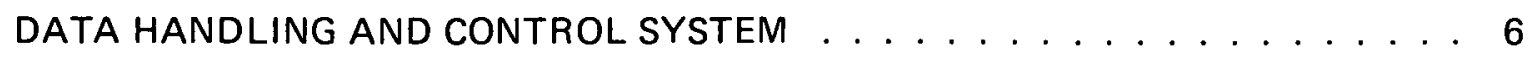

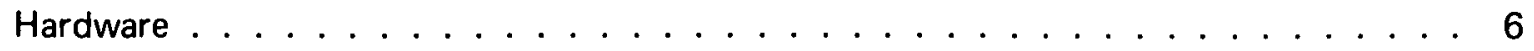

Data and Control of Terminal . . . . . . . . . . . . . . 6

Computer Interface . . . . . . . . . . . . . . . . 12

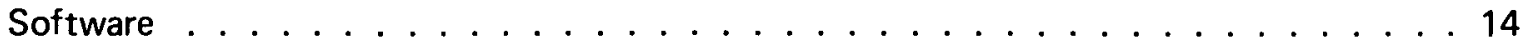

System Configuration ..................... . . 14

Basic Software Configuration . . . . . . . . . . . . . . . 14

Software Descriptions and Logic Flow . . . . . . . . . . . . . . . . . 15

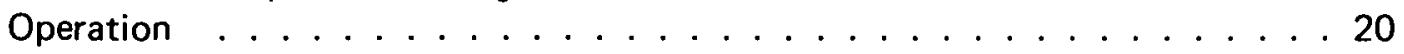

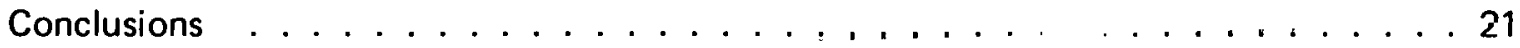

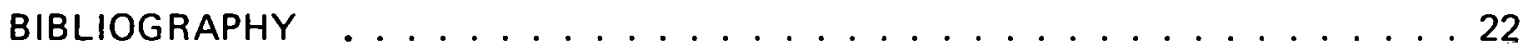

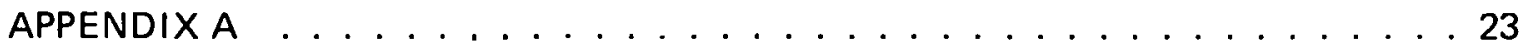

Data and Control Terminal Schematics and Logic Diagrams . . . . . . . . . . . . . 23

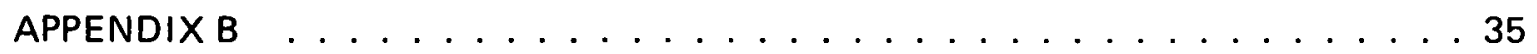

Computer Interface Schematics and Logic Diagrams . . . . . . . . . . . . . . 35

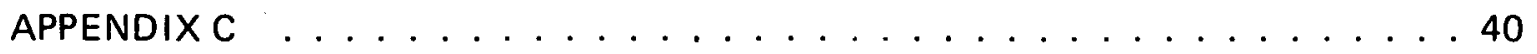

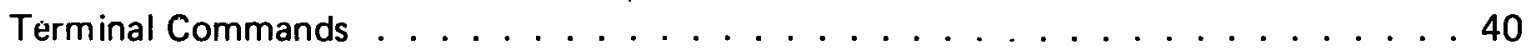

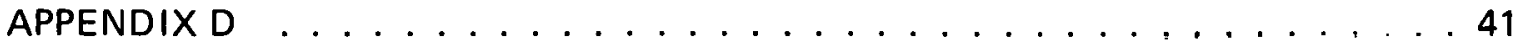

Software Flow Charts $\ldots \ldots \ldots \ldots$. . . . . . . . . . . . 41

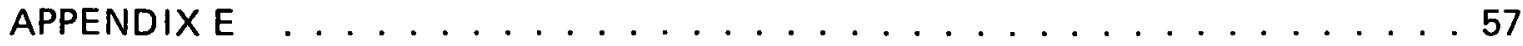

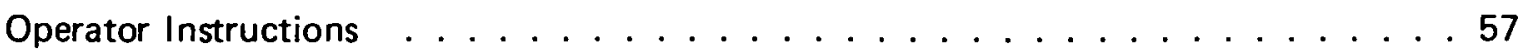




\section{SUMMARY}

A commercial ultrasonic test facility was interfaced to a medium-sized multiuser computer, and programs were written to accomplish data taking and analysis for all presently used test methods. The system is operational and in daily use. The ultrasonic data/control terminal was designed to incorporate a high degree of flexibility, thus making it easier to add any future tests to the system. In addition to normal test data, the system can supply a digitized ultrasonic RF waveform to the computer for Fourier analysis. All test results can be plotted on a local X-Y plotter or strip-chart recorder. Surfaces of revolution and flat plates have been inspected with good results. The transducer position may be changed between data scans via the computer. The capability exists for tracking a complex geometric shape with the transducer, provided the proper part description program is available. 


\section{INTRODUCTION}

Ultrasonic inspection methods utilize ultrasonic sound transmitted through a medium to detect density discontinuities internal to a part or a joint between two parts. A portion of the ultrasonic sound wave is reflected at each discontinuity or flaw, with the magnitude of the reflected energy dependent upon flaw size. Because of the small cross-sectional area of the beam, numerous passes must be made at different latitudes or positions of interest on a part. Large volumes of data are generated which must be analyzed and correlated to find the flaws at various locations.

A remotely located medium-sized multiuser computer was interfaced to a commercial ultrasonic test facility to accumulate, analyze, and manipulate data as well as to plot results, all in a matter of minutes. The multiuser computer configuration makes an efficient system in an intermittent-use environment, supplies a high degree of computing power, and gives the user the impression of having a dedicated computer at his disposal. The system is now operational and is in daily use in a development laboratory at the Oak Ridge Y-12 Plant. (a) The test facility will serve as a prototype instrument to develop new techniques to meet present and future design agency component inspection requirements. The capability also exists to position the transducer such that intricate geometric part shapes may be examined under program control. Radio frequency (RF) waveforms are digitized and sent to the computer which performs a Fourier analysis on the waveform. The ultrasonic data/control terminal is characterized by a high degree of flexibility which will allow the implementation of most future test requirements.

(a) Operated by the Union Carbide Corporation's Nuclear Division for the US Atomic Energy Cominission. 


\section{DATA HANDLING AND CONTROL SYSTEM}

\section{HARDWARE}

An ultrasonic transducer is excited by a pulse and transmits a burst of high-frequency energy through a suitable couplant to the part under test. Density discontinuities. encountered by the energy signal cause a portion of the energy to be reflected back to the transducer. The type of discontinuity will determine the amount of reflected energy. For example, an air pocket in a part whether caused by a crack or a poor bond between two surfaces will cause almost 100 percent of the incident energy to be reflected. The reflected energy signal is received by the transducer and directed to an Immerscope which determines the peak amplitude of the signal. I he Immerscope then yelierates a gate signal, meaning that the analog equivalent of the peak signal amplitude is ready on the analog output line. Two separate Immerscope channels with independent windows allow different gains to be employed or portions of the returning signal to be monitored. There is an analog output line and gate signal for each of the channels ( $A$ and $B$ ). A view of the ultrasonic test system is presented in Figure 1.

\section{Data and Control Terminal}

Various test instruments are envisioned to be used in place of the Immerscope. These instruments have varying analog output levels which require the capability of offsetting the signal. A dual-channel analog scaler (Figure 2) was developed to permit the test instrument analog output signals to be offset, scaled, and inverted. The scaler inputs are protected against amplitudes in excess of \pm 15 volts. Succeeding stages require the scaler outputs to be between 0 and +10 volts. A negatlve output de tector prevents negative values from reashing the succeeding stages and notifies the operator to change the scaler polarity switch via a light-emitting diode (LED). The scaler outputs are fed to an eight-channel multiplexer on Channels 0 and 1. Figure 3 is a block diagram which shows the signal flow for the system. Channels 2 and 3 of the multiplexer are connected to the "sample" and "hold" amplifiers which may be connected to external devices such as position potentiometers on another ultrasonic testing tank used for testing small parts. Channels 4 through 7 are available for future expansion of the system's capabilities. When a multiplexer channel is selected, the analng value on its input is delivered to an analog-to-digital converter (ADC) which converts the analog voltage to a digital value for transmissiuri to the computer.

In order to define the position on a part at which data were taken, a data synchronization (sync) mode must be selected to suit the particular test. Each data sync mode selects a dlfferent source of sync pulses which enable the terminal to take the next analog datum presented on the analog outputs of the ultrasonic test instrument. The first mode is encoder sync which selects the rotating table encoder. The encoder makes one revolution for each revolution of the table, and each encoder revolution generates 3,600 sync pulses plus a position zero marker. Each sync pulse is equivalent to 0.1 degree of table revolution. Table speed and hence the encoder pulse repetition frequency is much slower than the frequency of the Immerscope, which gives good assurance that the Immerscope will have an analog value ready to be read that corresponds to the position on a part represented by the encoder pulse. 


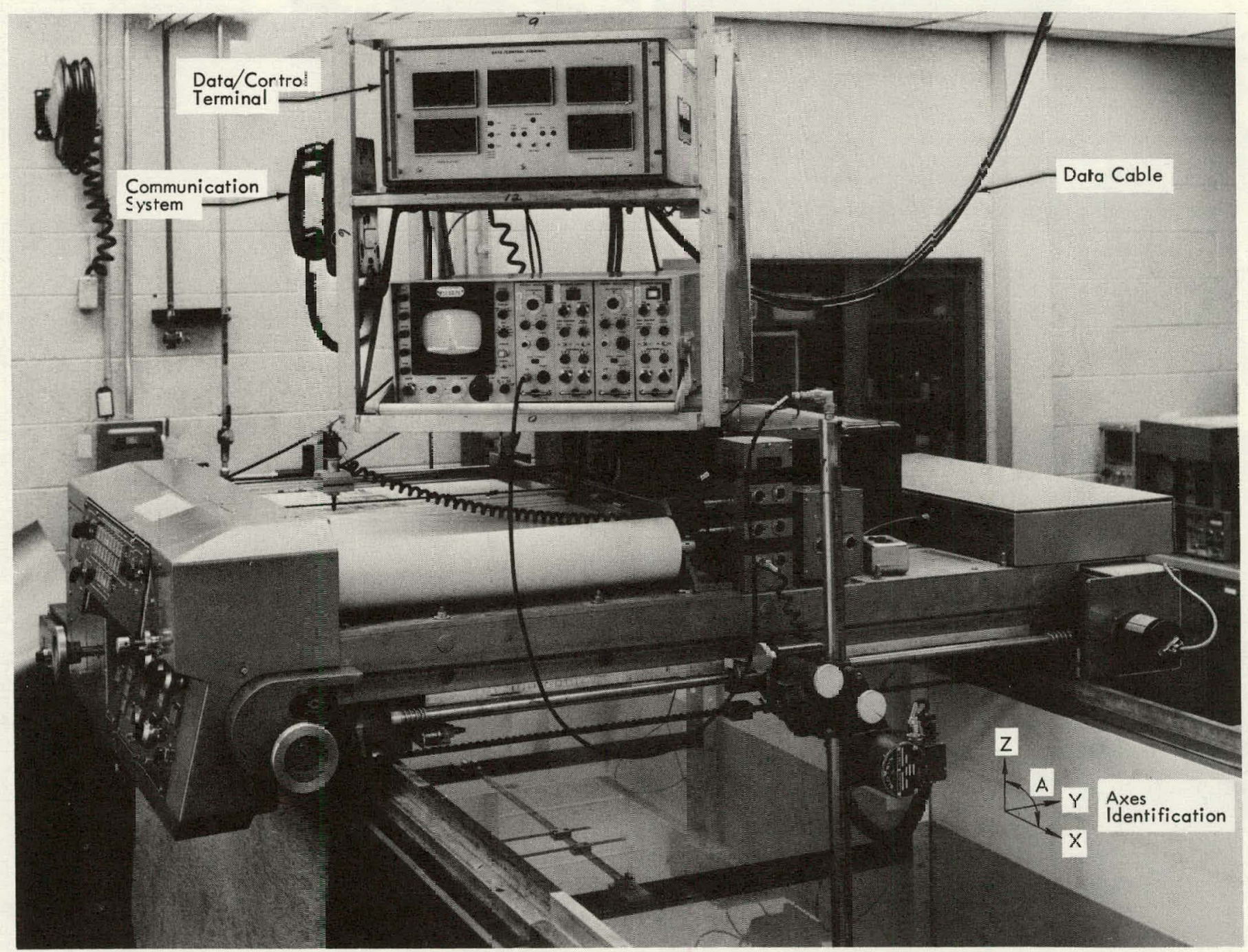

Figurə 1. ULTRASONIC TEST SYSTEM. 


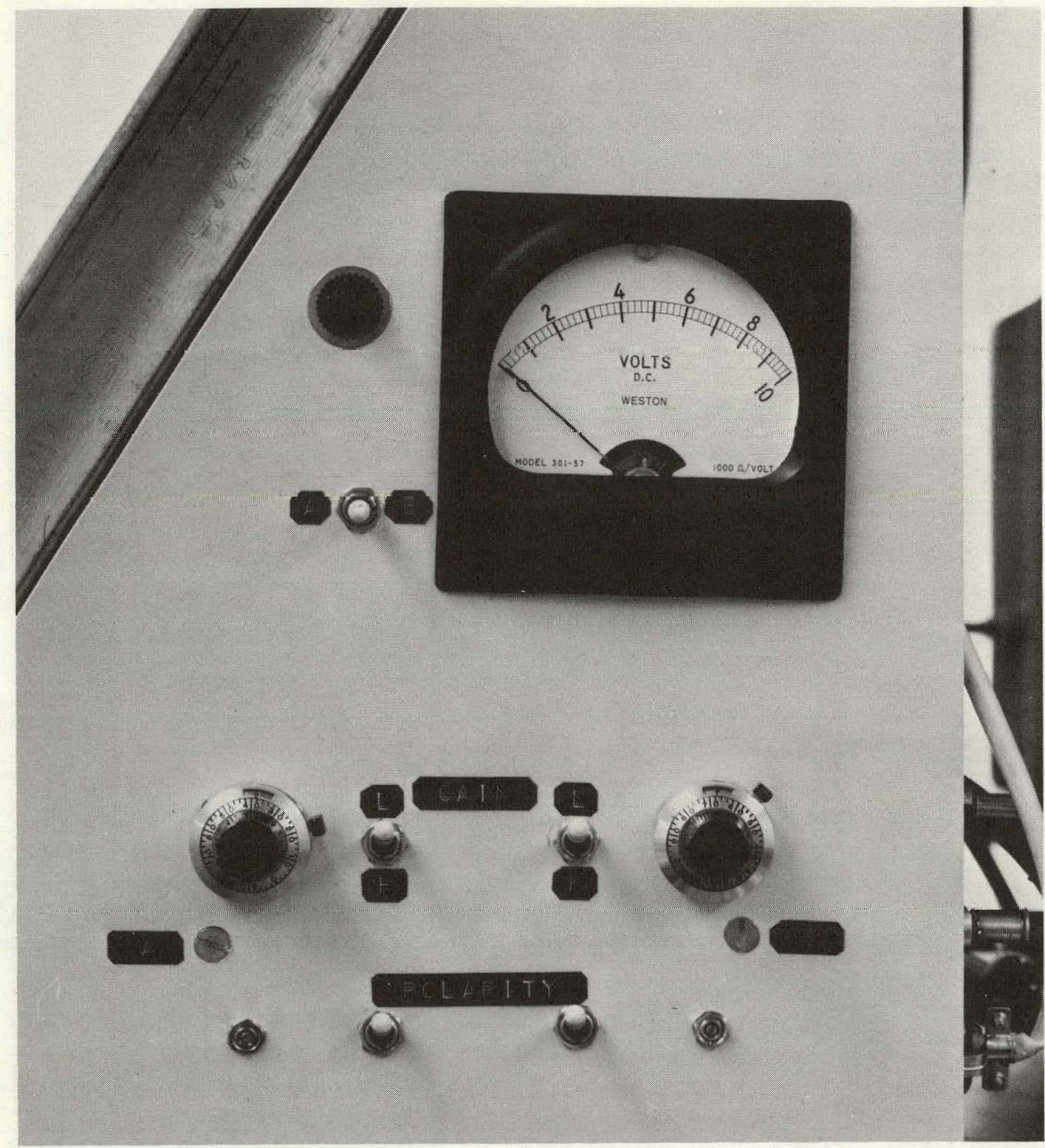

Figure 2. ANALOG SCALER.

146747

The other data modes are internal, external, and flat plate. The internal mode selects an internal 50-hertz clock and the external mode selects an externally supplied signal. The flat-plate mode selects the $Y$-axis encoder where each pulse from the encoder is equivalent to four mils of linear travel. Each of these three data sync modes are scalable; that is, a programmable number of pulses must be received from the selected source by the terminal before a sync pulse is issued. The length of a data scan is similarly programmable and is defined as the number of sync pulses (or data points) which will be accumulated in one direction along a part. The programmed number may be any number between 1 and 4,095. 


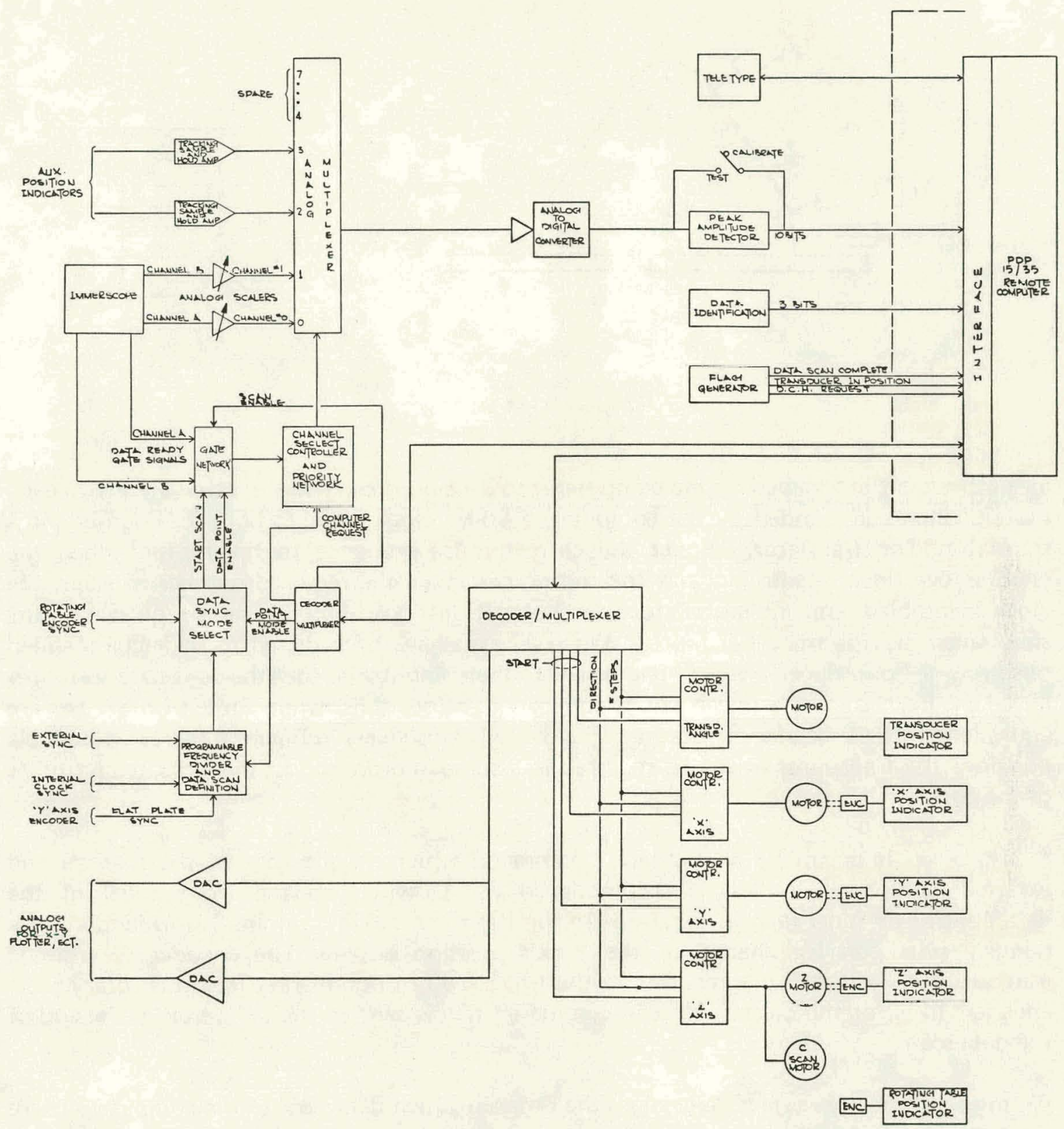

Figure 3. SIGNAL FLOW FOR THE ULTRASONIC TEST SYSTEM.

There are two basic classes of parts presently being tested by the system. One is a flat plate where the transducer is moved across the plate with a scan defined as one excursion across the part. The second is a surface of revolution where a part is mounted on a rotary table with the transducer fixed during each scan. Here, a scan is defined as one revolution of the part. Figure 4 provides a pictorial sketch of these methods showing the allowable paths of transducer movement. When a scan is completed, the transducer position may be changed under computer control. The $X, Y$, and $Z$ axes and transducer angle (A) are driven by stepping motors which may be controlled manually or by the computer. (See Figures 1 and 4 for axes identification.) Under computer control, the number of steps required for each 


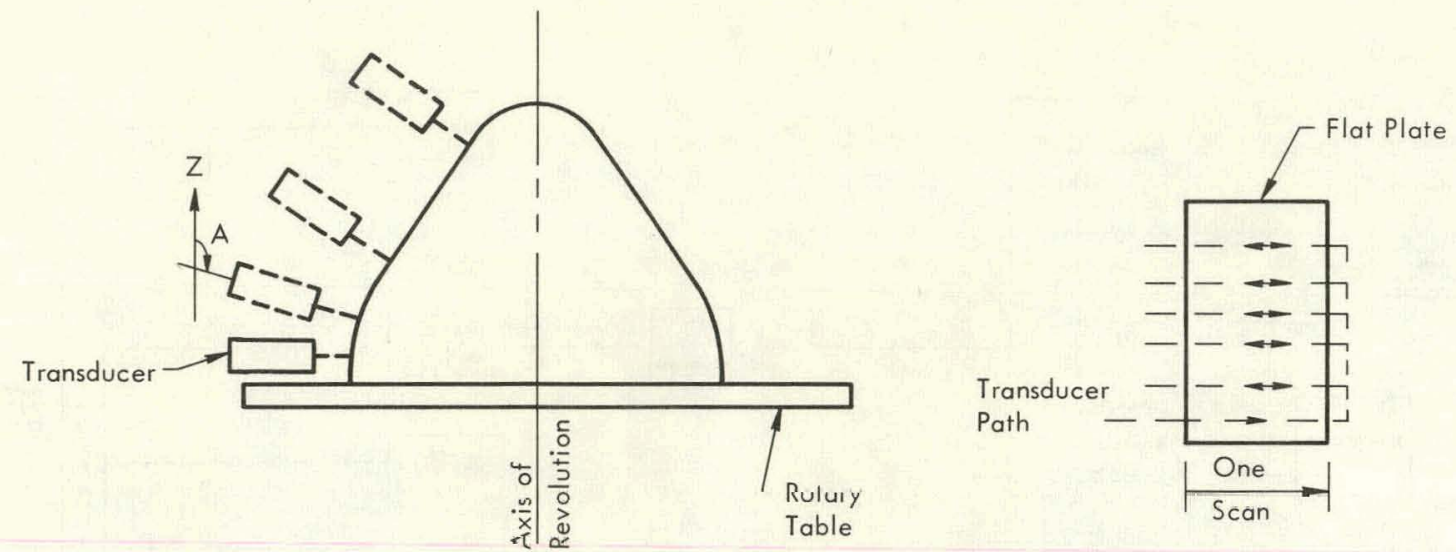

Figui' 4. TLST MODEE.

axis movement are loaded by the computer into a 12-bit down counter associated with each motor. When commanded by the computer, a $50-\mathrm{Hz}$ clock is fed to both the counter and a translator. The translator supplies the correct pulse sequence to the motor. When the counter overflows, signifying that the motor has taken the required number of steps, the clock is disabled, and the motor stops and holds its last position. This same sequence occurs simultaneously for the other motors. When all axes have been driven to their commanded positions, a "transducer arrived" flag is sent to the computer so that the next data scan may be taken. Each step of a linear axis is equivalent to four mils, while those of the A axis are equivalent to 0.05 degree of rotation. The dashed transducers in Figure 4 represent possible positions the transducer might be required to assume in order to test the indicated latitudes of the part.

$\wedge$ data scan is begun by an "initiate" command which, in the case of the internal and external data sync modes, is accomplished via a switch on the front panel of the data/control terminal seen in Figure 5. In the flat plate mode, "initiate" is generated by a minus-to-plus polarity change of the $\mathrm{Y}$-axis position display. The encoder sync mode generates the "initiate" command with the first zero position marker from the rotary table encoder. In all of the modes, a "scan complete" flag is sent to the computer at the end of the data scan.

An internal priority system determines the order in which data flow to the computer. There are two ways in which data may be requested. One is when the Immerscope issues the gate signal signifying that data are ready; the other is when the computer requests a channel of the analog multiplexer to be read. Multiplexer Channels 0 and 1 are self addressing while Channels 2 through 7 are addressed only by the computer. The priority system is set up such that Immerscope Channel A (multiplexer Channel 0) has precedence over Channel B (multiplexer Channel 1) and the computer request. Channel B is next in line, with the computer request having the lowest priority.

Along with each data word sent to the computer are three identification bits which identify the analog multiplexer channel from which the data originate. Data consist of ten bits, therefore a complete data word consists of thirteen bits which includes the three identification bits. Each data word is deposited in a table in the computer memory through 


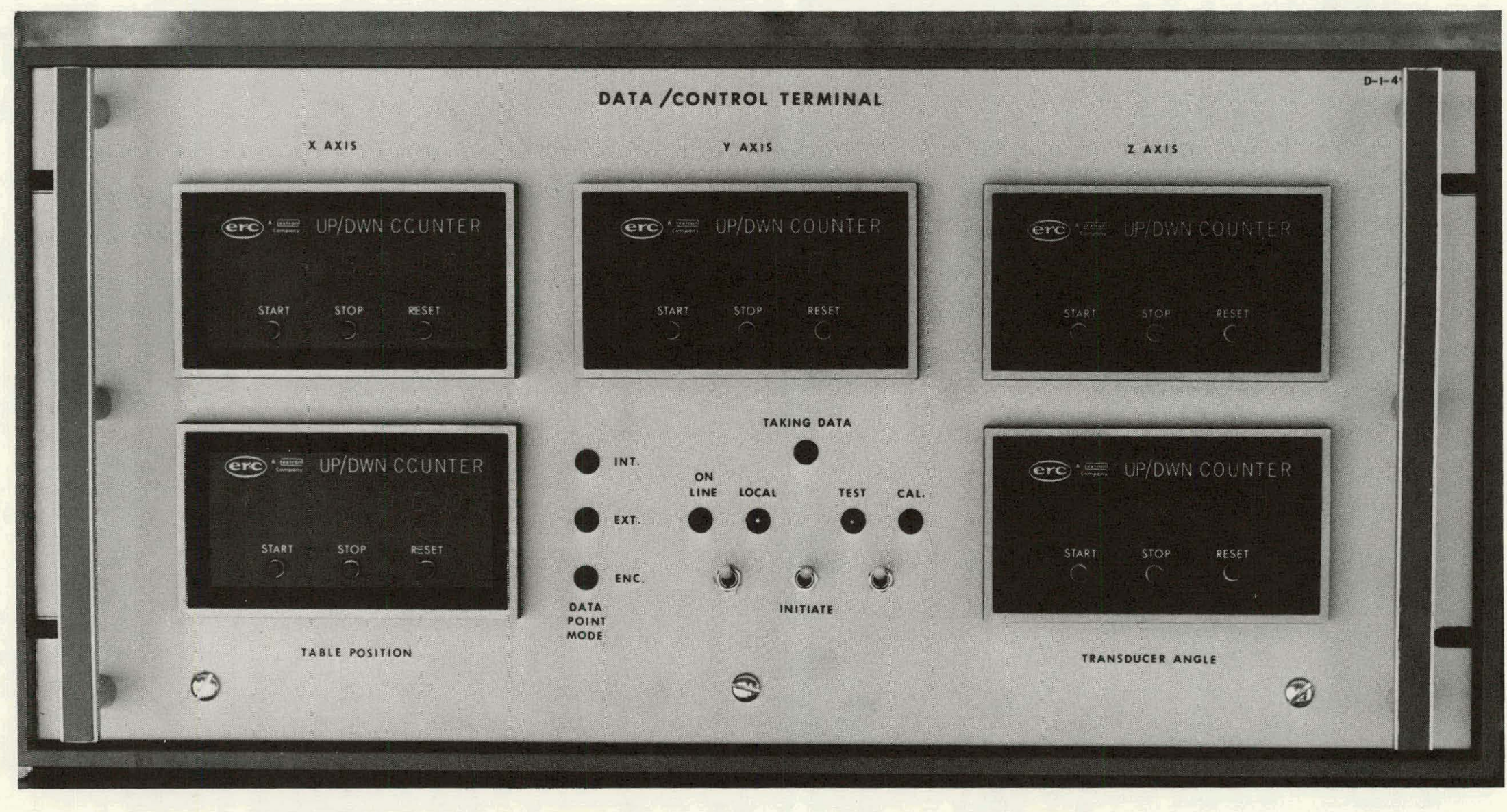

Figure 5. DATA/CONTROL TERMINAL.

146916 
a cycle-stealing process known as direct memory access (DMA). This process steals a four-microsecond cycle from the computer, automatically increments a word counter, determines the memory location of the next word of the table, and deposits the data word in this memory location. When the word counter overflows, the computer is signalled, via an automatic priority interrupt (API), that the table is full. Thus, the computer is not bothered with the time-consuming process of servicing an interrupt for each data word deposited.

A peak amplitude detector is available for finding the peak amplitude obtained during calibration. The detector compares the first data word with zero. If the first word is greater than zero, it is stored in place of zero. The second data word is then compared with the first and the second stored in place of the first if it is larger. This sequence continues until the stored word becomes larger than the incoming word. In this fashion, the peak amplitude is found and sent to the computer. Circuitry is provided to eliminate false peaks due to such factors as noise. This detector is enabled by the "cal" switch on the terminal front panel, as seen in Fiyures 3 and 5.

Two analog output channels are available which can be used for various control functions. The buffered digital-to-analog converters (DAC) are loaded by the computer with the digital equivalent of the required output voltage. Once loaded, the output will hold this value until updated. At present, the primary function of these outputs is to plot the analysis results on a X-Y plotter or strip-chart recorder.

Fourier analysis of the returning ultrasonic signal can be performed by the computer by employing a sampling oscilloscope to sample the waveform. The sampling unit is scanned by the computer via the DAC outputs, and the analog value of each sampled point on the waveform is fed into the terminal via Channel 0 or 1 for digitization and transmission to the computer. Appendix A provides data and control terminal schematics and logic diagrams.

\section{Computer Interface}

In order to obtain bidirectional communication between the data/control terminal and the computer, an intermediary interface is needed. (Schematics and logic diagrams can be found in Appendix B.) The purpose of this interface, which is located at the computer, is to process tlags and data from the terminal and to tranısmit commands to the terminal. ( $\mathrm{An}$ explanation of the commands is given in Appendix C.) Figure 6 provides a view of the multiuser computer system to which the ultrasonic data/control terminal is connected. The interfaces to all external users are located in the second cabinet from the right. The data cable, which can be seen leaving the terminal in Figure 1, enters the computer interface cabinet through a port in the floor beneath the interface cabinet in Figure 6.

The interface must be turned "on line" by the computer before it can accept any flags from the terminal. A light on the terminal panel (Figure 5) indicates the state of the terminal, either "on line" or "local". An "off line" (local) command may be generated either by the computer (via the interface) or by a switch on the terminal panel. This switch also serves as an "emergency stop" since all functions terminate when in the "off line" or "local" condition. 


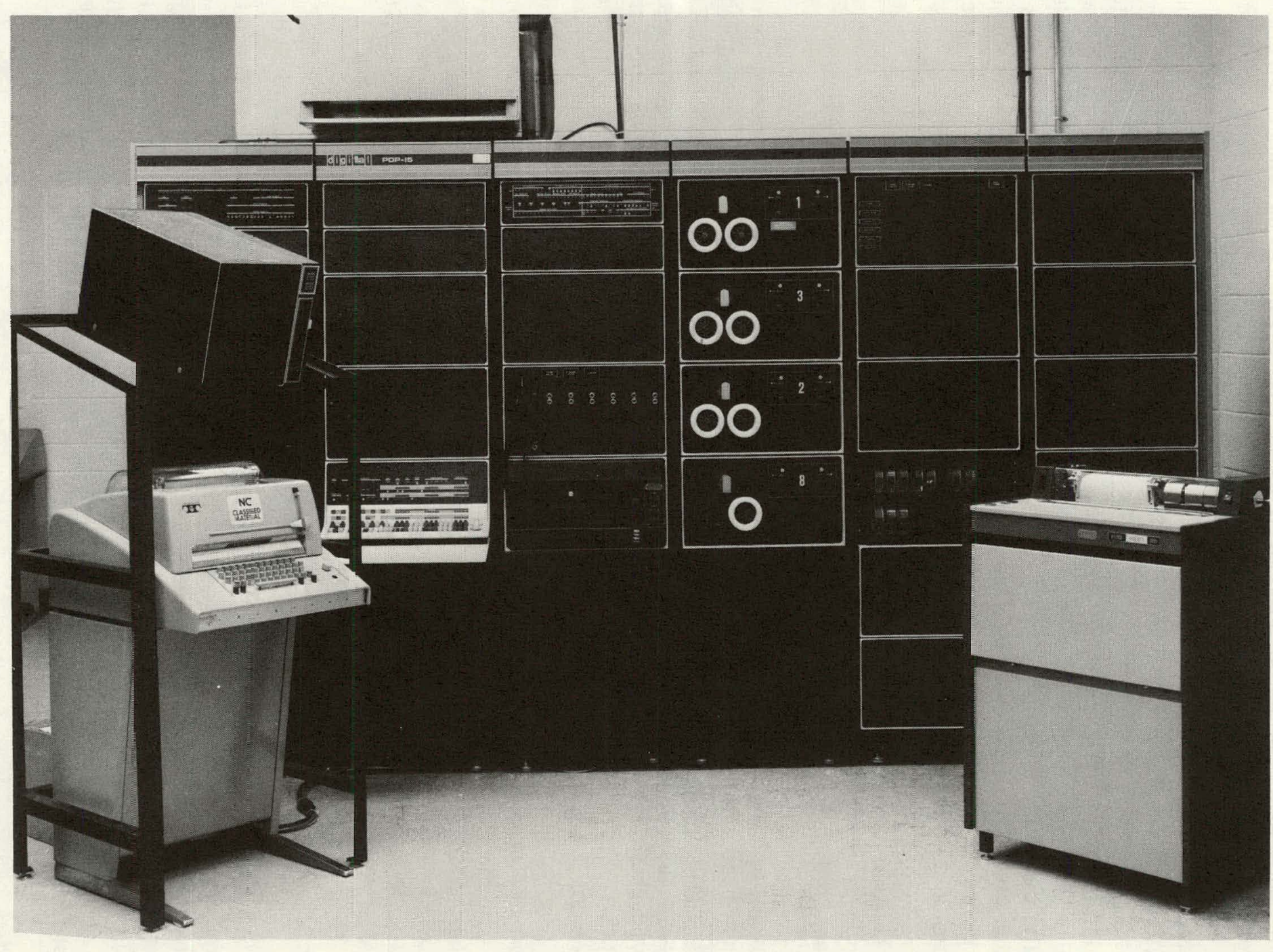

Figure 6. PDP 15/35 COMPUTER SYSTEM. 
When a flag is received from the terminal, the computer receives an API. The computer identifies the system originating the interrupt and proceeds to determine which flag in the system is requesting service. When the flag is identified, a unique circuit in the interface automatically clears the flag. It does not, however, clear any other flag which might also be requesting service.

As previously mentioned, the test data are accepted and deposited via DMA in a particular location in memory without interrupting the computer. When a datum is ready, the terminal sends a special flag to the interface which, in turn, requests a data channel (DCH) transfer. The input/output $(\mathrm{I} / \mathrm{O})$ controller responds with a $\mathrm{DCH}$ grant signal. Next, the interface supplies the address of a word-count register which is incremented by the controller. Finally, the datum is deposited in a memory address which is the incremented contents of the current address register. This sequence is accomplished without interfering with the job that the computer is running. By stealing some processor time, acquisition of a datum delays the task in progress by only four microseconds.

\section{SOFTWARE}

\section{System Configuration}

Software for the ultrasonic nondestructive test system is designed to operate on a medium-sized multiuser computer. The machine consists of $16 \mathrm{~K}$ words of core storage, $262 \mathrm{~K}$ words of disk storage, and four magnetic tape units of $150 \mathrm{~K}$ words each. The programs operate under the management of a real-time executive (RSX). This monitor allows several users to share the computer simultaneously. Programs operating under this executive are chained and overlayed into logical units called "tasks". Each task is designed to execute in a specific partition, or particular area of core memory, and operate at one of 512 priority levels. The assignment of a priority to a task depends upon the relative importance of the task. RSX is therefore a program-management executive rather than a true time-share system. The tasks are stored on the disk until requested by the executive or another program. Inter-task communication is implemented through user commons which are external to the partitions. The ultrasonic software consists of 68 programs divided into 17 tasks. These programs use one partition of $4 \mathrm{~K}$, one system common of 300 words, 7,200 words on the disk for data, one magnetic tape unit, and 4,096 words of auxiliary core.

\section{Basic Software Configuration}

The software must transmit information to receive data from the ultrasonic interface. This communication is donc in an assembly-level lanyuaye (MACRO) and is capable of controlling four axes of transducer movement, two digital-to-analog converters (DAC), eight analog channels, and four data sync modes. The flow of execution must be controlled by the ultrasonic operator. This requirement is met through the interactive use of the Teletype and a high-level language (FORTRAN) which decodes the operator's commands and performs the necessary routines.

All data gathered from an ultrasonic test must be available for analysis at a later date. Therefore, data are stored on magnetic tape, and 35 unique file names are provided for each 
tape. Six analysis routines are implemented in addition to Teletype and graphic display of all data. Extensive checks are made throughout execution, and the operator is informed of malfunctions. The programs are designed to facilitate modifications.

\section{Software Descriptions and Logic Flow}

The first and main task for the ultrasonic test system is initiated from the console Teletype at the computer. Control of all the programs is then passed to the remote Teletype (Block 1 of Figure 7) located at the ultrasonic test tank. The program identifies itself and asks for one of six major modes of operation (Block 2). The first mode (setup, Block 3) allows the operator to either load the two DACs or move the four stepping motors (axes control). These options allow the operator to set the scale on the plotters and position the transducer.

The second major mode (Block 4) allows the operator to standardize the data. It collects the data necessary to convert a relative signal level to a flaw depth which allows comparison of data gathered at different instrument settings. The computer stores the average signal level together with a slot depth and DB scale factor. This information is stored with all future test data. The next step in the conversion is a curve-fitting routine (Block 5) which fits these data to one of 11 curve types. The coefficients returned from this test are saved and kept for any future test.

To implement the actual data gathering from a test scan, the operator requests the test mode (Block 6). He can select one of five different tests:

1. Rotating scan save. This test stores all of the data from any number of scans taking a word of data every one-tenth degree from the rotating table. This option can use one or both Immerscope channels. It can increment the four axes between runs with either an operator-supplied index or a contour following $X-Y$ motor pulse file.

2. Rotating scan maximum. This option stores only the largest corresponding value for any number of scans. It has all the options of "rotating scan save". This test is used to determine the largest flaw in a particular plane.

3. Flat-plate save. This test uses an independently controlled $Y$ axis to gather data using a calculated distance between data points. The $X, Z$, and $A$ axes are moved either from an operator-supplied index or a contour following $X-Y$ motor pulse file. This type of test is used to gather data from a flat surface.

4. Flat-plate maximum. This test saves only the largèst corresponding values of $Y$ for all values of $X, Z$, and $A$ and is used to determine the largest flaws on a flat plate. The same motor-handling capabilities as in Test 3 are available. A composite data file is saved which will allow the operator to quickly determine if a part is within tolerance limits.

5. RF wave form. This test collects data from a waveform displayed on a sampling oscilloscope. The waveform is characterized by sampling at $X$ positions which are set by a DAC and are determined by an operator-defined number of points. This option is used to analyze the frequency of an ultrasonic signal rather than its relative amplitude. The information can be used to determine the response of a transducer or the absorption spectrum of a material. 


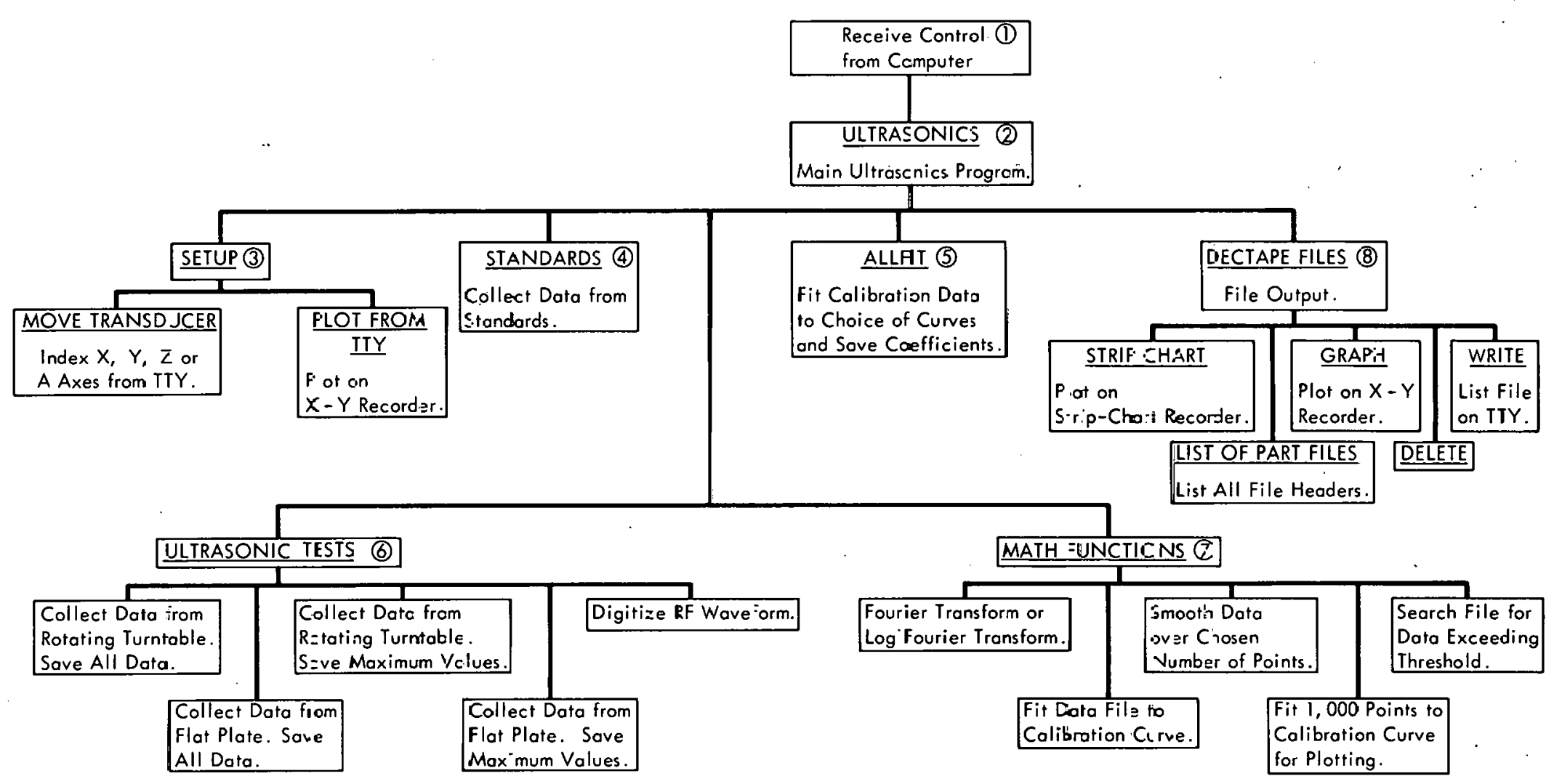

Figure 7. SOFTWARE PROGRAM. (Circled Numbers are the Major Blocks in the System) 
All of the tests store the data with a header which contains the type of test, number of run, number or words per run, calibration information, and 72 characters of identification which are supplied by the operator (Figure 8). The storage of this header information insures that all pertinent information is available at a later date. The identification is used only to avoid confusion between data files.

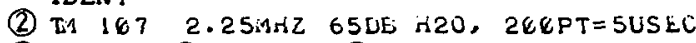

(3) TEST-1 (4) 1 FUIVS (5) $26 E$ WURLS/RUIV

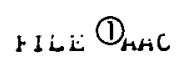

(1). File name

(2) Identification. Up to 72 characters may be inputted by the operotor.

(3) Test type. A " -1 " represents data gathered from a wave form.

(4) Number of runs. Inputted by the operator.

(5) Number of words per run. Supplied by the operator.

Figure 8. SAMPLE HEADER.

The data analysis routines (Block 7 of

Figure 7) give the operator mathematical capabilities in handling the data. He has the options to:

1. Smooth the data by averaging. A variable number of points, forming a "window", are averaged over the full data set contained therein. (The process is actually an integration of the area.) This technique removes noise from the signal (see Figure 9).

2. Perform a Fourier analysis on the data. The frequency, amplitude, and phase which are results of the transform can be written on the Teletype or saved on magnetic tape. Figure 10 is a plot showing a sample of the results obtainable from this test.

3. Search the data file for any values above a selected threshold. The initial and final location of a series of values above this threshold as well as the maximum value within this series is written on the remote Teletype. This procedure allows the operator to relate location, length, and depth of a flaw. This option allows a three-dimensional definition of a flaw if used with several consecutive scans.

4. Convert the signal level to depth in mils using the calibration curve. The coefficients for the curve can come from either the values stored with the test or from the most recent coefficient filc.

5. Compute and store 1,000 points on the calibration curve. Coefficients for this curve can come from either the values stored in a test file or the most recent coefficient file. The output is saved on tape. The purpose of this function is to provide a graphic display of the calibration curve (Figure 11).

All of the options, except threshold and possibly the Fourier analysis routines, store the computed data in a scratch file which can be permanently scaled for graphic display. This file is handled in the same manner as a normal data file.

File output (Block 8) allows the operator to graph any data file on the $X-Y$ plotter or strip-chart recorder. These data can be scaled to magnify an area of interest. The data can also be printed on the remote Teletype. The heading for the data file is printed when any of the five options are used. The headings for all the data files can be listed as a tape directory for the operator. Also, any data file can be deleted. 


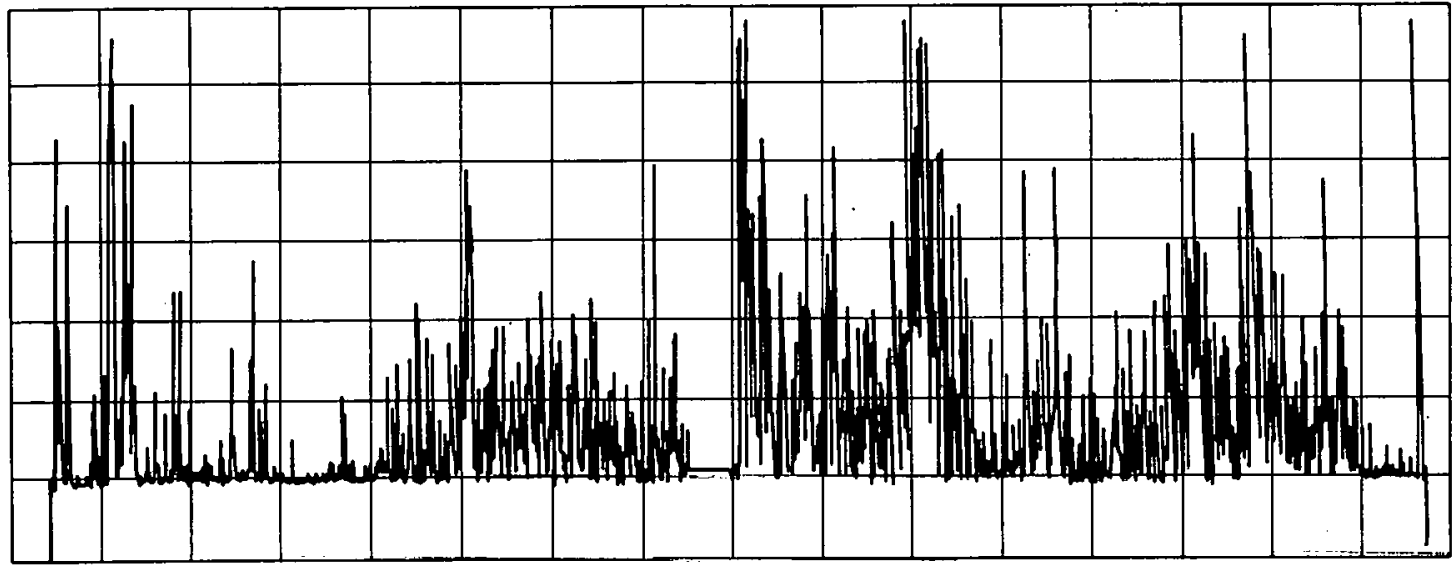

(a) Original Data. (3, 600 points - rotation scan graphed on strip-chart recordér)

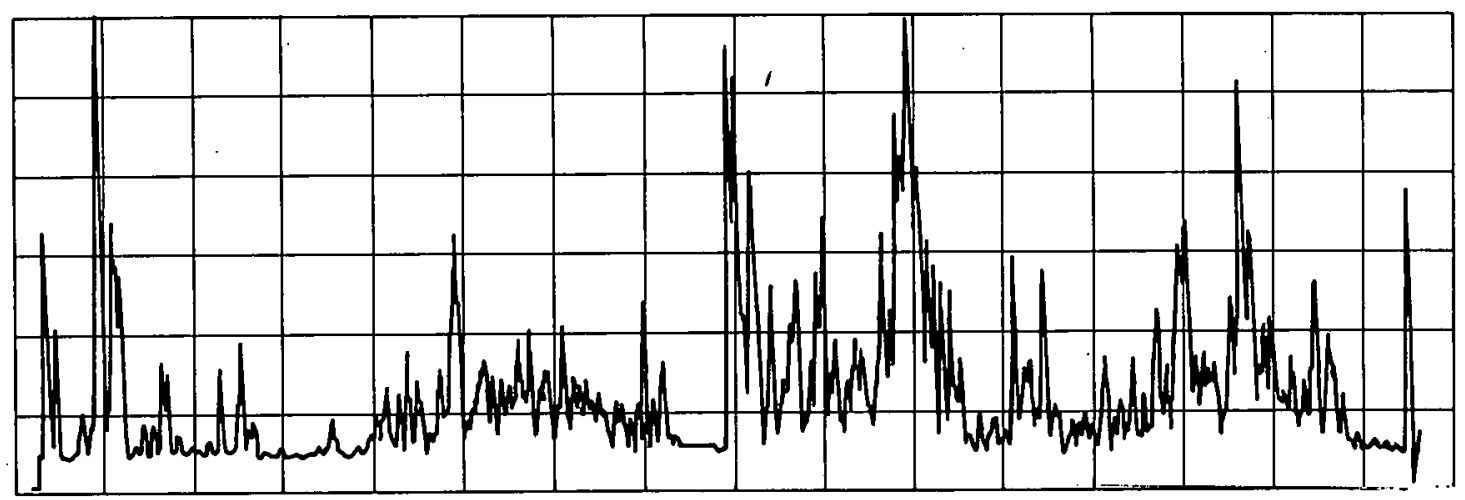

(b) One-Degree Integration of the Original Dato. (window width of $10 \mathrm{pts}$ )

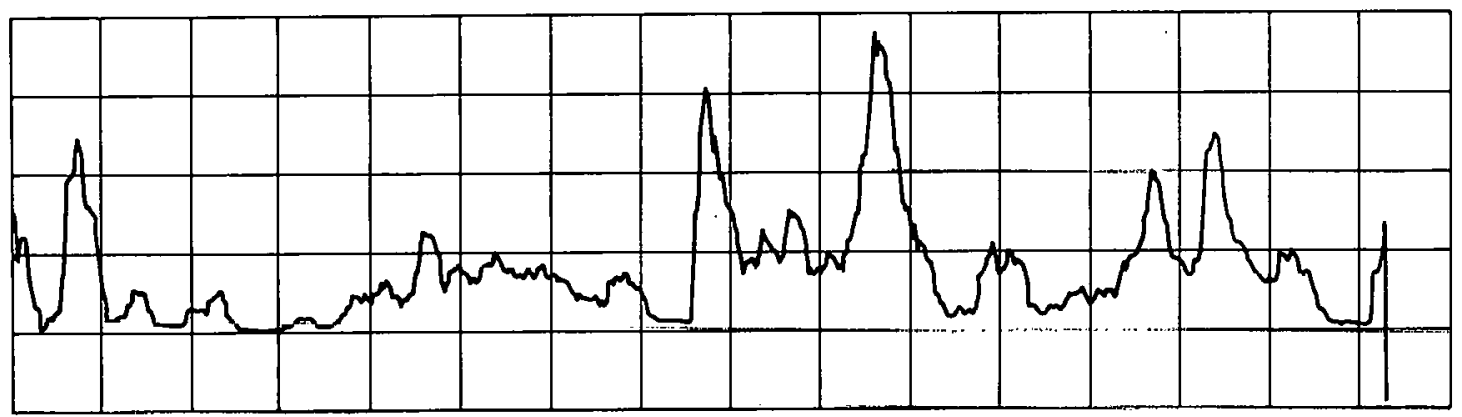

(c) Five-Degree Integration. (window width of 50 pts)

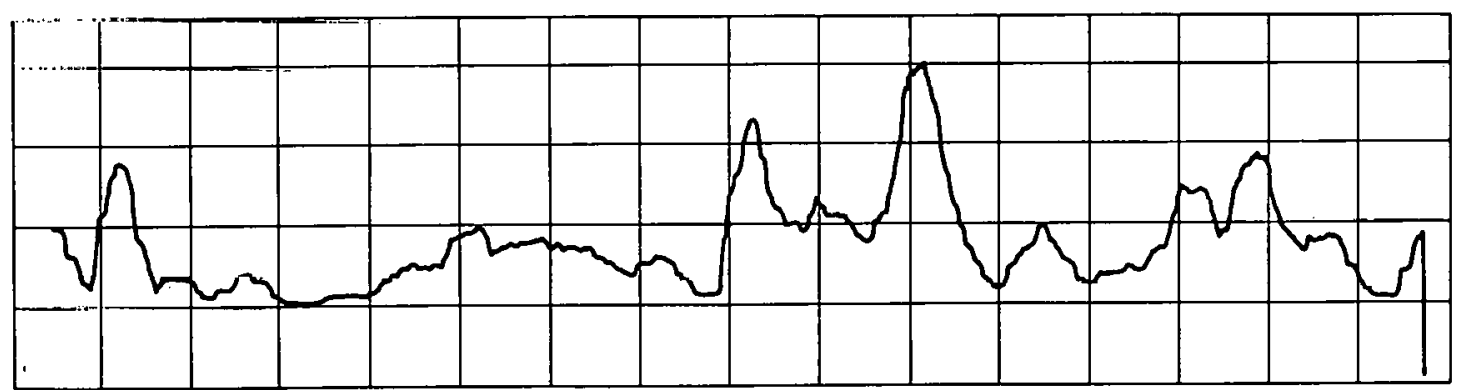

(d) Ten-Degree Integration. (window width of 100 pts)

Figure 9. EFFECT OF INTEGRATION ON THE BASIC ULTRASONIC DATA. 


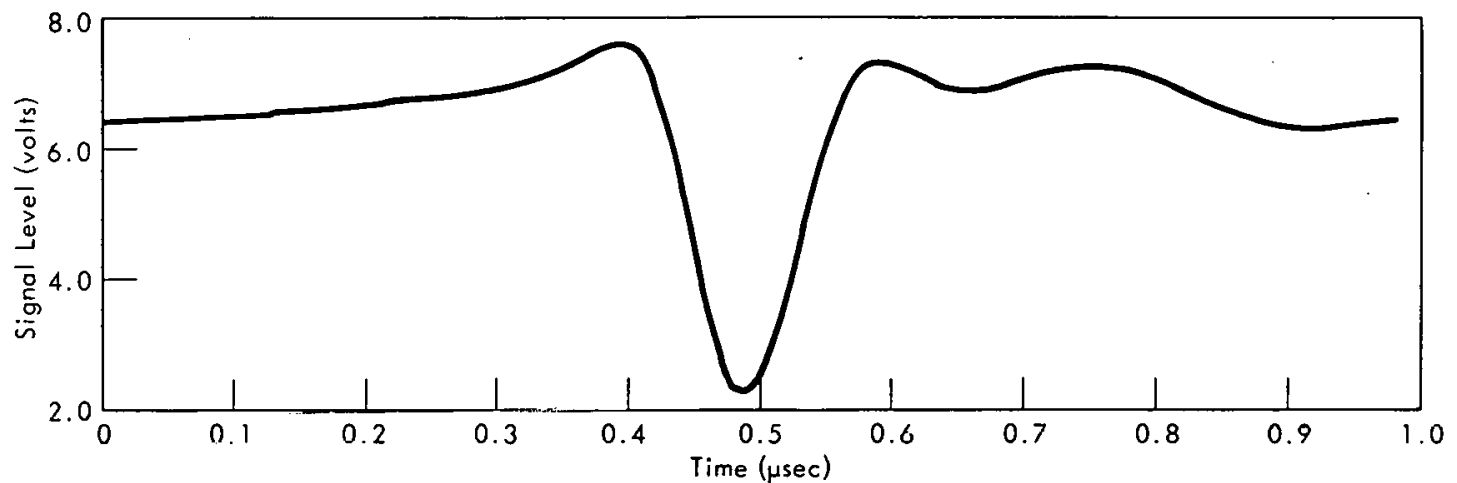

(a) Plot of a Waveform from a Sample Using a $10 \mathrm{MHz}$ Transducer. (sampling interval of $0.01 \mu \mathrm{sec}$ )

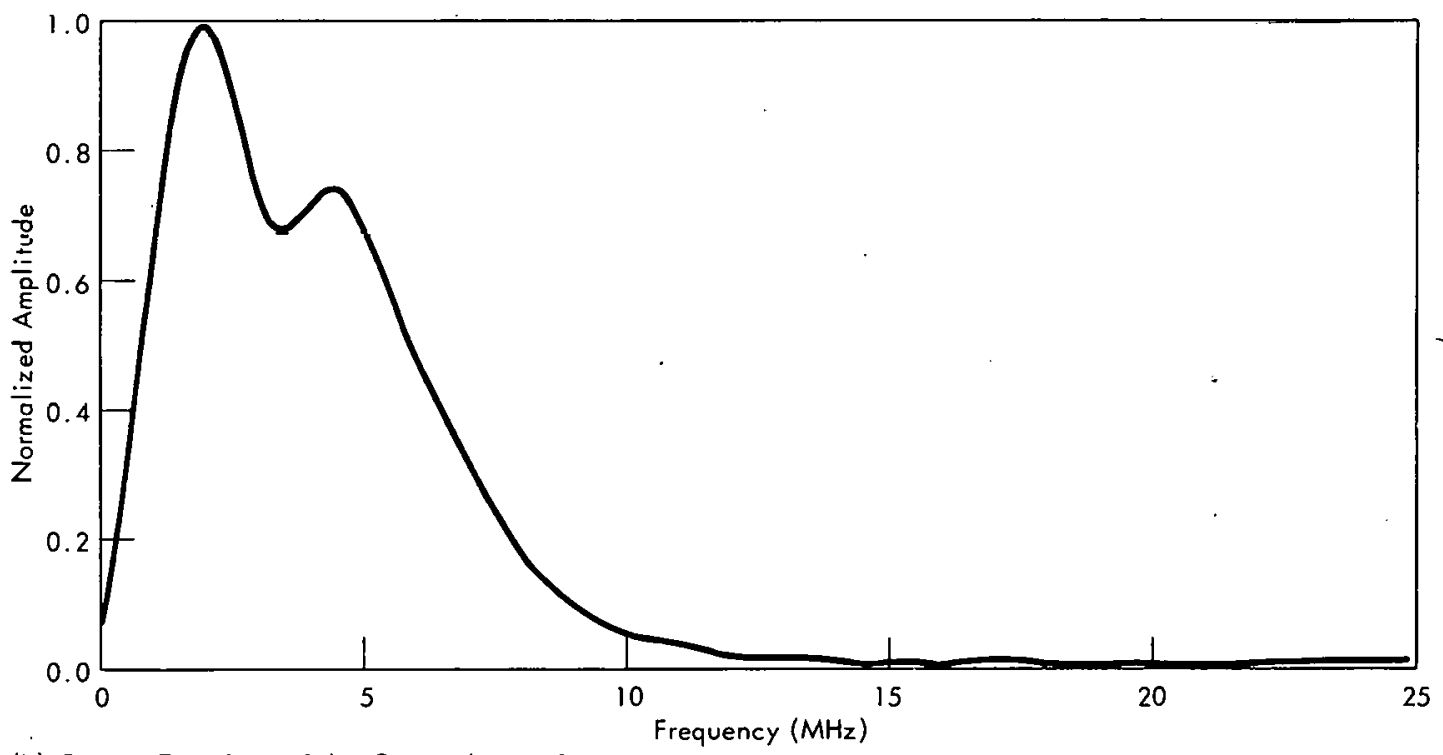

(b) Fourier Transform of the Original Waveform.

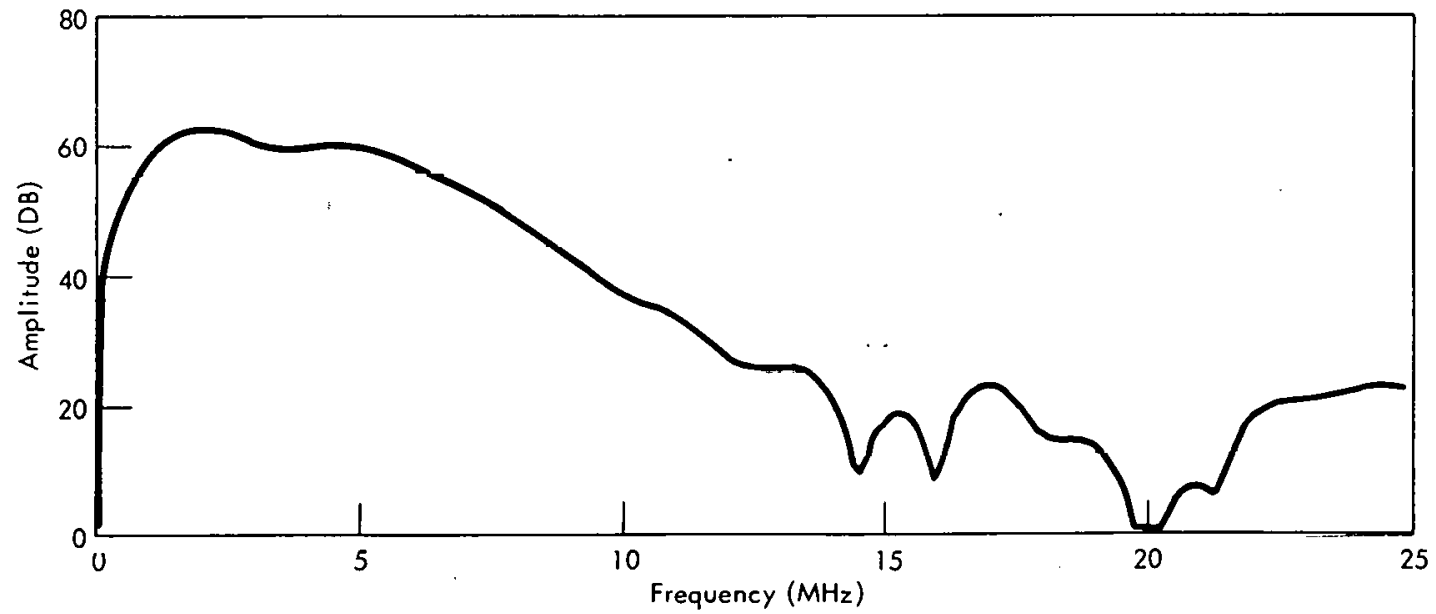

(c) Log of the Fourier Transform of the Original Data.

Figure 10. FOURIER ANALYSIS OF THE ULTRASONIC DATA. 


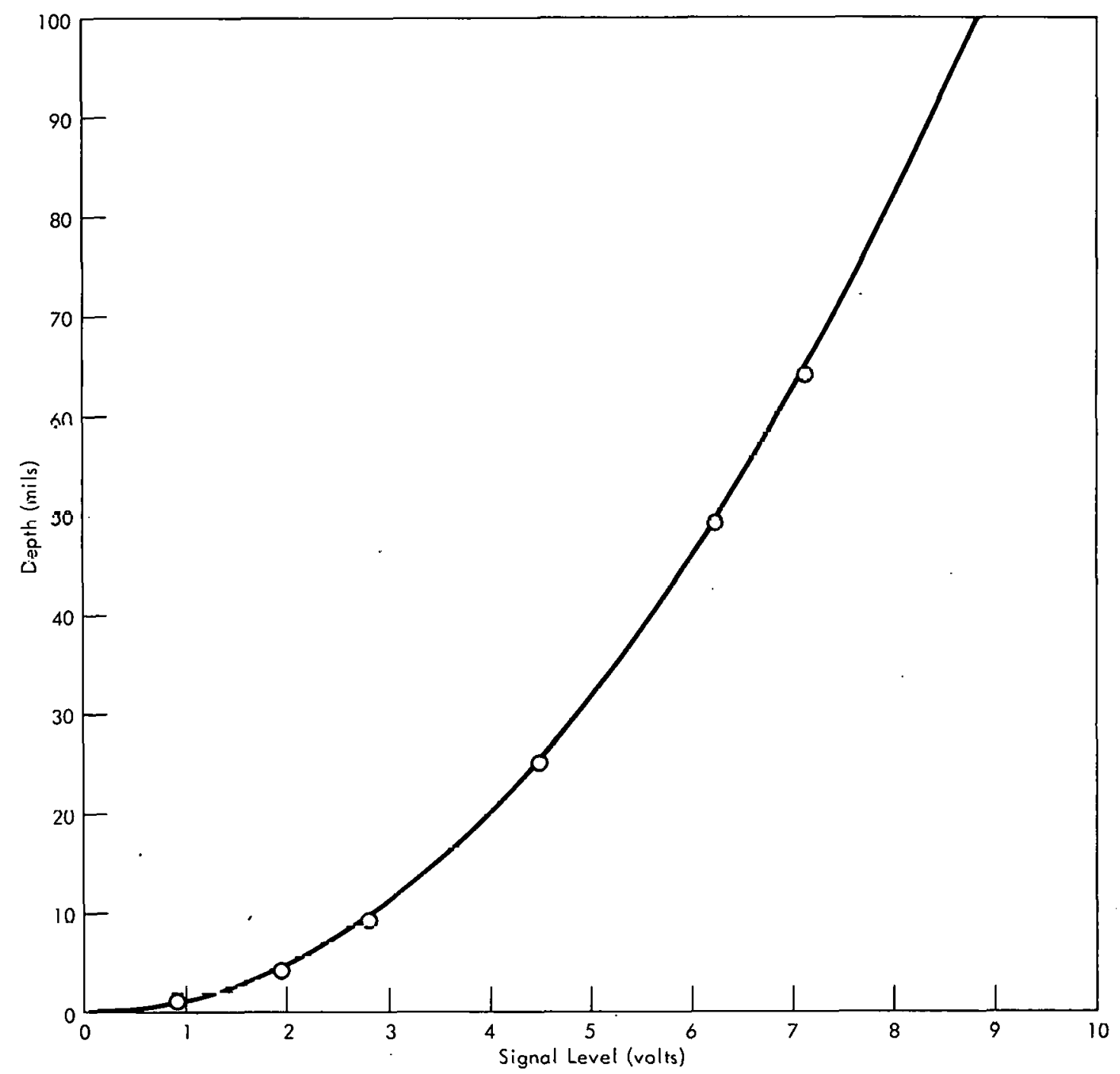

Figure 11. CALIBBRATION CURVE of SIX-ruINis FIT TO A SECOND-ORDER POLYNOMIAL. (Gtonderd Daviation $=\mathbf{0 . 2 3 7}$

All six modes of operation return to the main task upon completion. These modes give the ultrasonic operator a basic operating system which can be expanded as new options are required. A complete set of software flow charts can be found in Appendix $U$.

\section{Operation}

Certain conventions have been followed throughout the program. Major modes identify themselves by typing the mode name followed by three asterisks and a request for an input. All commands are single-letter inputs which, in some cases, are followed by a file name and an optional run number (an unrecognizable input will cause the request to repeat). In the case of a numeric input, all values are integers (no decimal point), except when a decimal point occurs in the request. An example of the latter is the standards routine request ".LEVEL". Error statements are preceded by three asterisks and, if severe, will cause the 
program to restart. A severe error is followed by an integer number. If this number is negative, the error probably cannot be corrected at the remote device; and, if this error repeats, the computer system operator should be notified. An example of this type of error is "***DISK ERROR IEV $=-12$ ".

The emergency stop for this system is the "off-line" switch. It stops everything under computer control. The switch isolates the interface from the computer; and, if the system is in the process of taking data or driving the motors, the switch terminates the program. Another terminal condition is encountered when turning the power on while the system is "on line".

In order to start the ultrasonic series of programs, the ultrasonic operator requests the computer operator to initiate his program. When started, the remote ultrasonic Teletype responds "ULTRASONICS**" and asks for the first option. The flow of logic, as the operator sees it on his remote Teletype, is given in Appendix $E$.

\section{CONCLUSIONS}

The multiuser computer allows efficient use of computer time and supplies more computing power than a minicomputer. It also gives the user the impression of being a dedicated computer. The ultrasonic test system has been operational for six months and has supplied good and fast results.

The data/control terminal and associated hardware were designed to have a high degree of flexibility. A very minimum amount of work should be required to accommodate any new test methods. The major effort would be in interfacing signals to the terminal and in modifying the existing sof tware to accommodate the new test. 


\section{BIBLIOGRAPHY}

Moyer, M. W. and Gray, D. H.; Expanding the Capability of a Laboratory U/trasonic Testing Facility; to be published in Materials Evaluation, Journal for the American Society for Nondestructive Testing. 


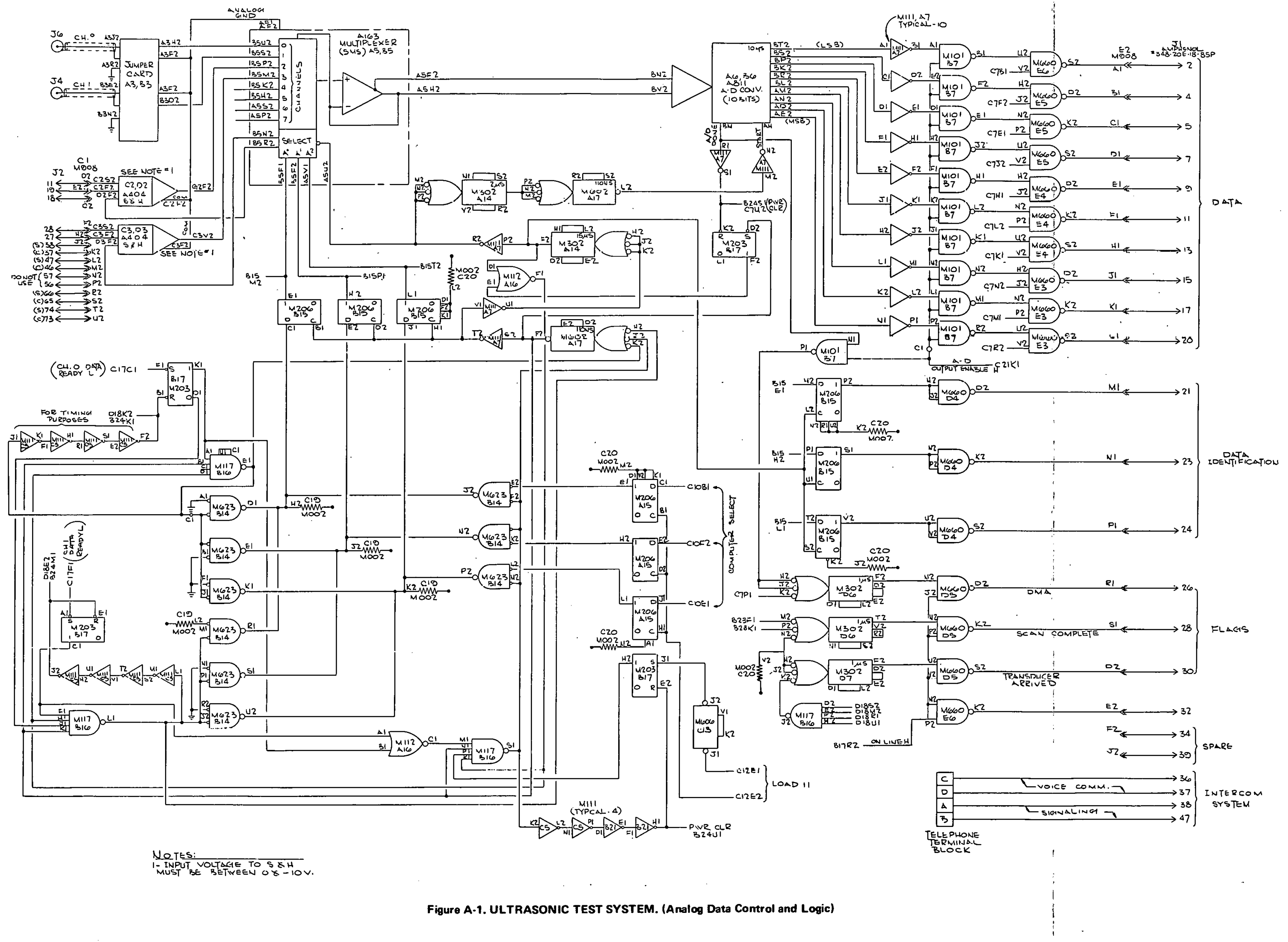




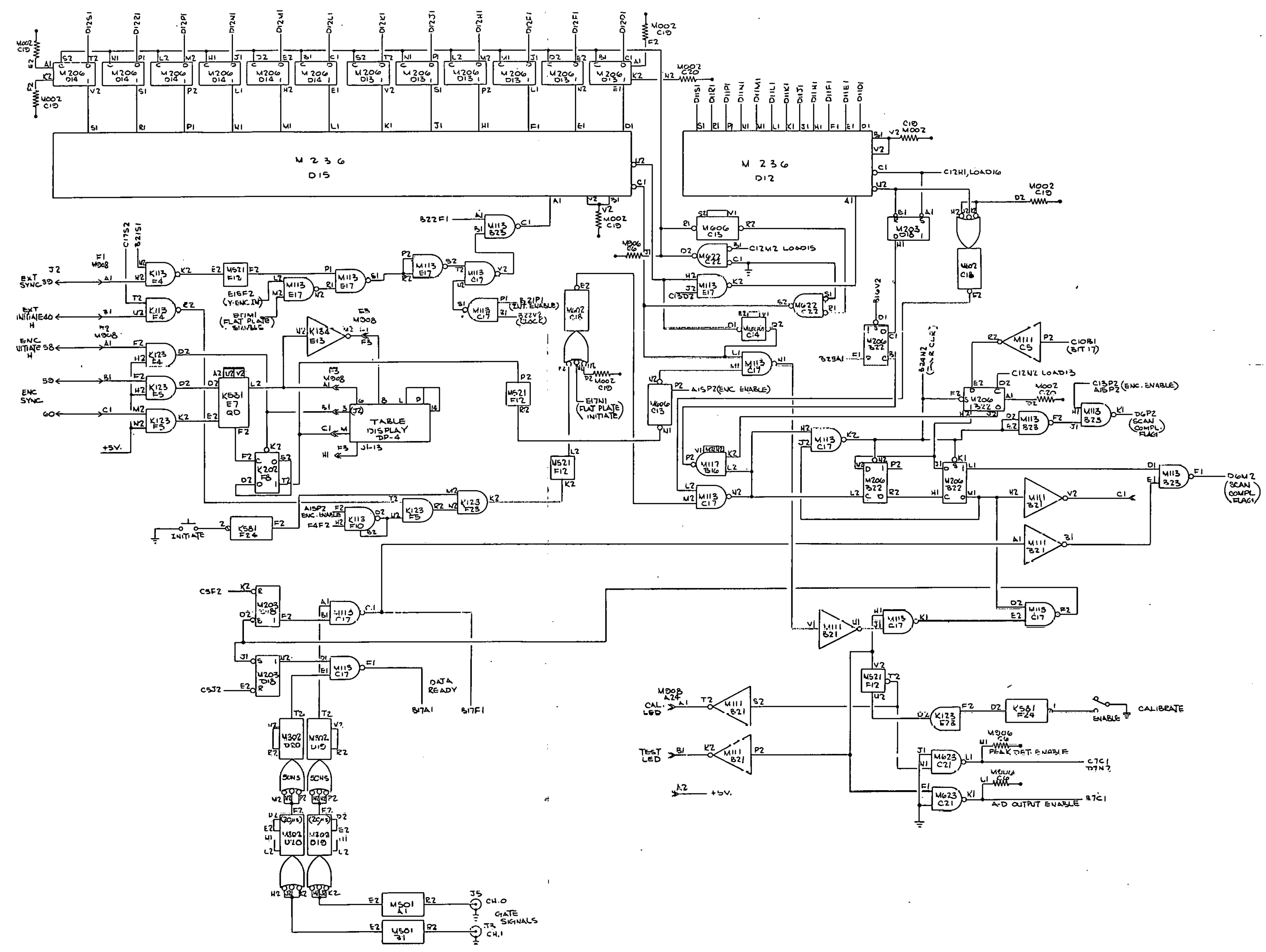

Figure A-2. ULTRASONIC TEST SYSTEM. (Sync Control - Data Enabling Circuit) 


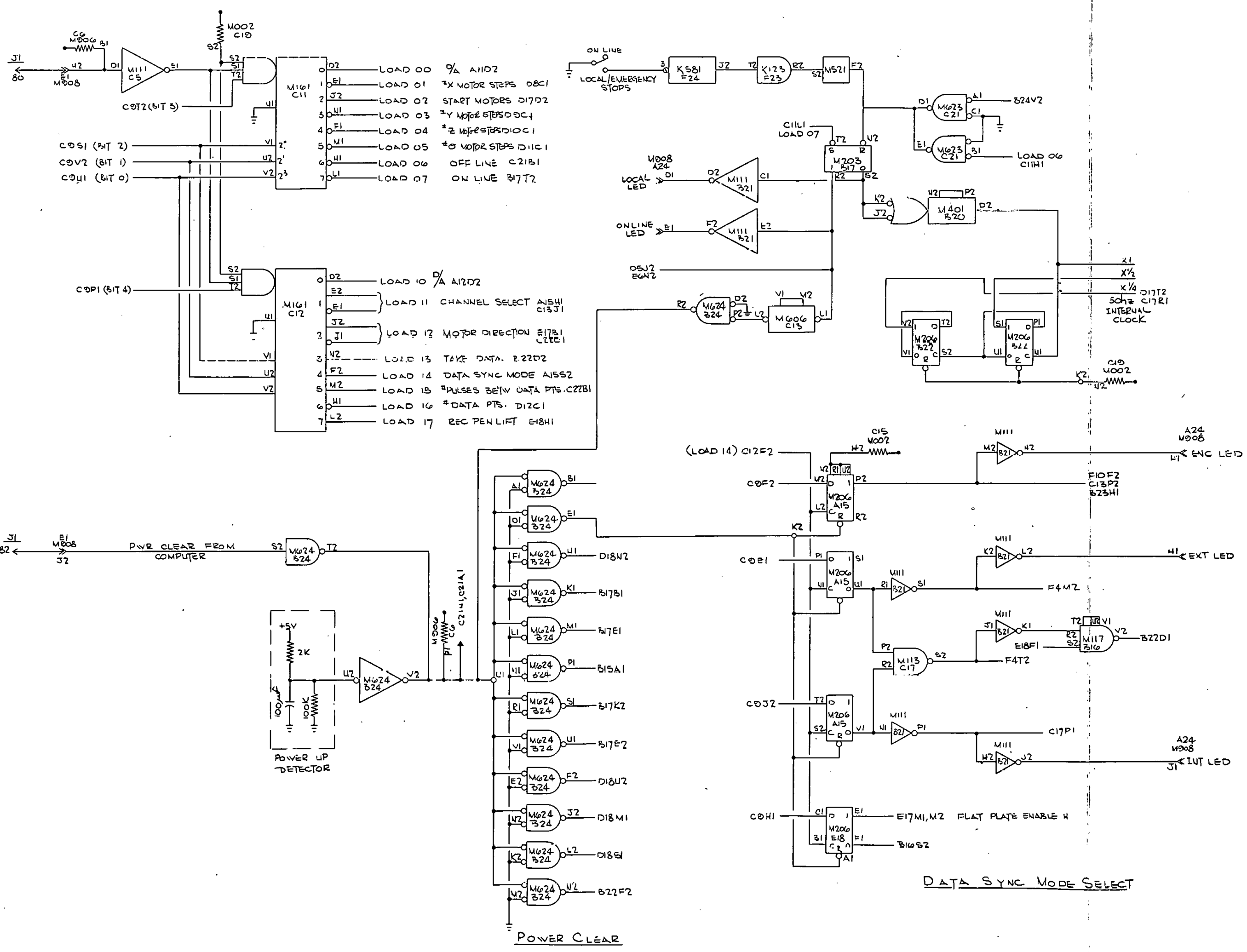

Figure A-3. ULTRASONIC TEST SYSTEM. (Miscellaneous Logic) 


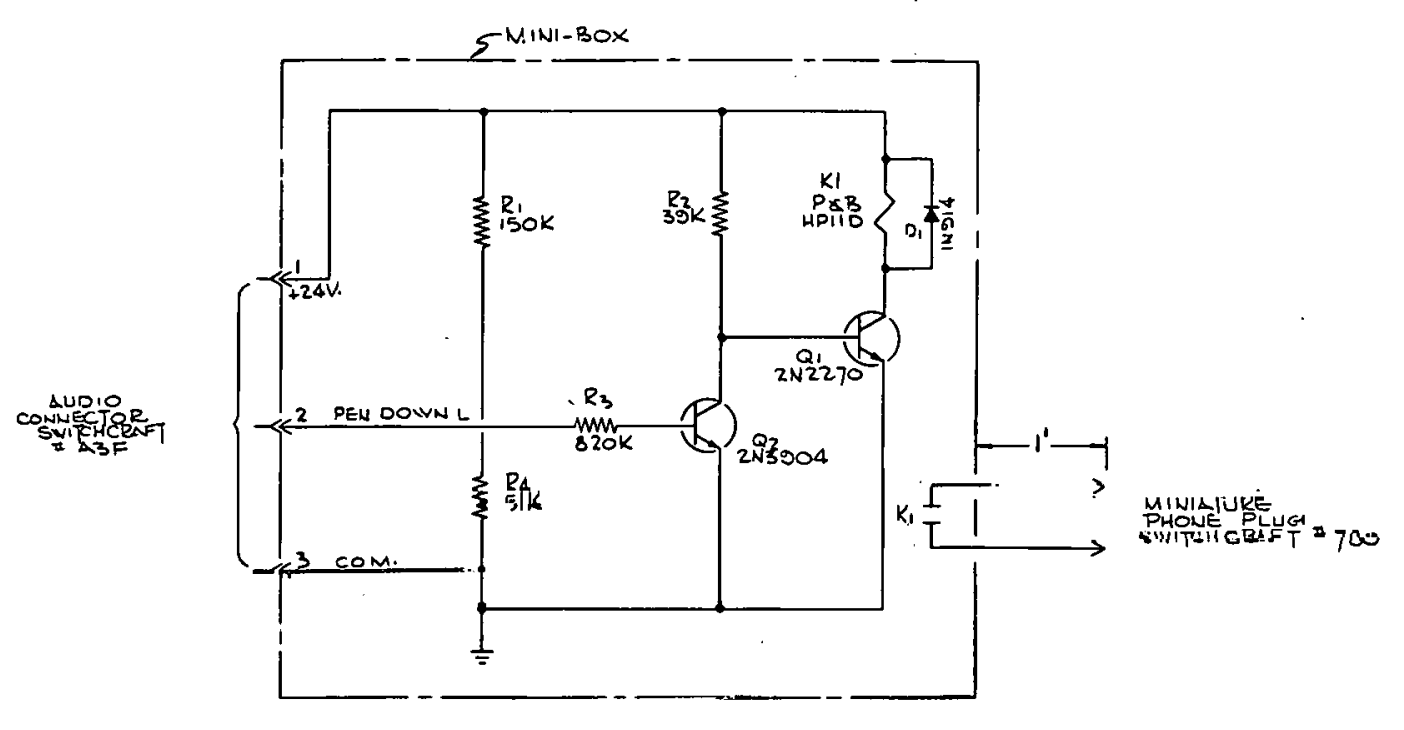

LLTRASONIC PEN LIET-

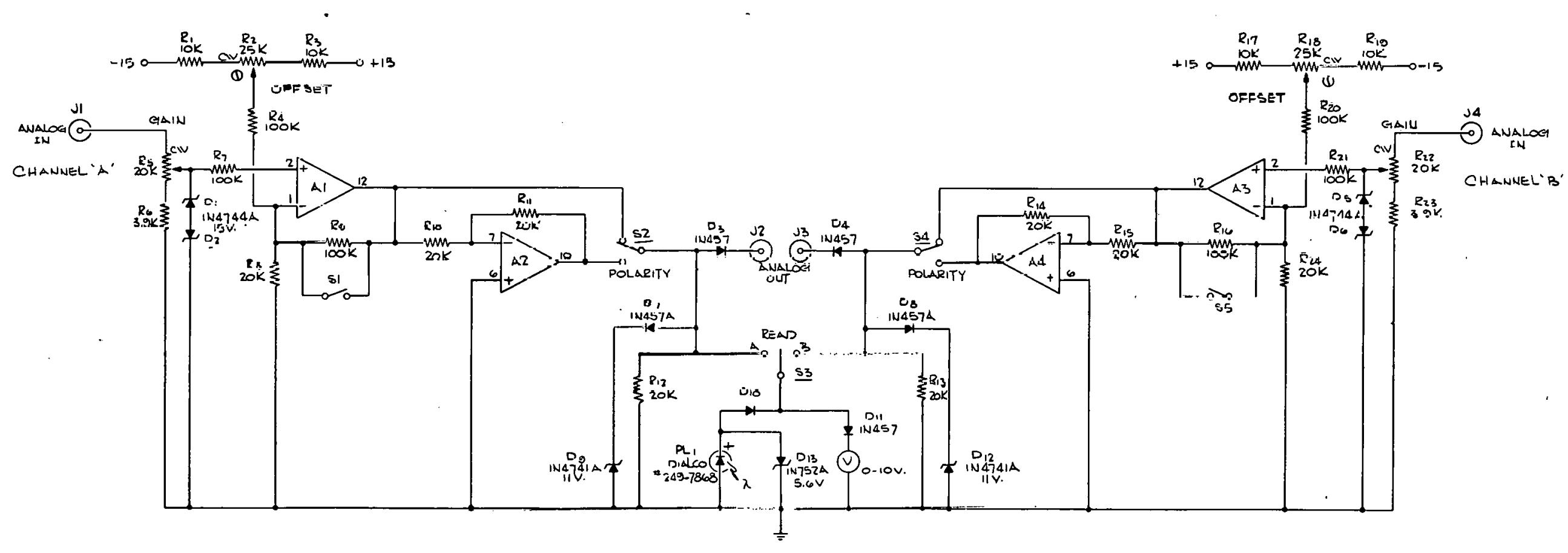

$\triangle N A L O G$ SCALER

Figure A-4. ULTRASONIC TEST SYSTEM. (Miscellanoous Schematics) 


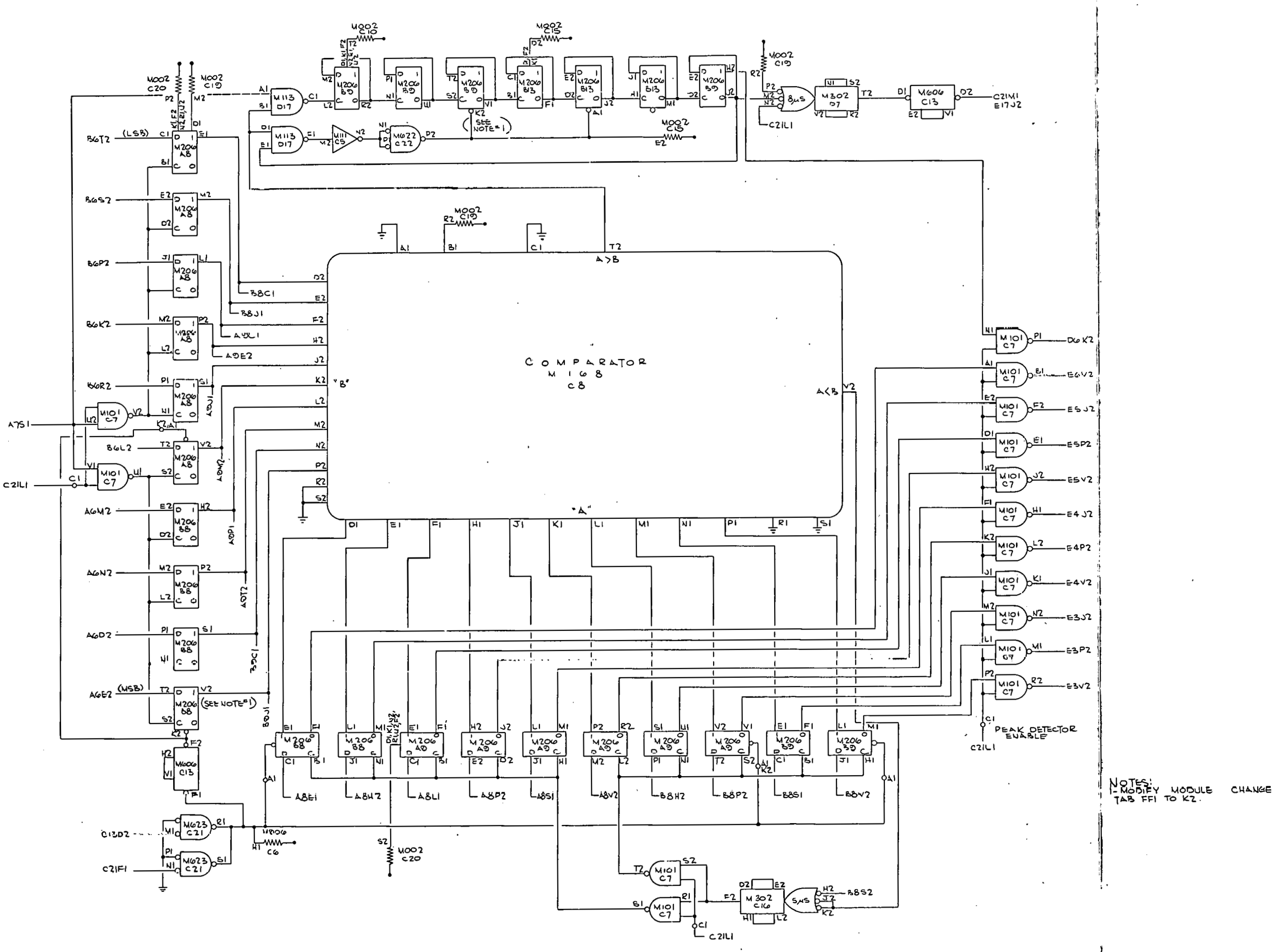

Figure A5. ULtRASONIC TEST SYSTEM. (Peak Detector Logic Diäram) 


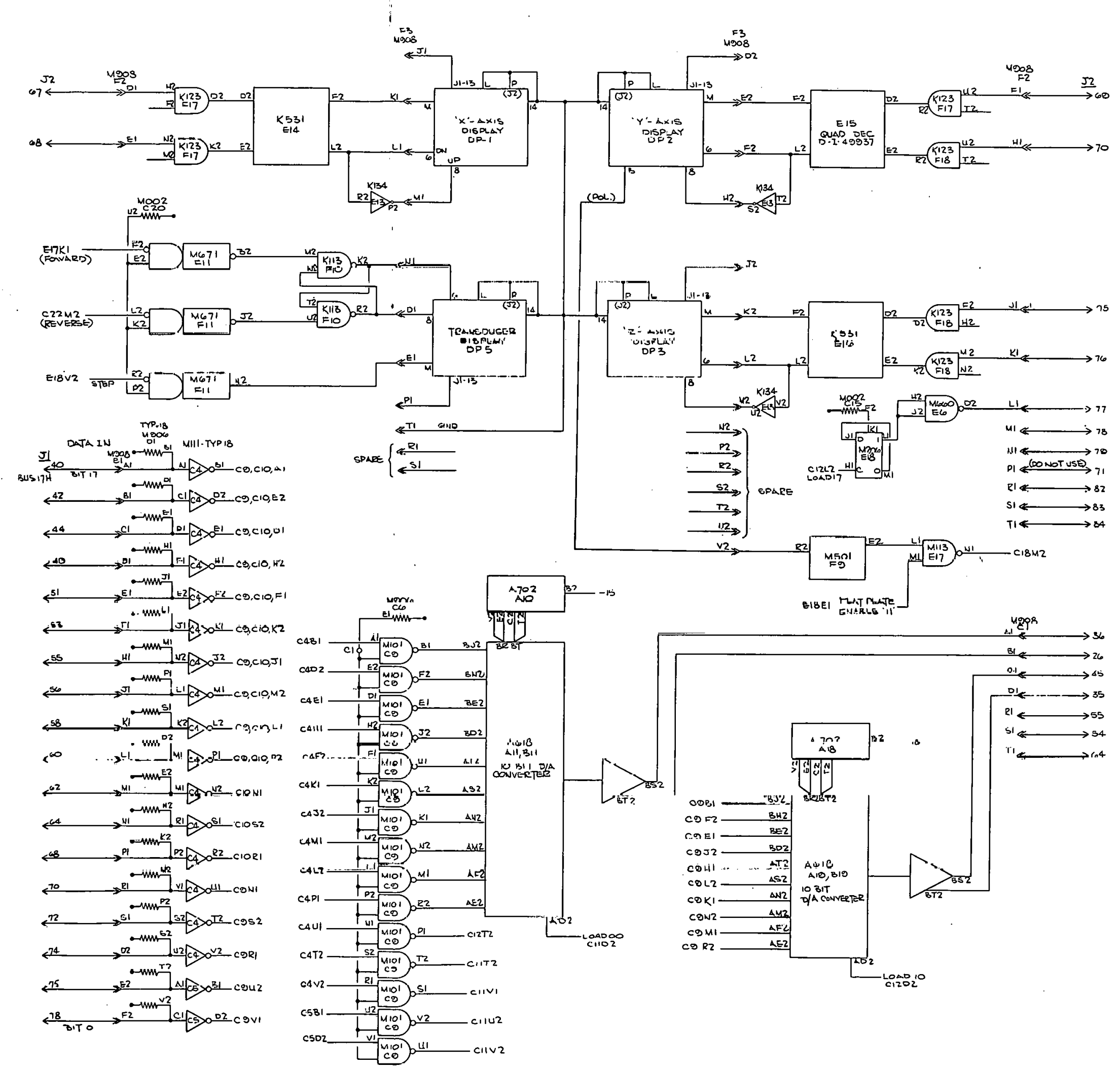

Figure A-6. ULTRASONIC TEST SYSTEM. (Analog Output and Displays) 


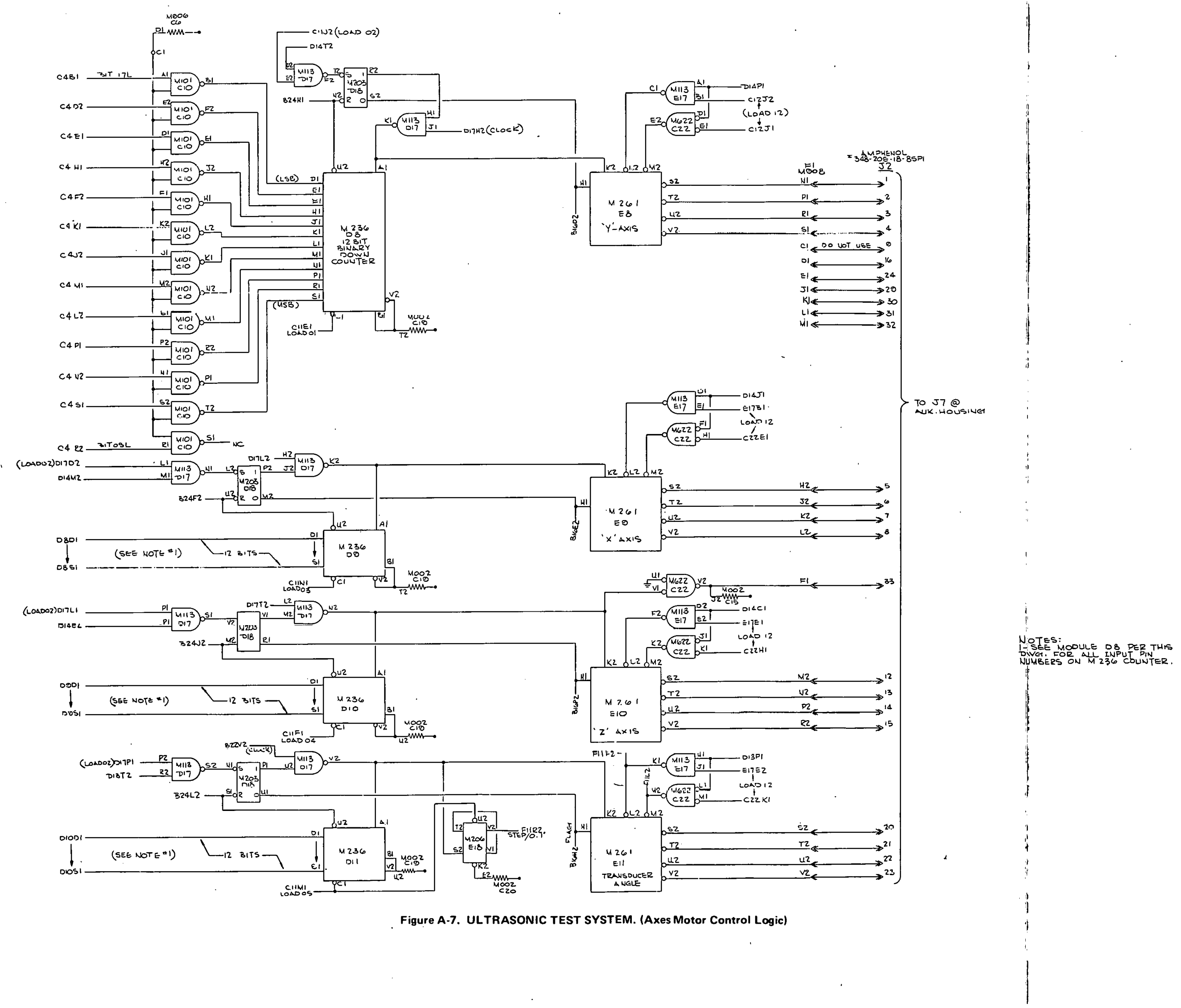



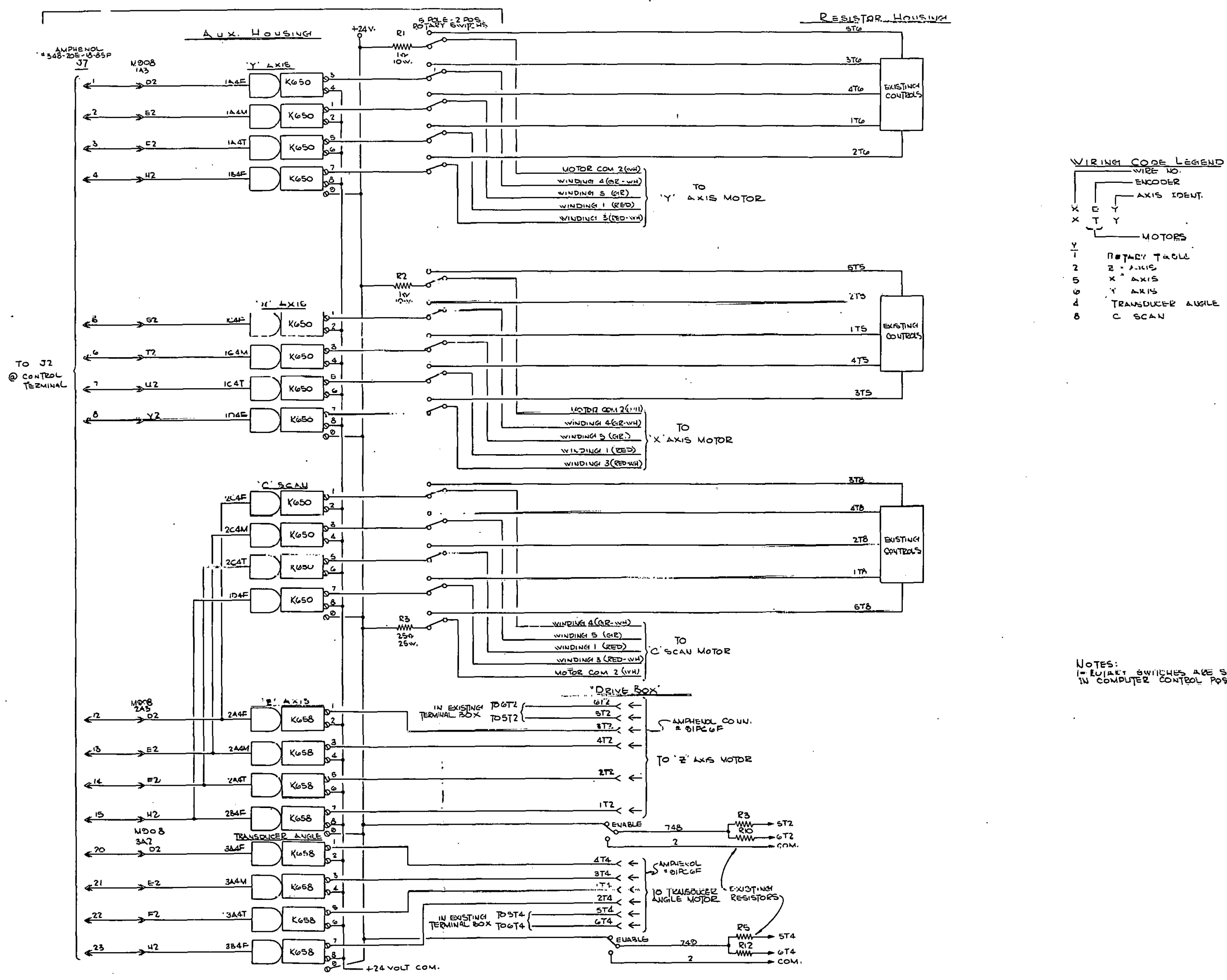

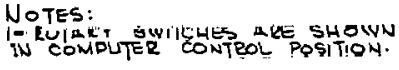

Figure A-8. ULTRASONIC TEST SYSTEM. (Auxiliary Resistor Housing Logic) 


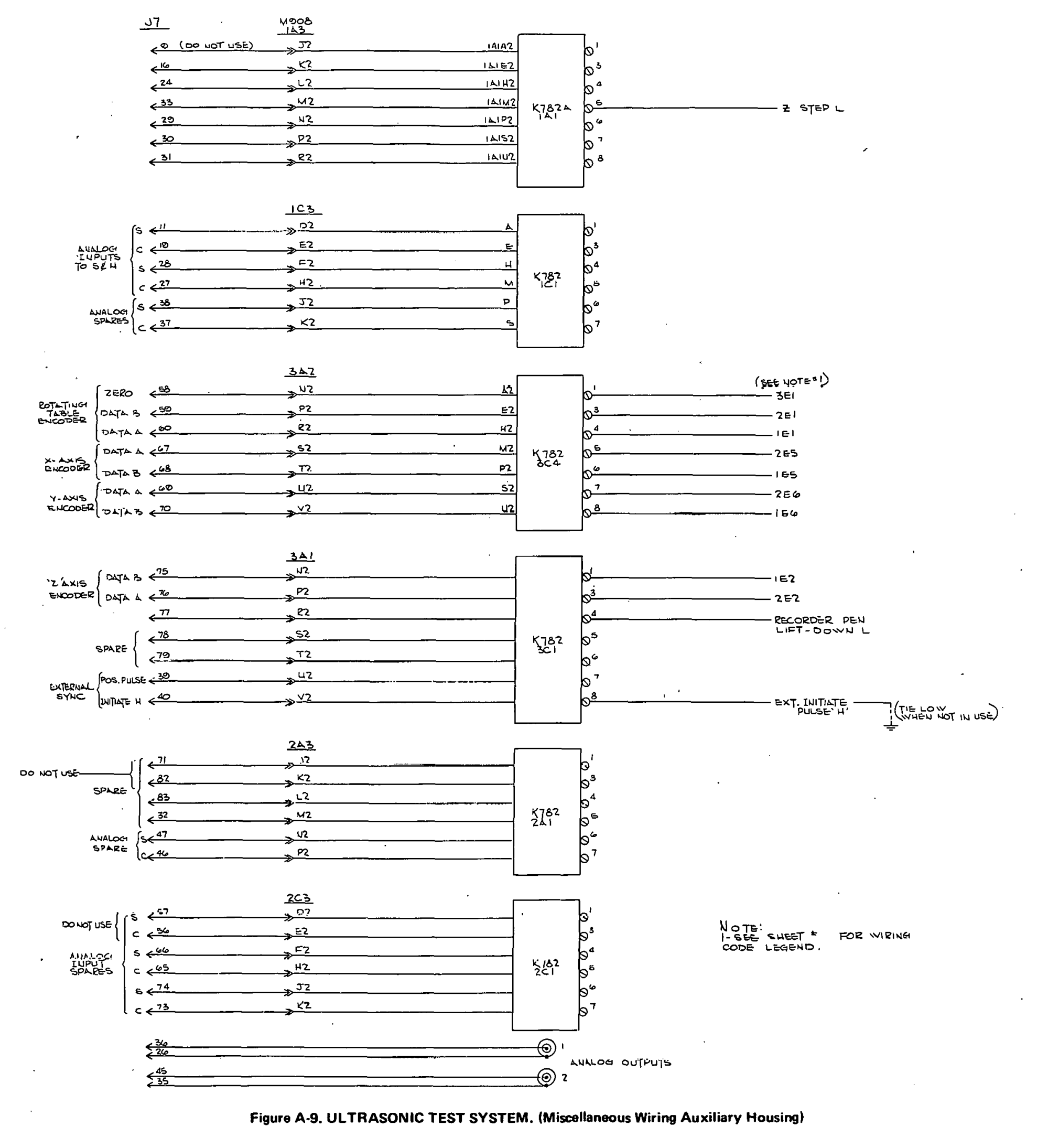



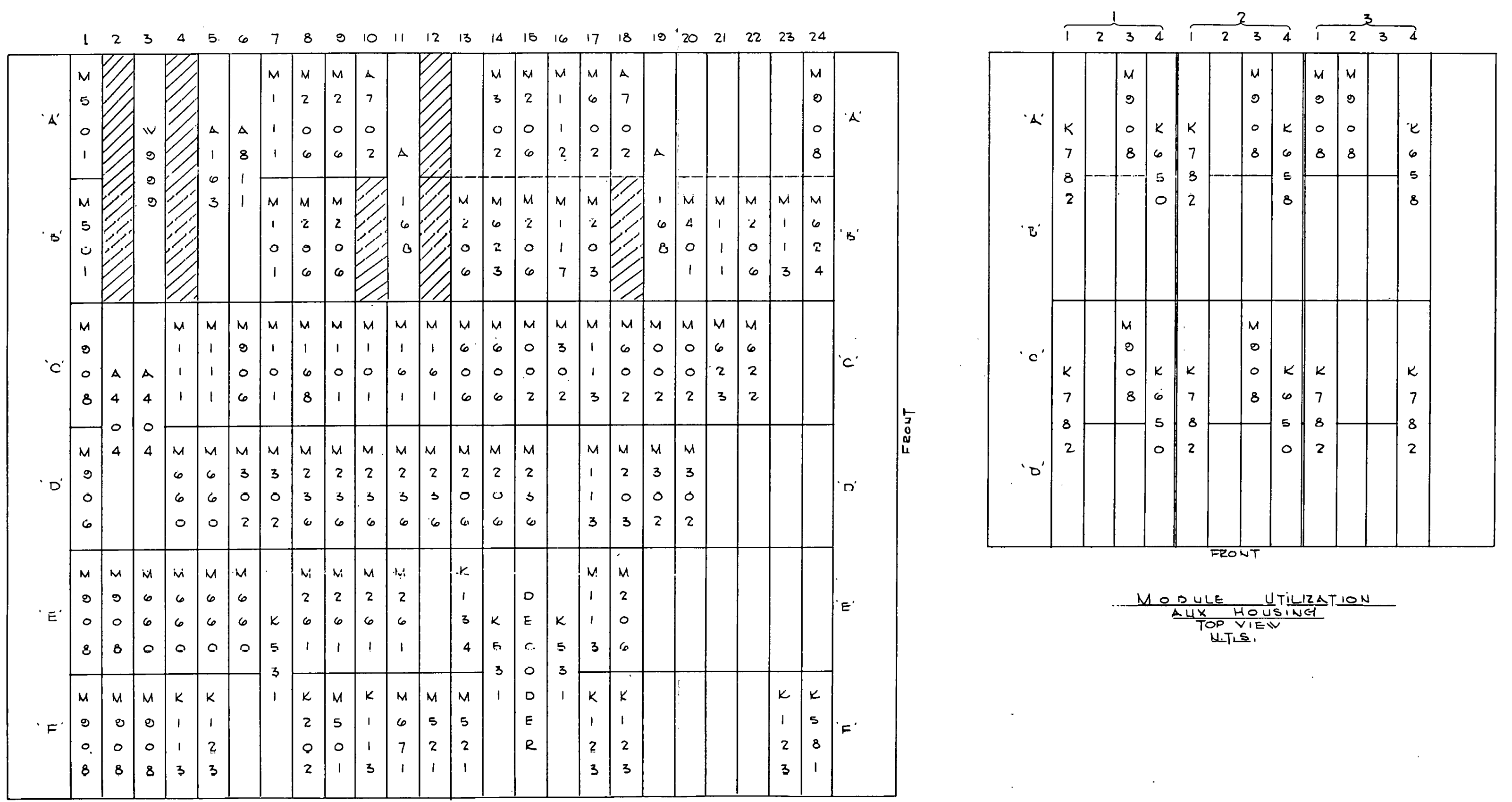

\section{$\frac{M O D U L E \text { UT ULIZATION }}{\text { DMTA/.CONTROL TERMINAL }}$ BOTIOM VIEN}

$\mathbb{Z}$ UNUSABLE 


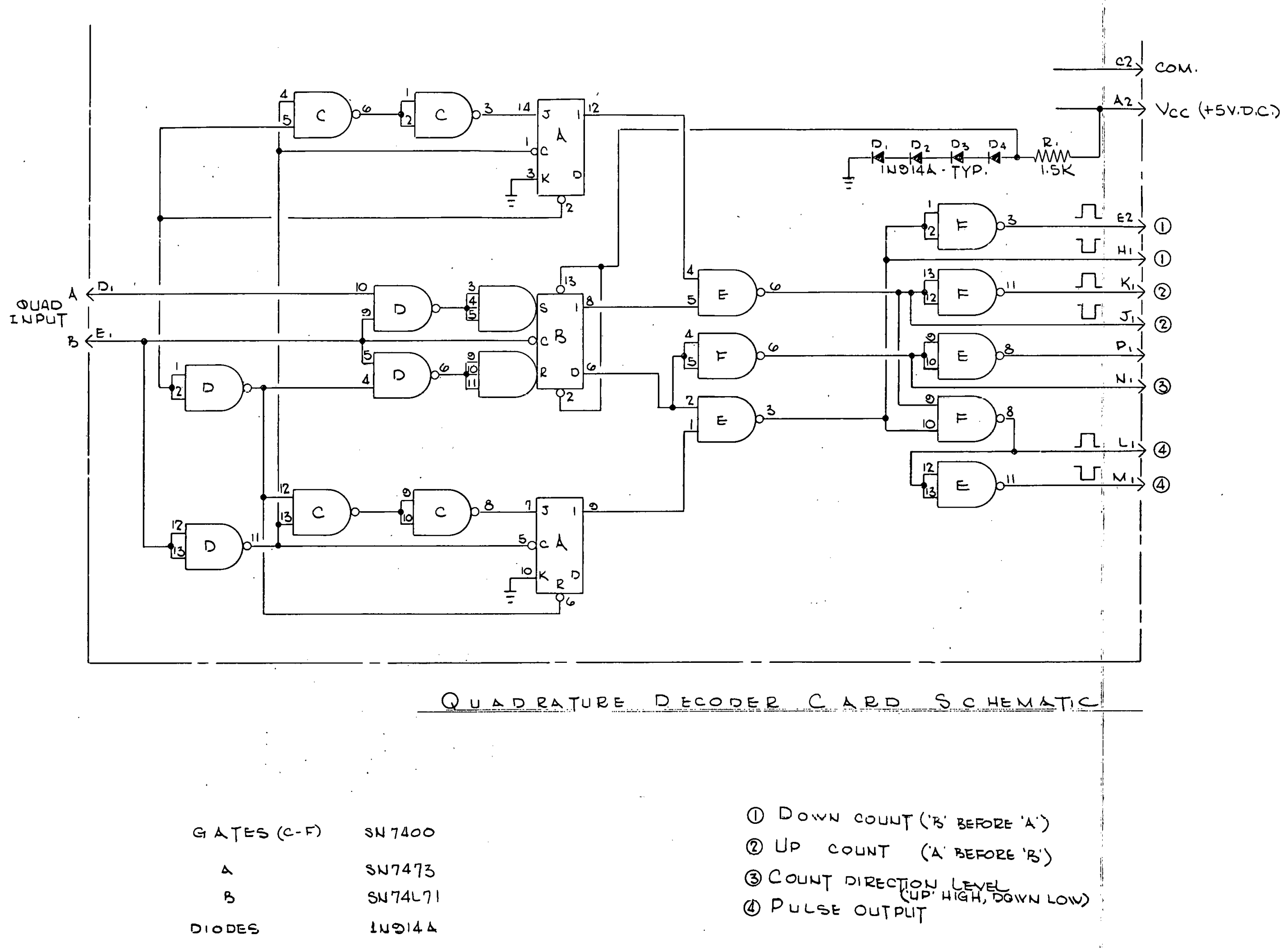

Figure A-11. NDT INSTRUMENTATION AND SYSTEM. (Quadrature Decoder Card Schematic) 
8

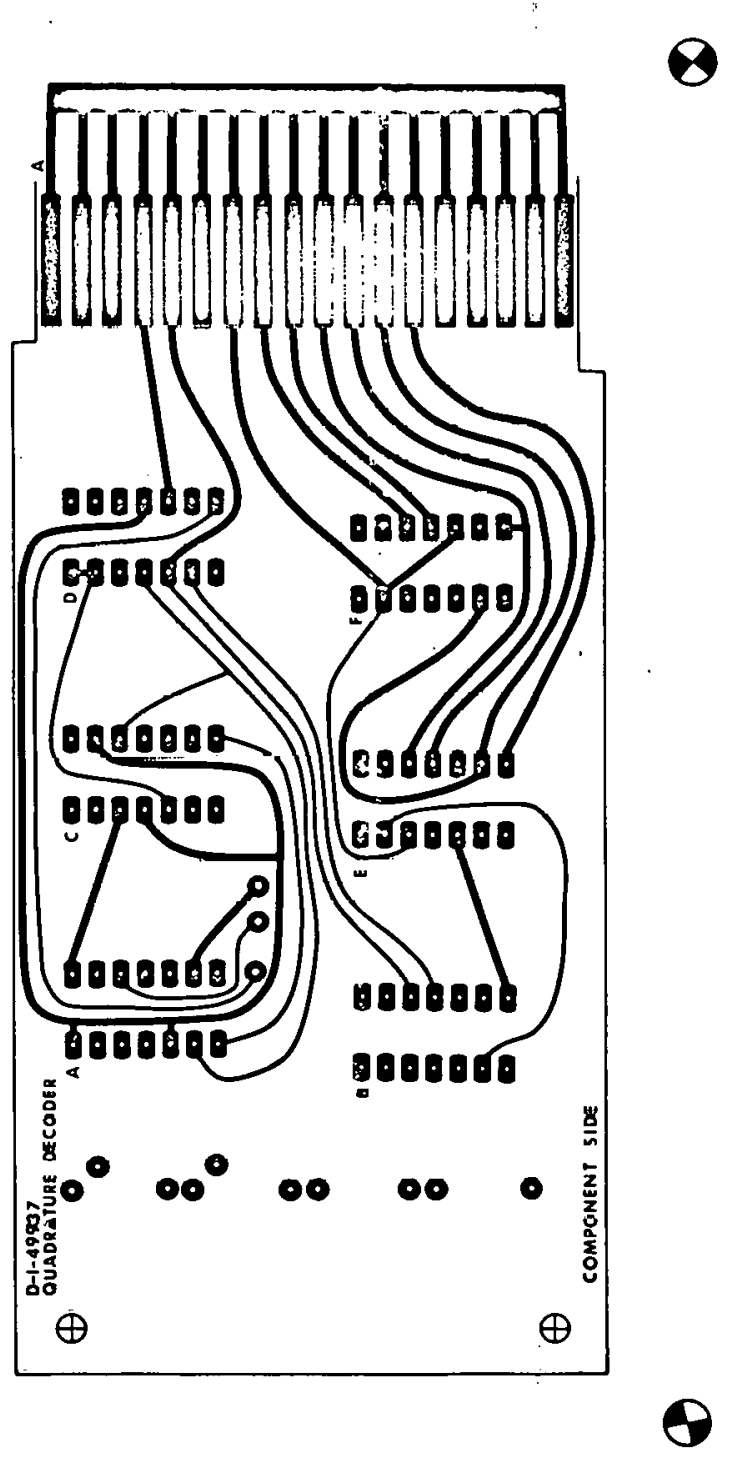

8

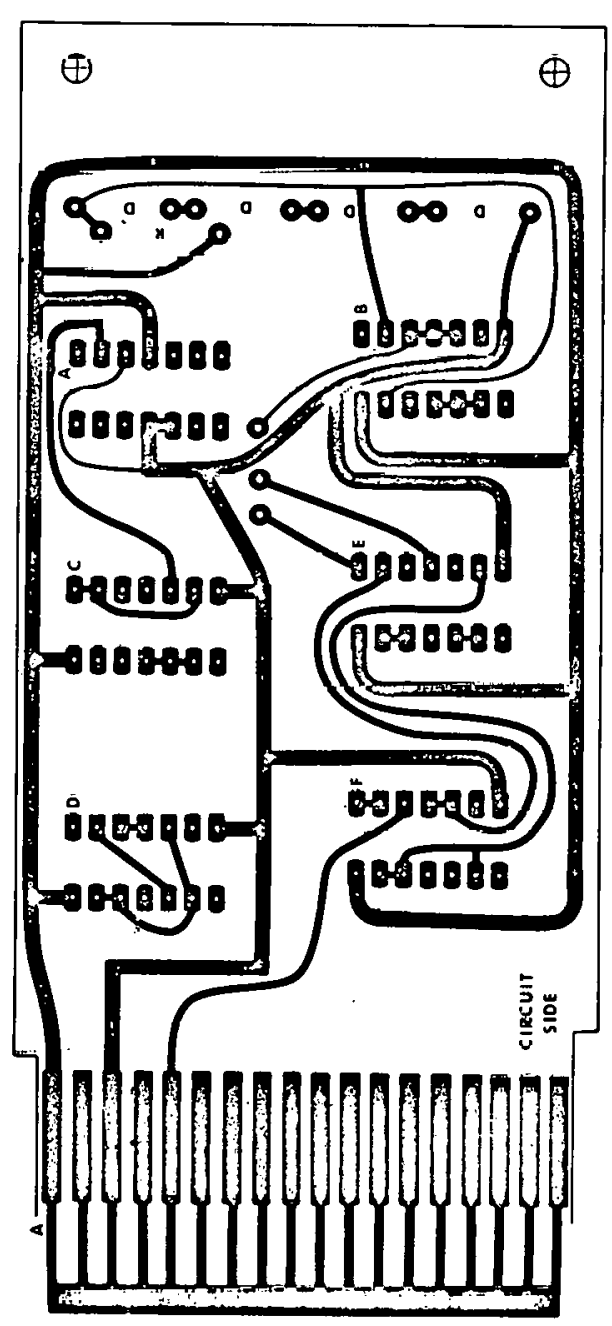

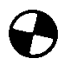
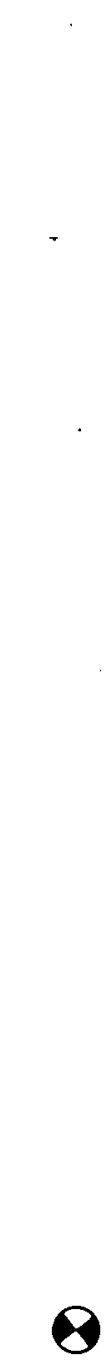

Figure A-12. NDT INSTRUMENTATION AND SYSTEM. (Quadrature Decoder Board) 


\section{COMPUTER INTERFACE SCHEMATICS AND LOGIC DIAGRAMS}
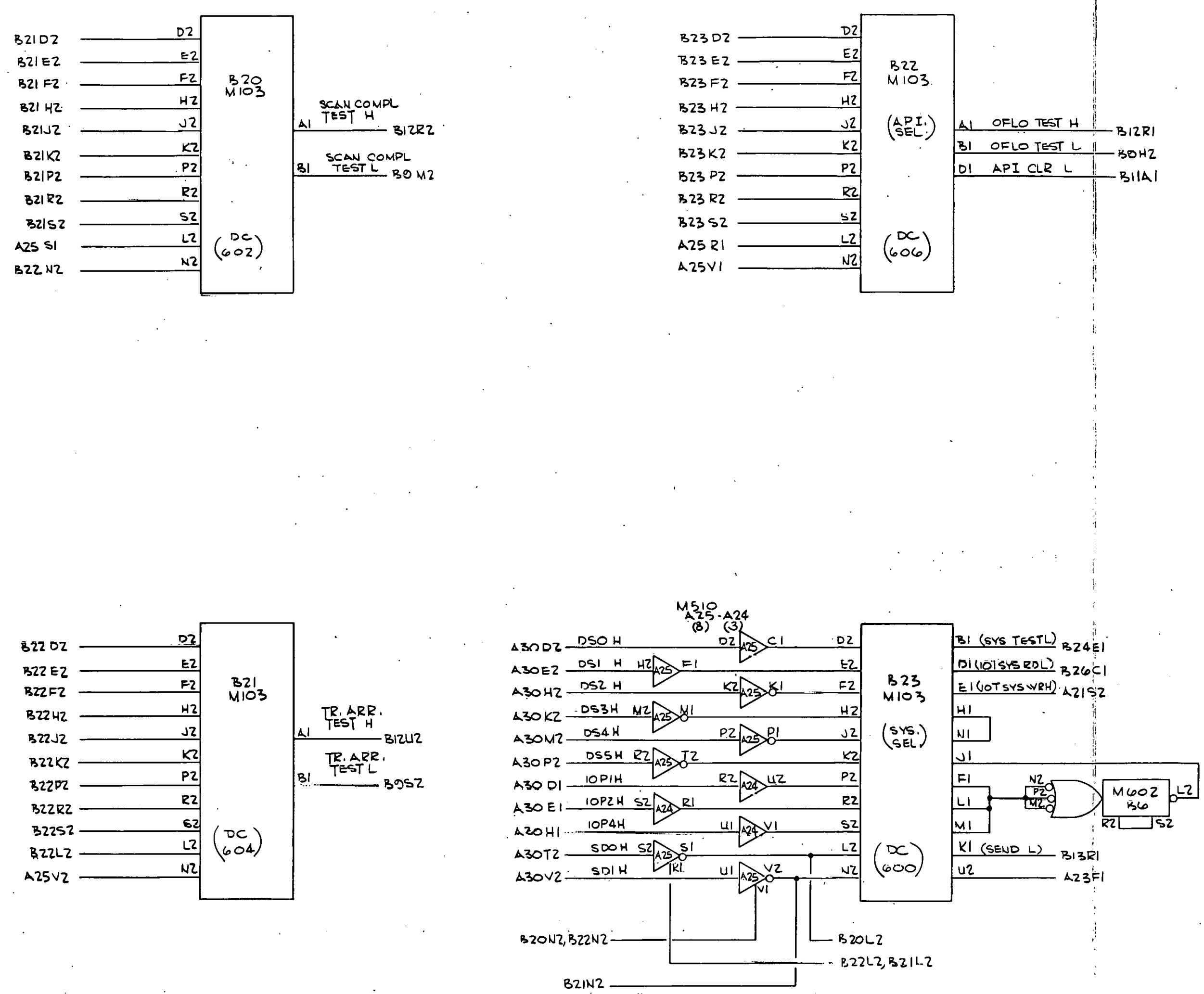


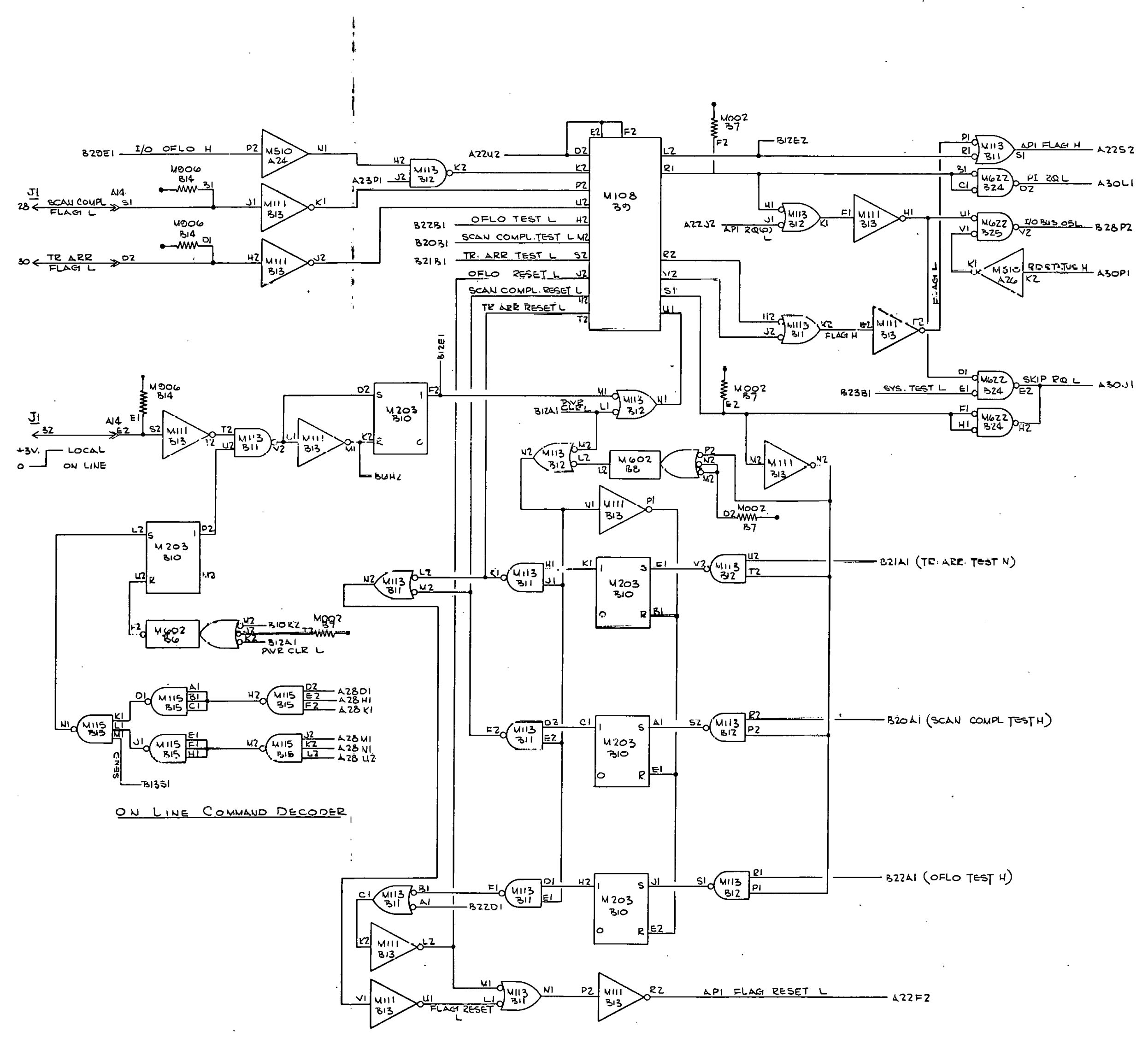

Figure B-2. ULTRASONIC TEST SYSTEM. (Computer Interface - Flag Processing) 


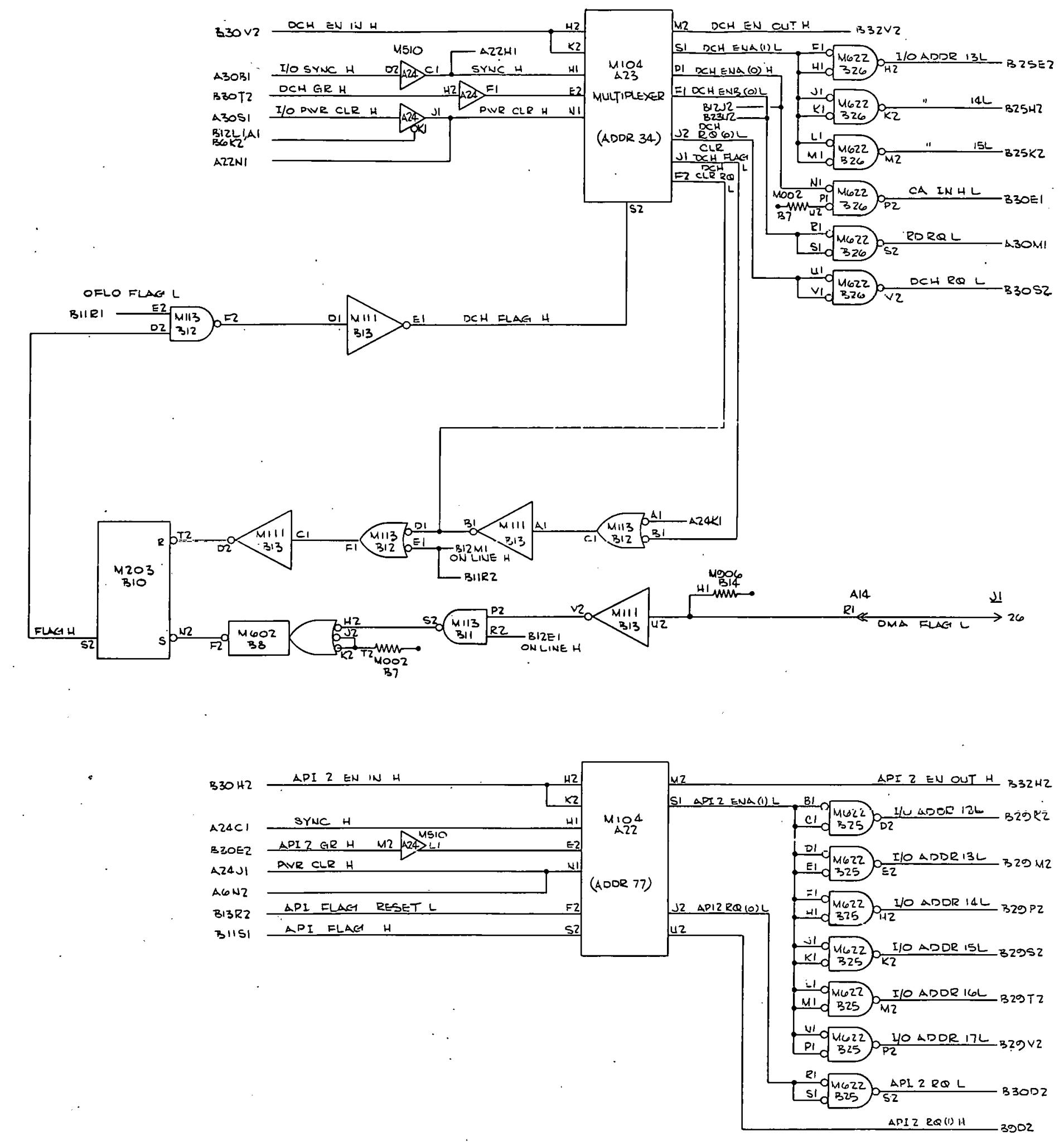




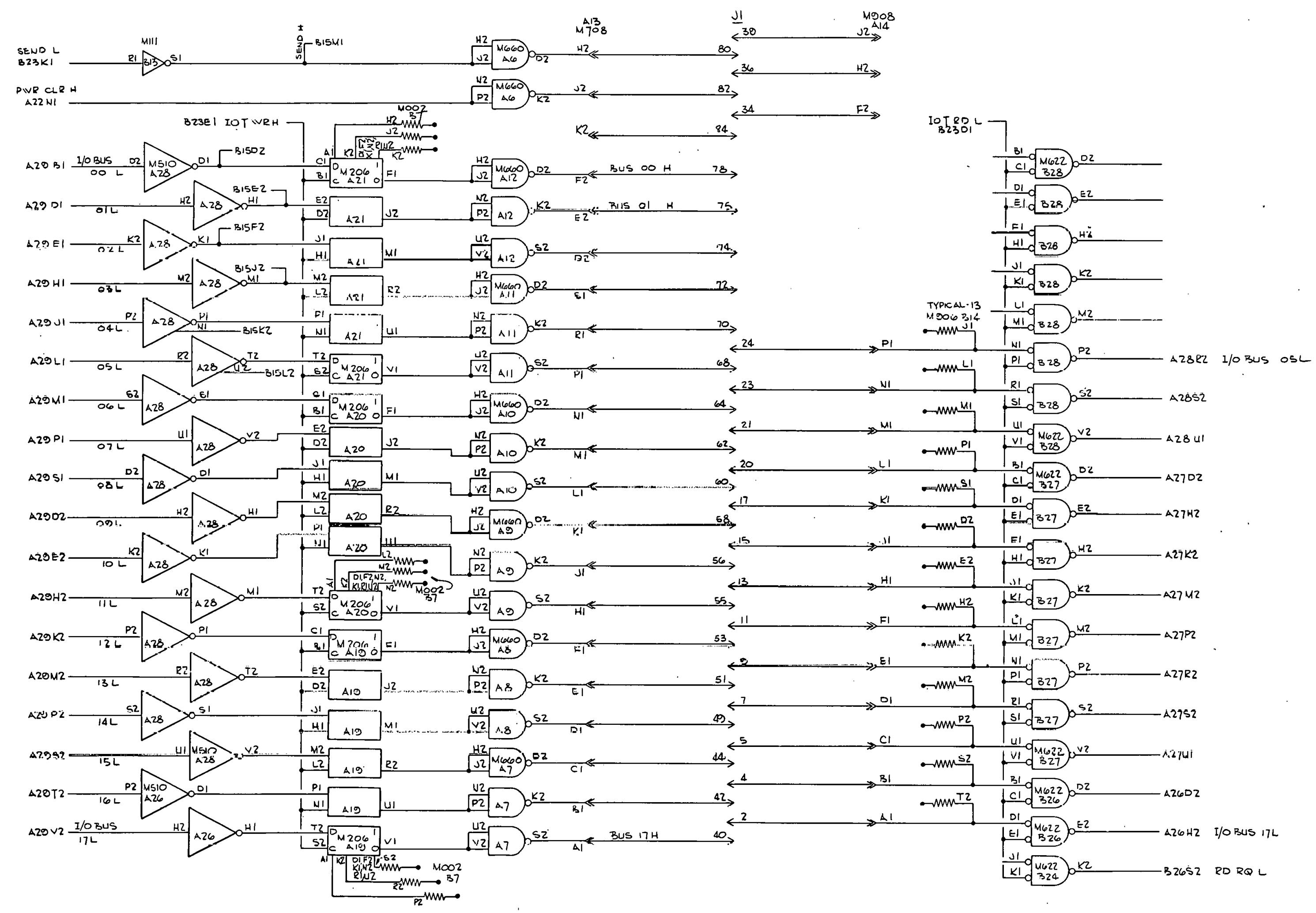

Figure B-4. ULTRASONIC TEST SYSTEM. (Computer Interface - Commands Processing) 


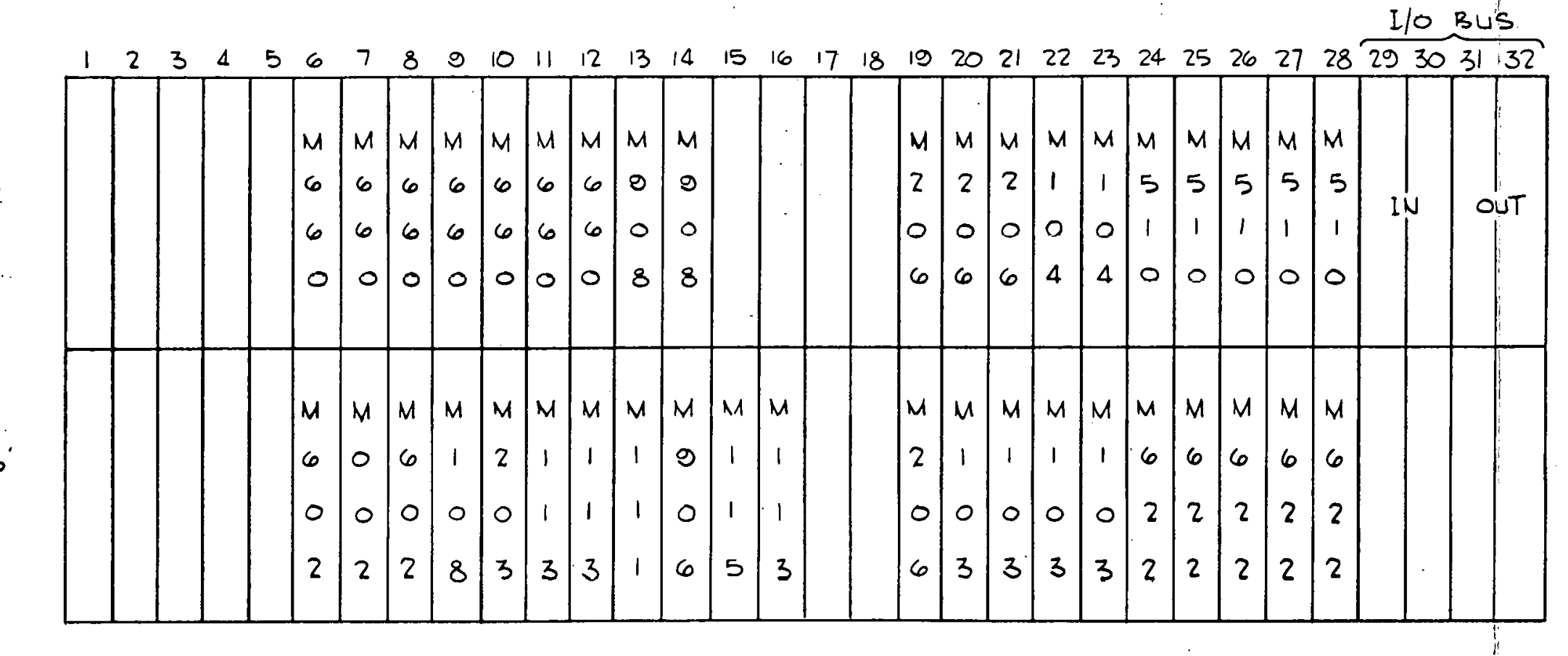

Figure B.5. ULTRASONIC TEST SYSTEM. IModule Utilization) 


\section{TERMINAL COMMANDS}

Commands to the data set are delivered via a coded 18-bit word which is loaded into the (IOT) in acumulator and transmitted by performing a system write input/output transfer (he command word designate the particular command and the latter twelve bits carry data or subcommands associsted with the command. For example, the rotating table encoder is selected as the data sync mode with the octal code 4200028. Each command is defined in Table C-3.

\begin{tabular}{|c|c|}
\hline Function & $\begin{array}{l}\text { coder } \\
\text { loctall }\end{array}$ \\
\hline $\begin{array}{l}\text { System Test } \\
\text { System Read } \\
\text { System Write }\end{array}$ & $\begin{array}{l}706001 \\
706002 \\
706004\end{array}$ \\
\hline 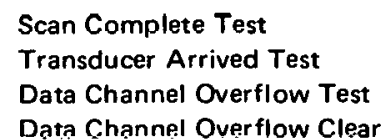 & \\
\hline
\end{tabular}

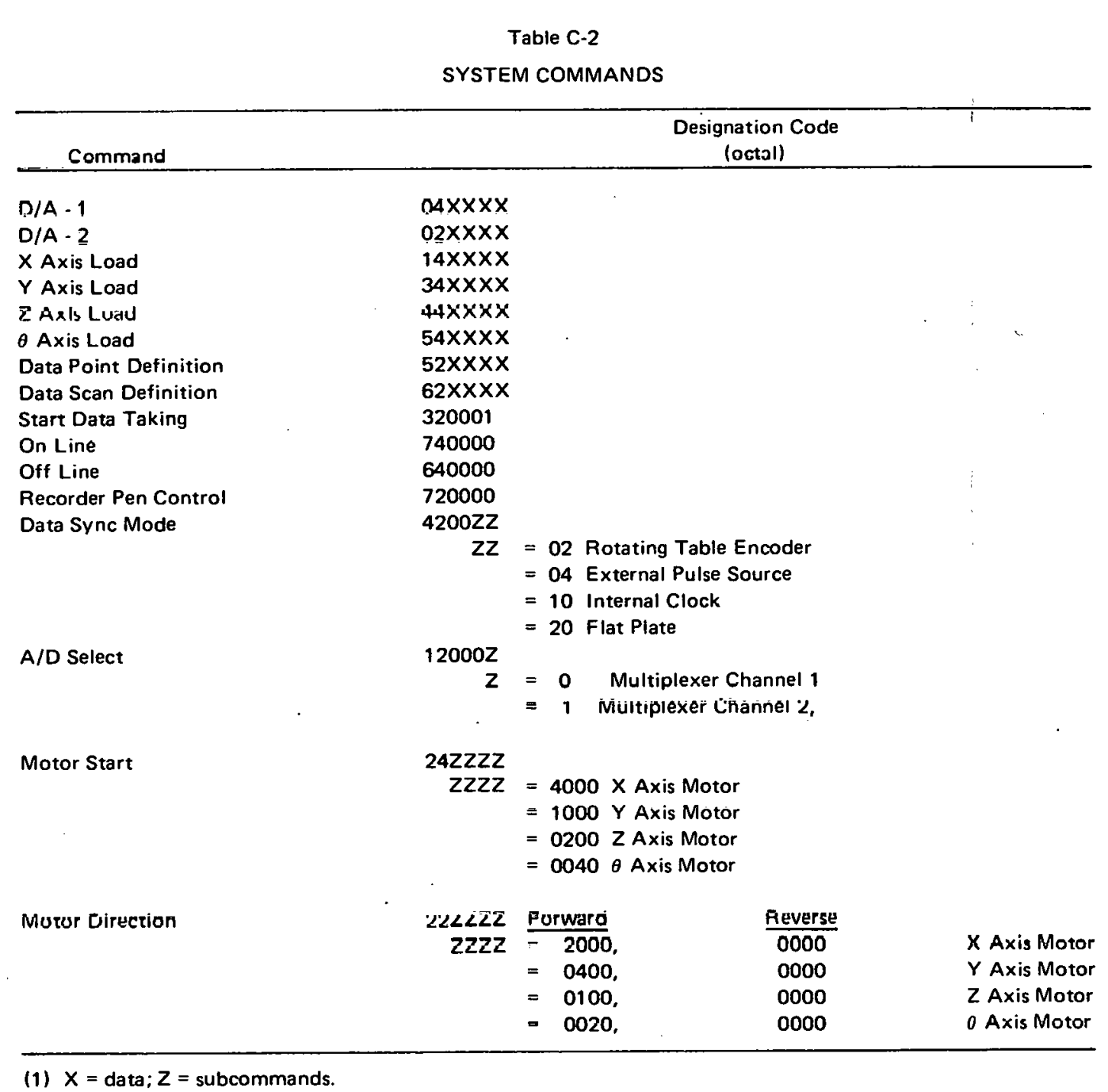

Table C-3
ULTRASONIC DATA SET COMMAND DEFINITIONS

\begin{tabular}{|c|c|}
\hline$X, Y, Z$, and $\theta$ Axis Load & $\begin{array}{l}\text { Allows the number of steps which the respective axis is to take to be } \\
\text { lod ded. }\end{array}$ \\
\hline Motor Start & Starts the motor designated by the enabled bits. \\
\hline Motor Urection & 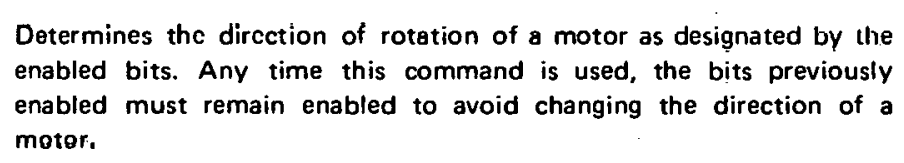 \\
\hline \multicolumn{2}{|c|}{ Motor slarl andu Uirection curnmands may be combined into one 18-bit word. } \\
\hline A/D Select & 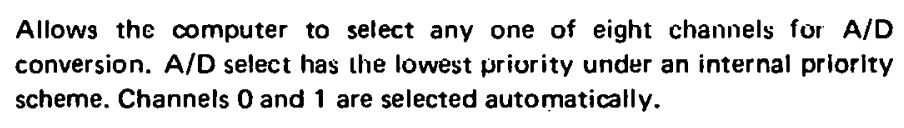 \\
\hline Start Data Taking & Enables the data set to begin taking data on the next initiate pulse. \\
\hline On Line & 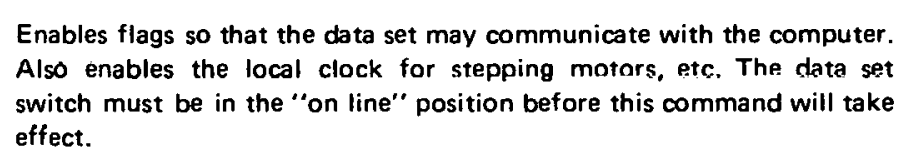 \\
\hline $\begin{array}{l}\text { Off Line } \\
\text { llocal emercencev stool }\end{array}$ & 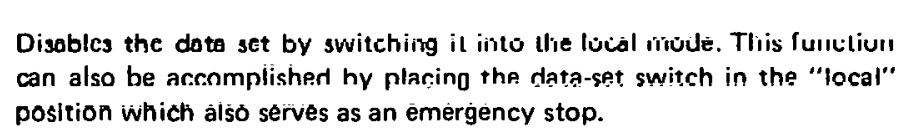 \\
\hline Data Sync Mode Select & $\begin{array}{l}\text { Specifies for the data set the source of pulses that define each point at } \\
\text { which to take data. }\end{array}$ \\
\hline Data Point Definition & 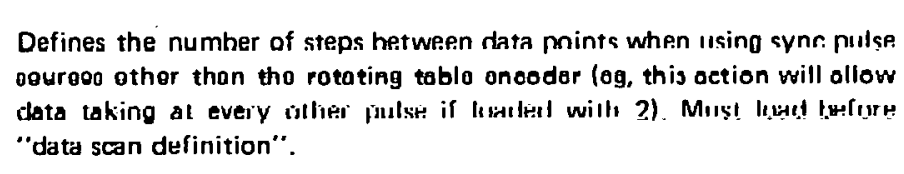 \\
\hline Data Scan Definition & 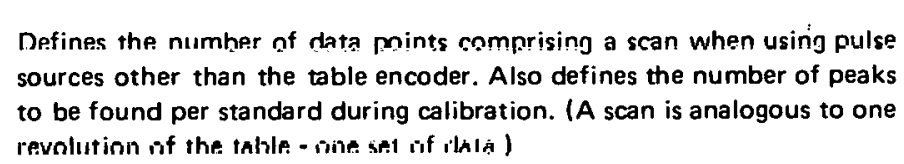 \\
\hline
\end{tabular}


APPENDIX D

SOFTWARE FLOW CHARTS

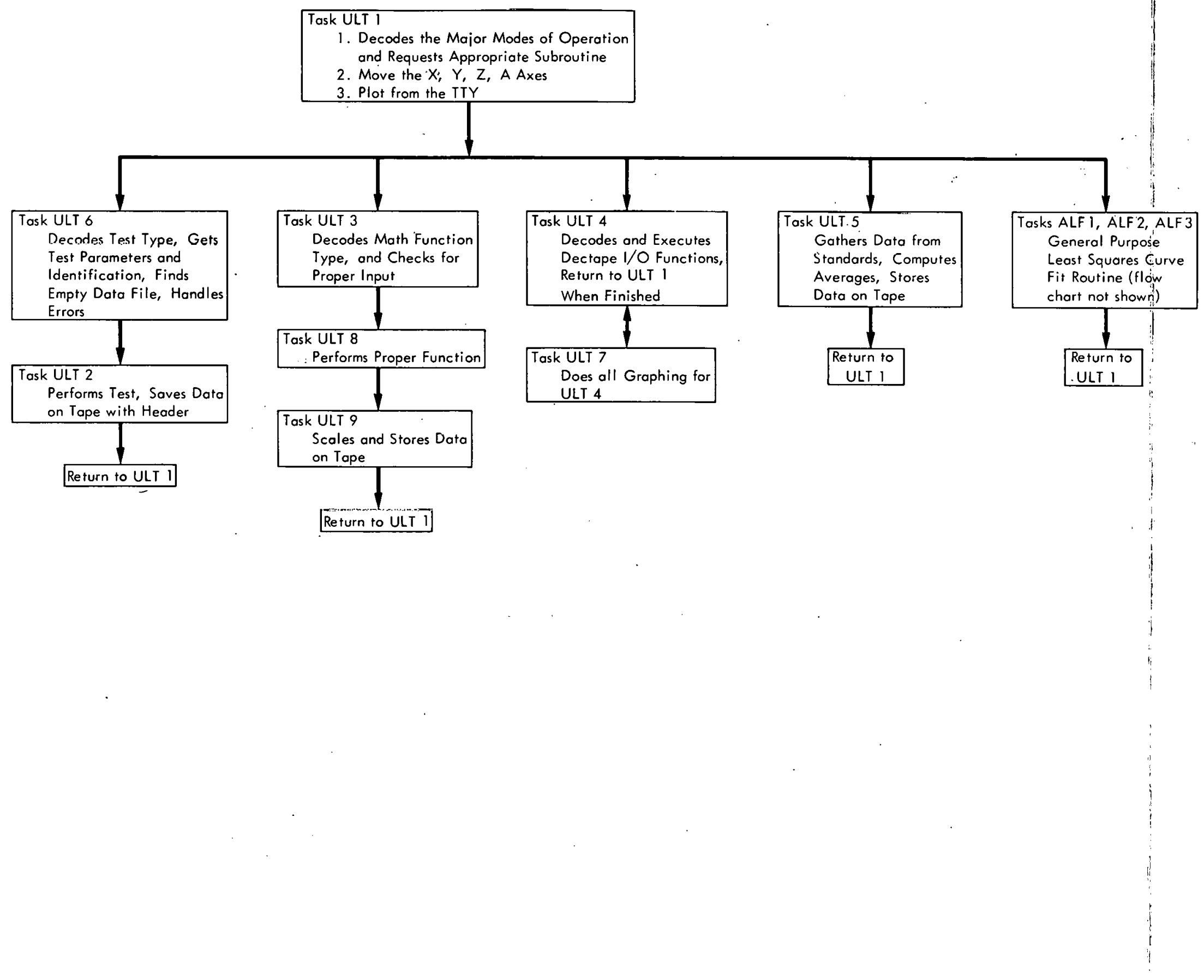


Program TALK

Task ULTI (main task)

Dimension J(250), $\mathrm{Al}(20)$

Common/Coml/J, Al
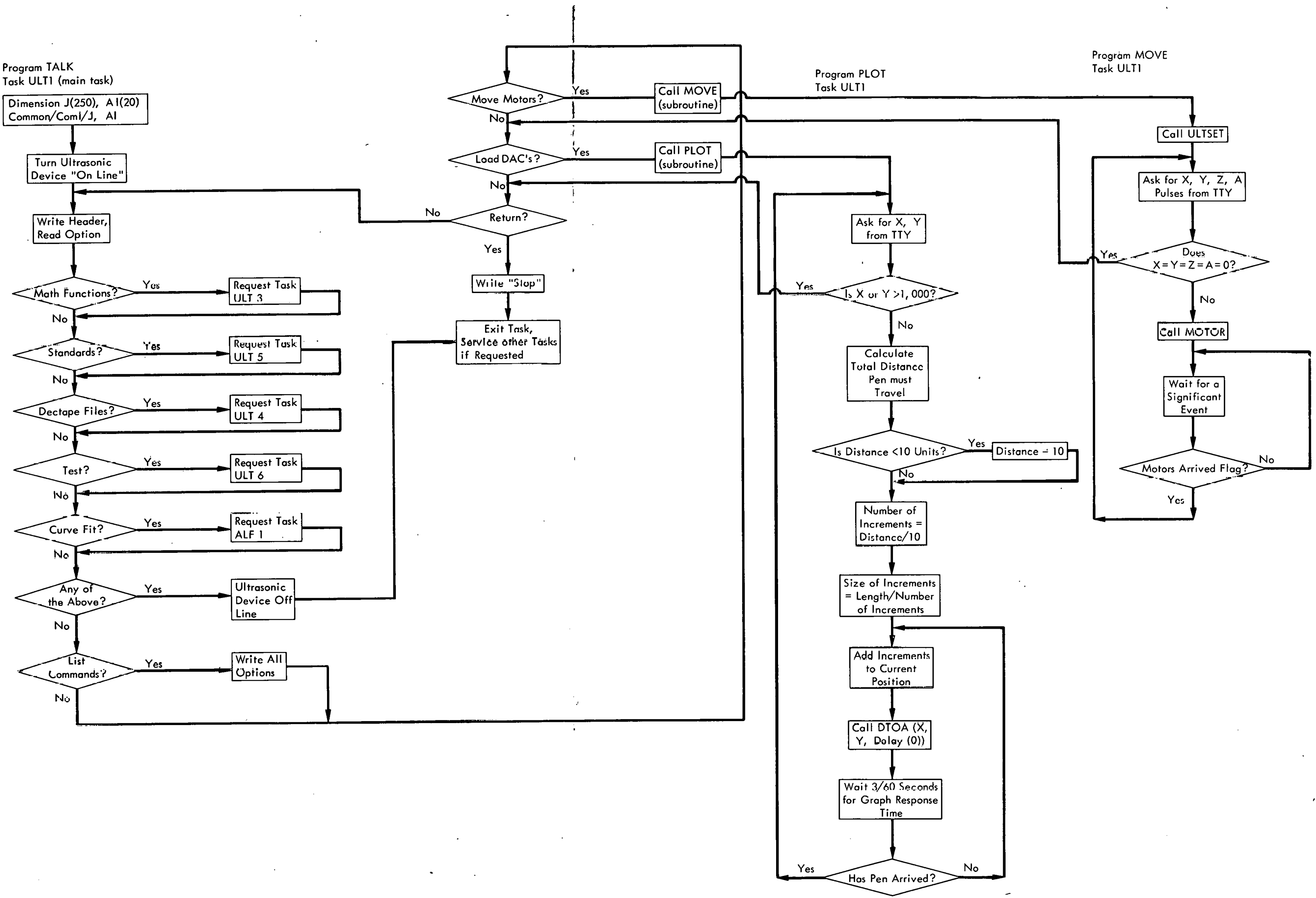
Program MOTOR

Used in Tasks ULTI and ULT2

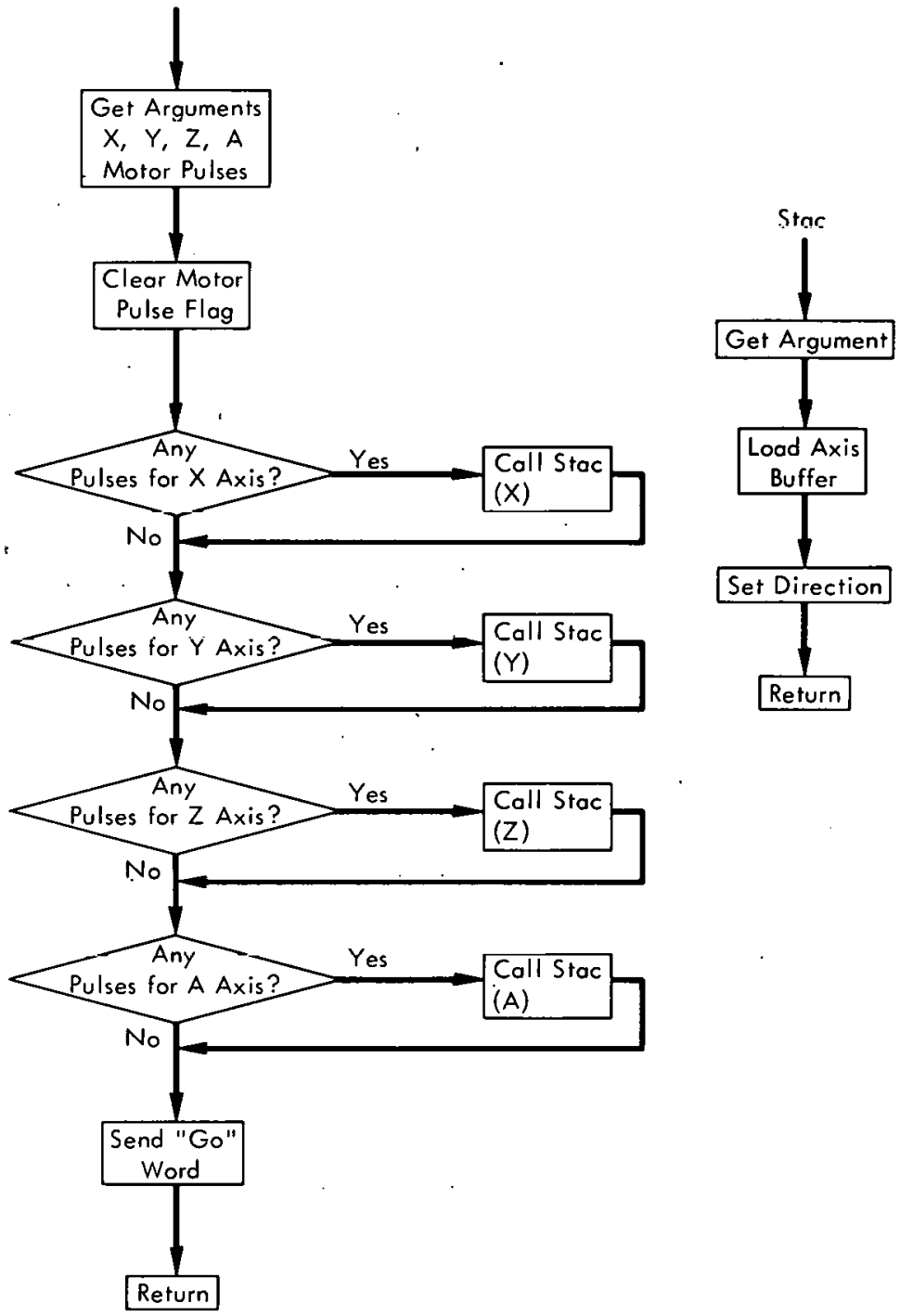

Program DTOA Used in Tosks ULTI and ULT6

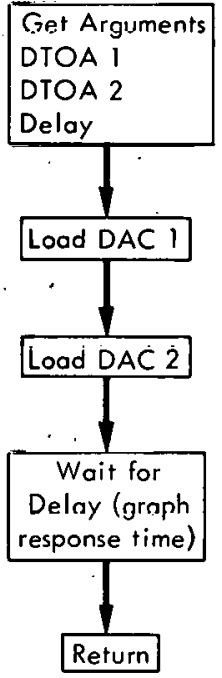


Program TTL (contains subroutines TTL, UPDWN, ULTON,

ULTOF, ULTSET and the interrupt handling routine)

Used in All Tasks
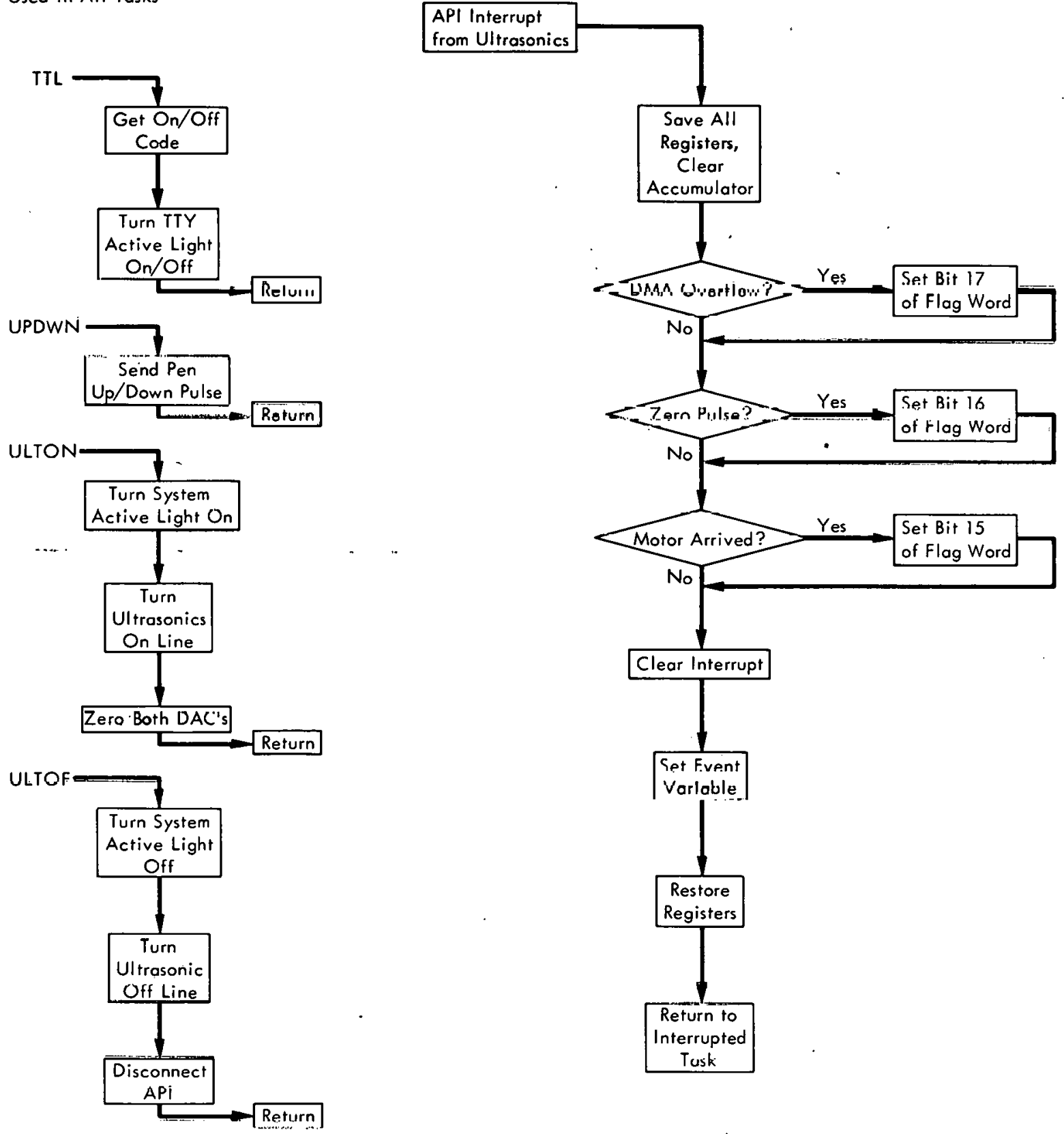

ULTSET

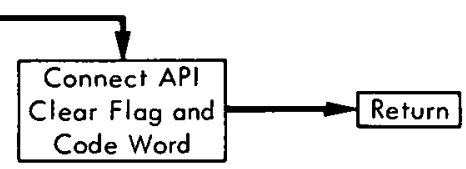


Program ERR

Task ULT6

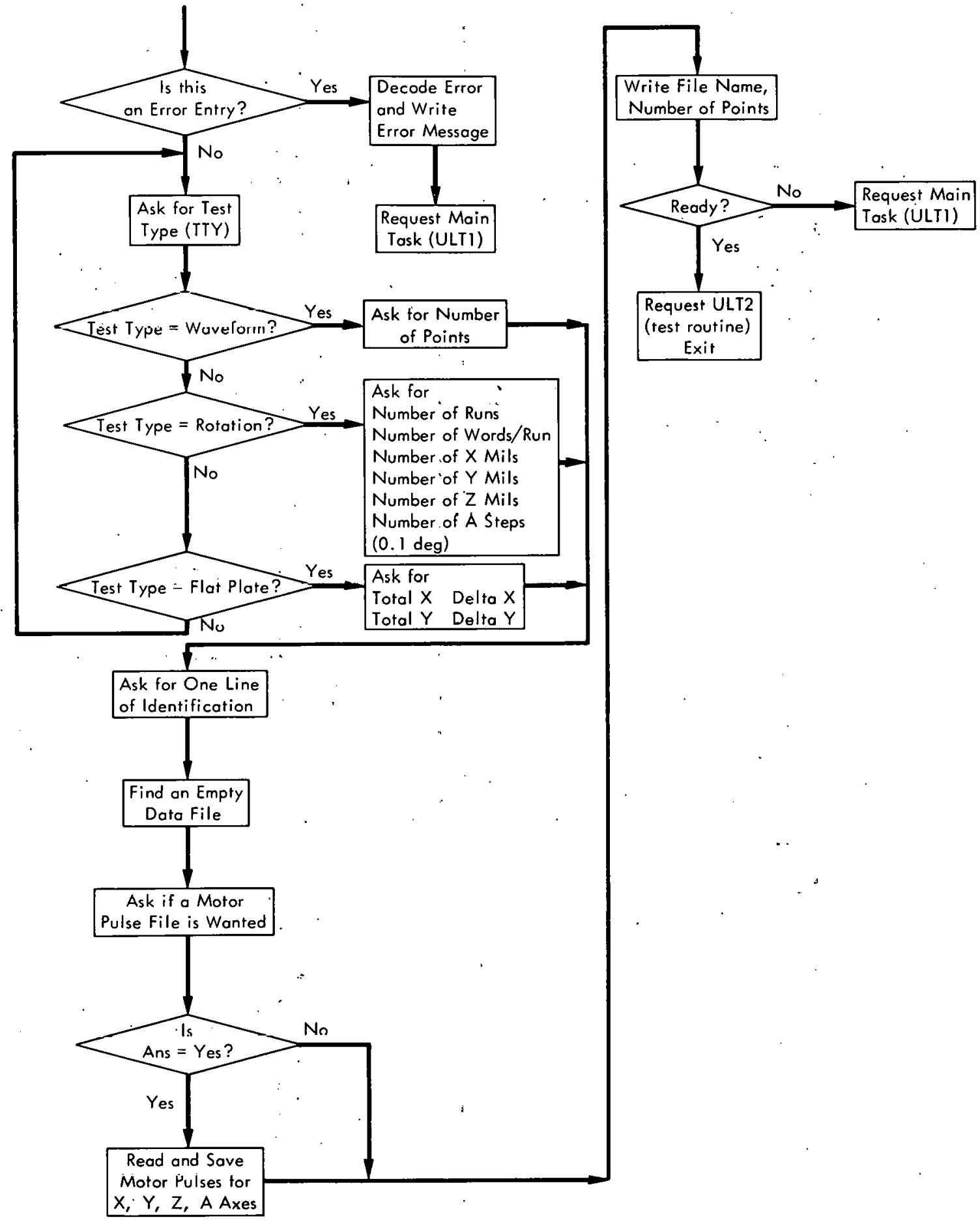




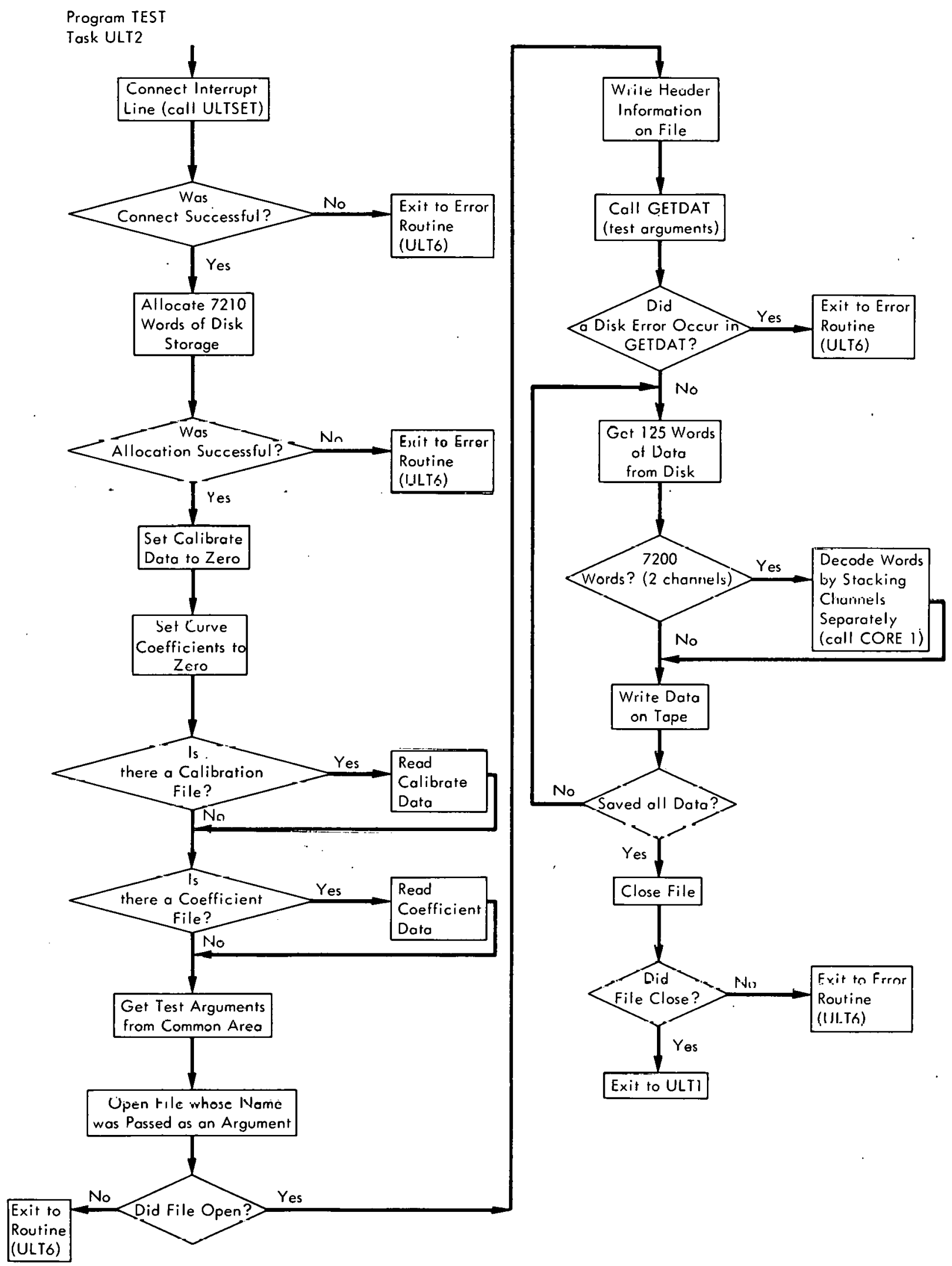




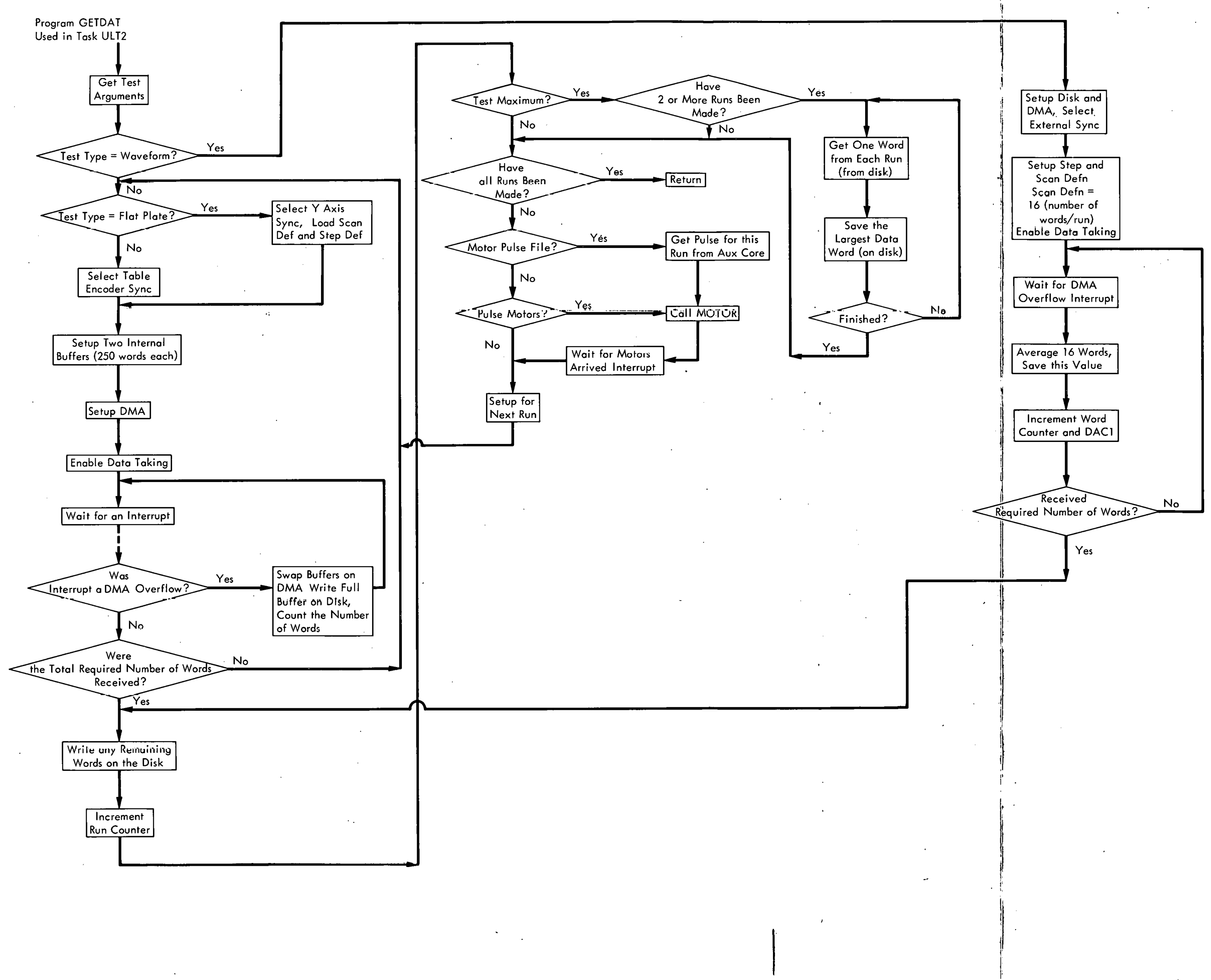




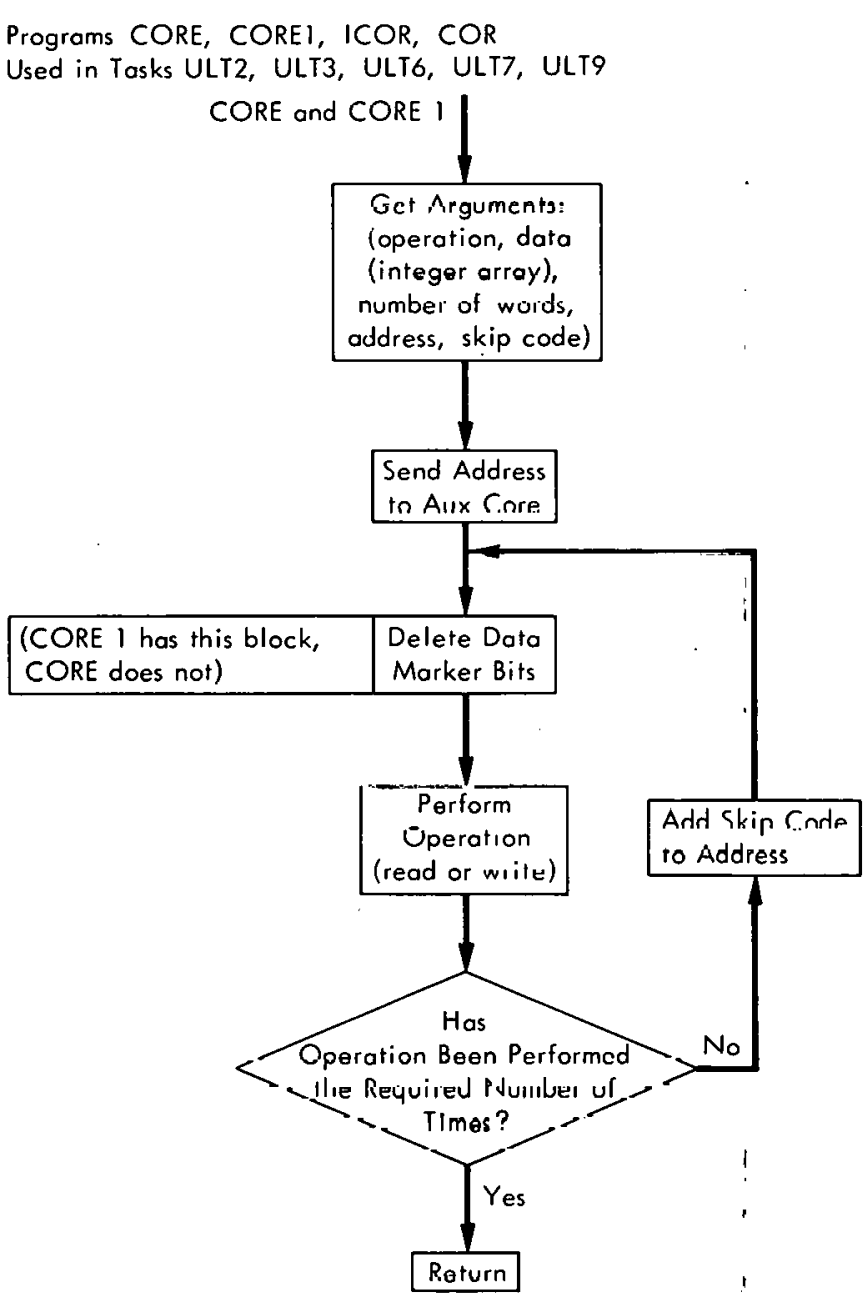

COR

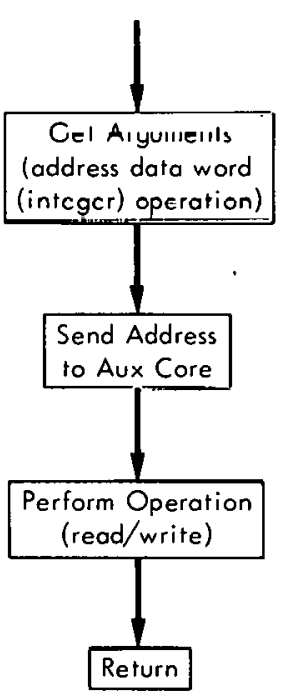

COR

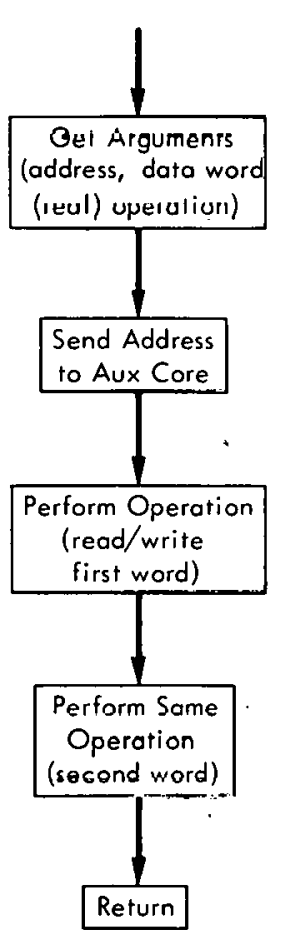




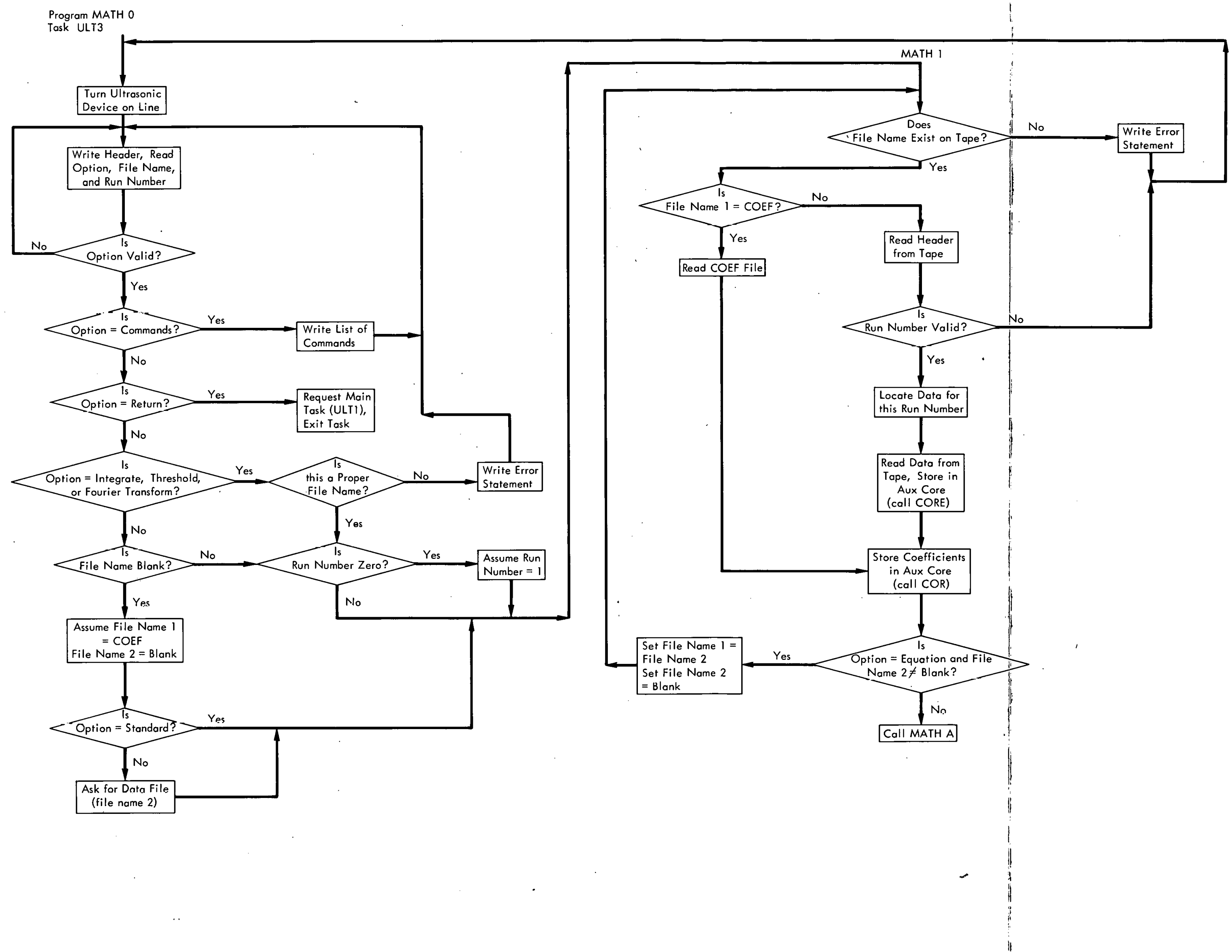




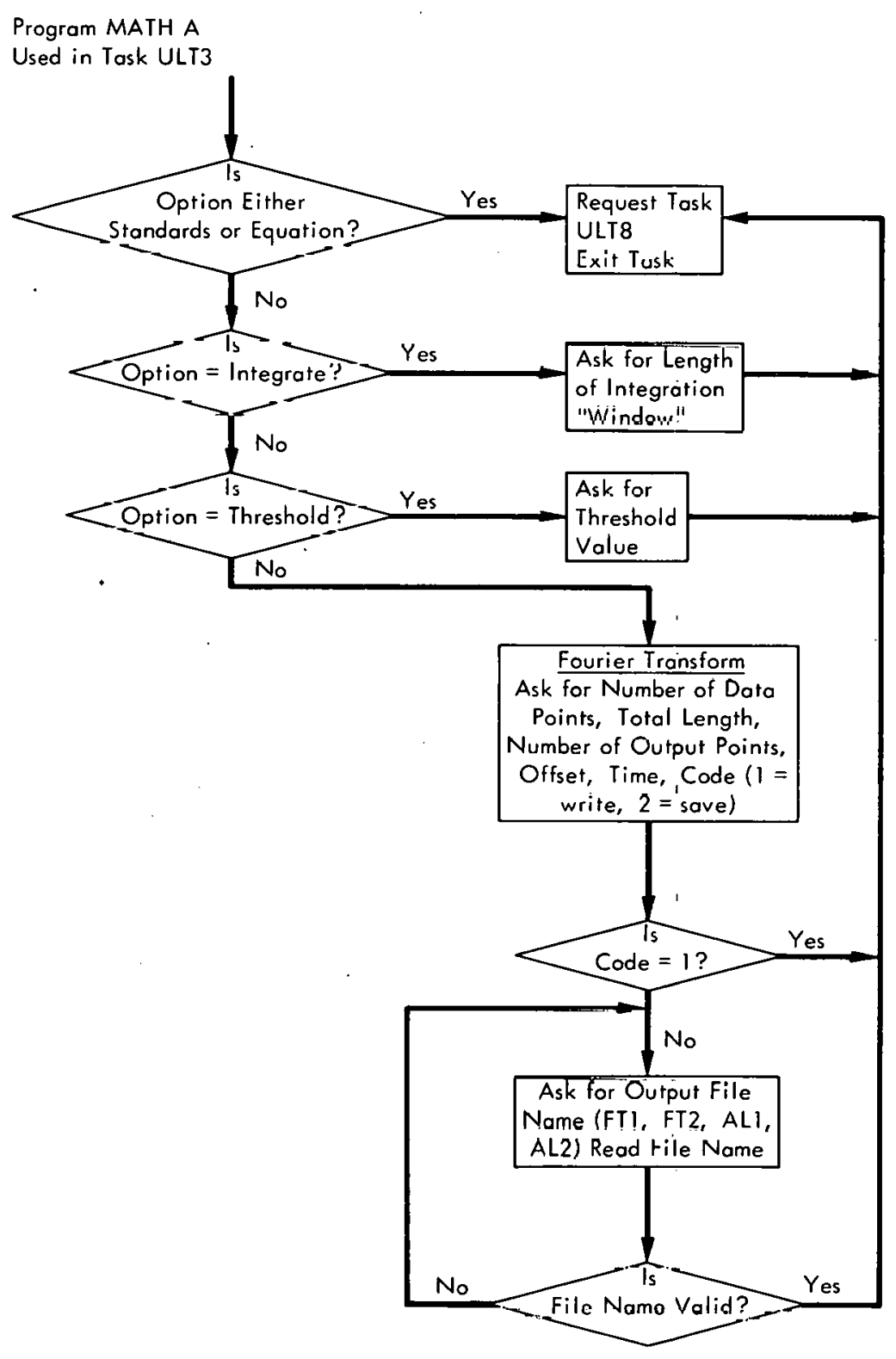

Program MATH 2

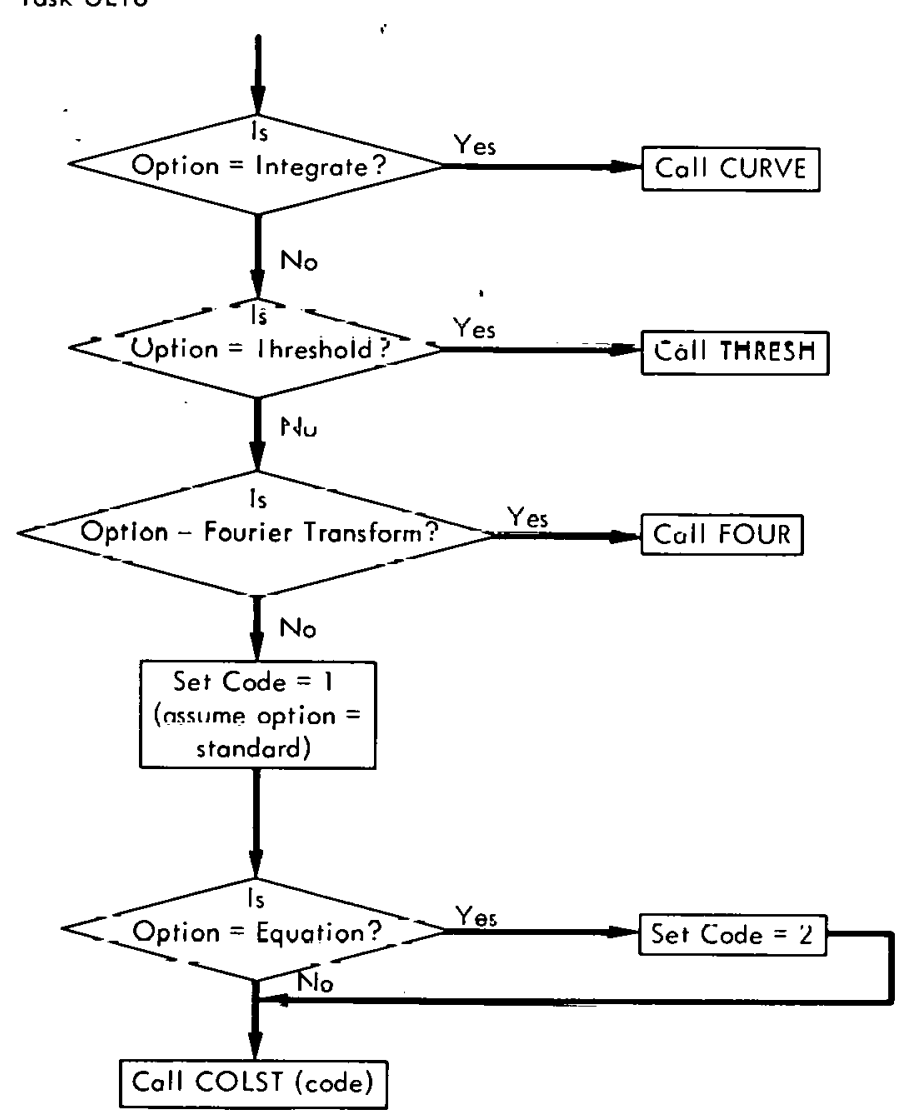


Program CURVE

Used in Task ULT8

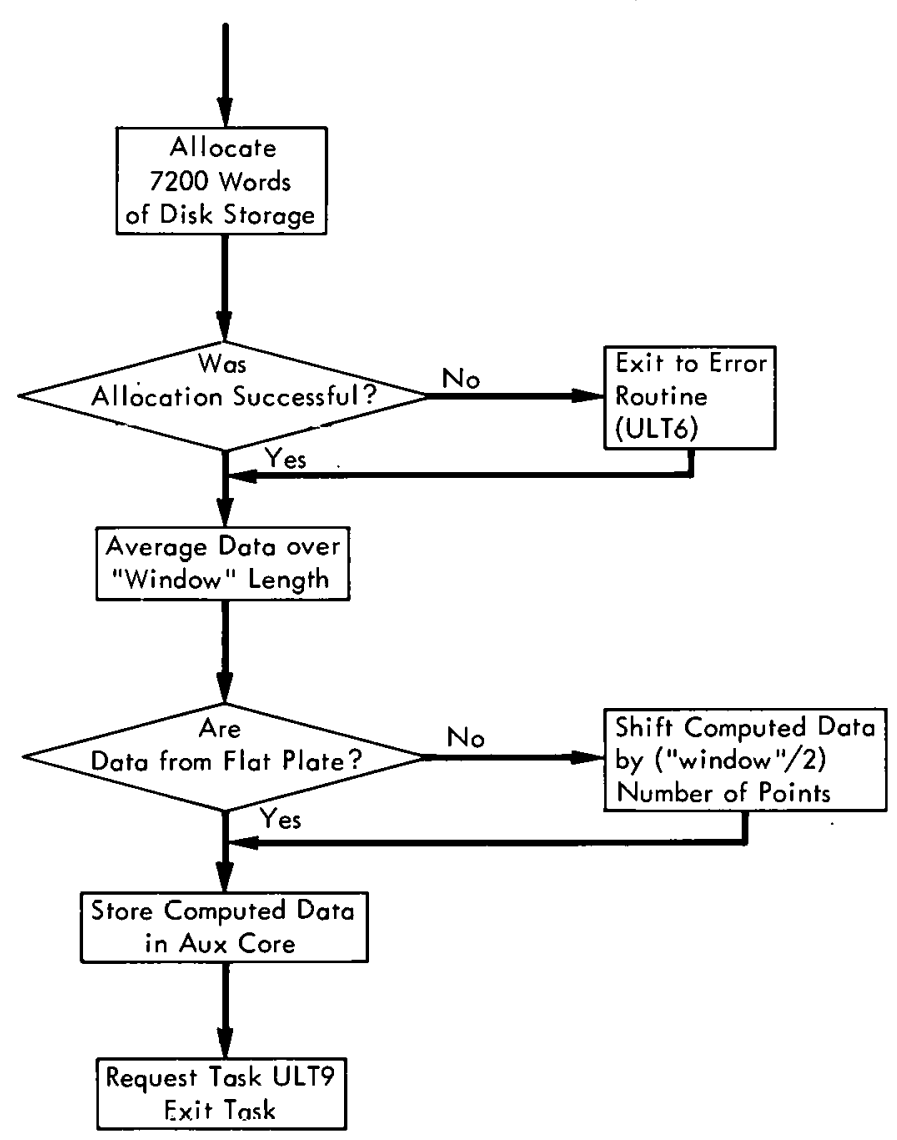

Program THRESH

Ssed in Tusk ULT8

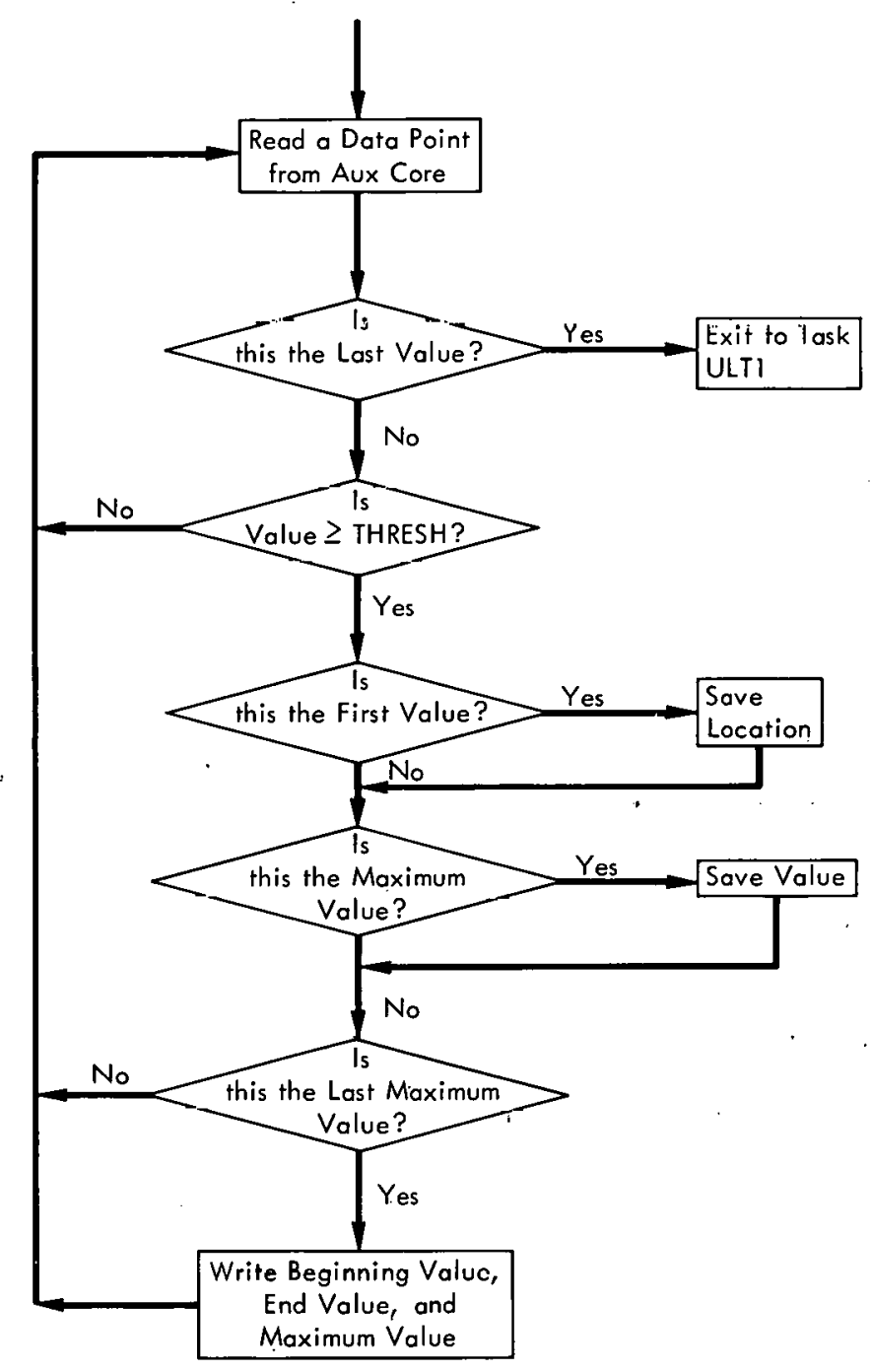

Program FOUR

Used in Task ULT

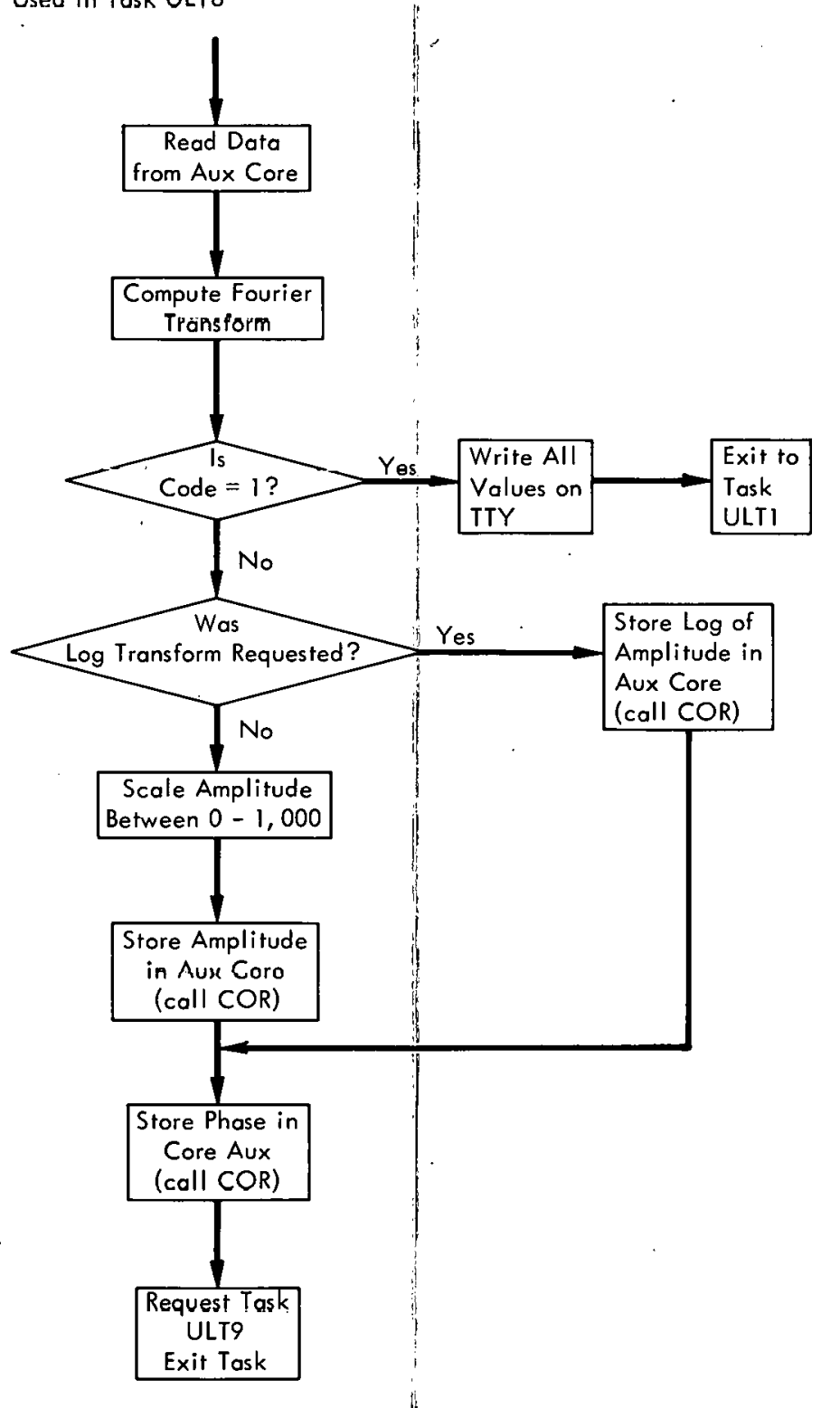




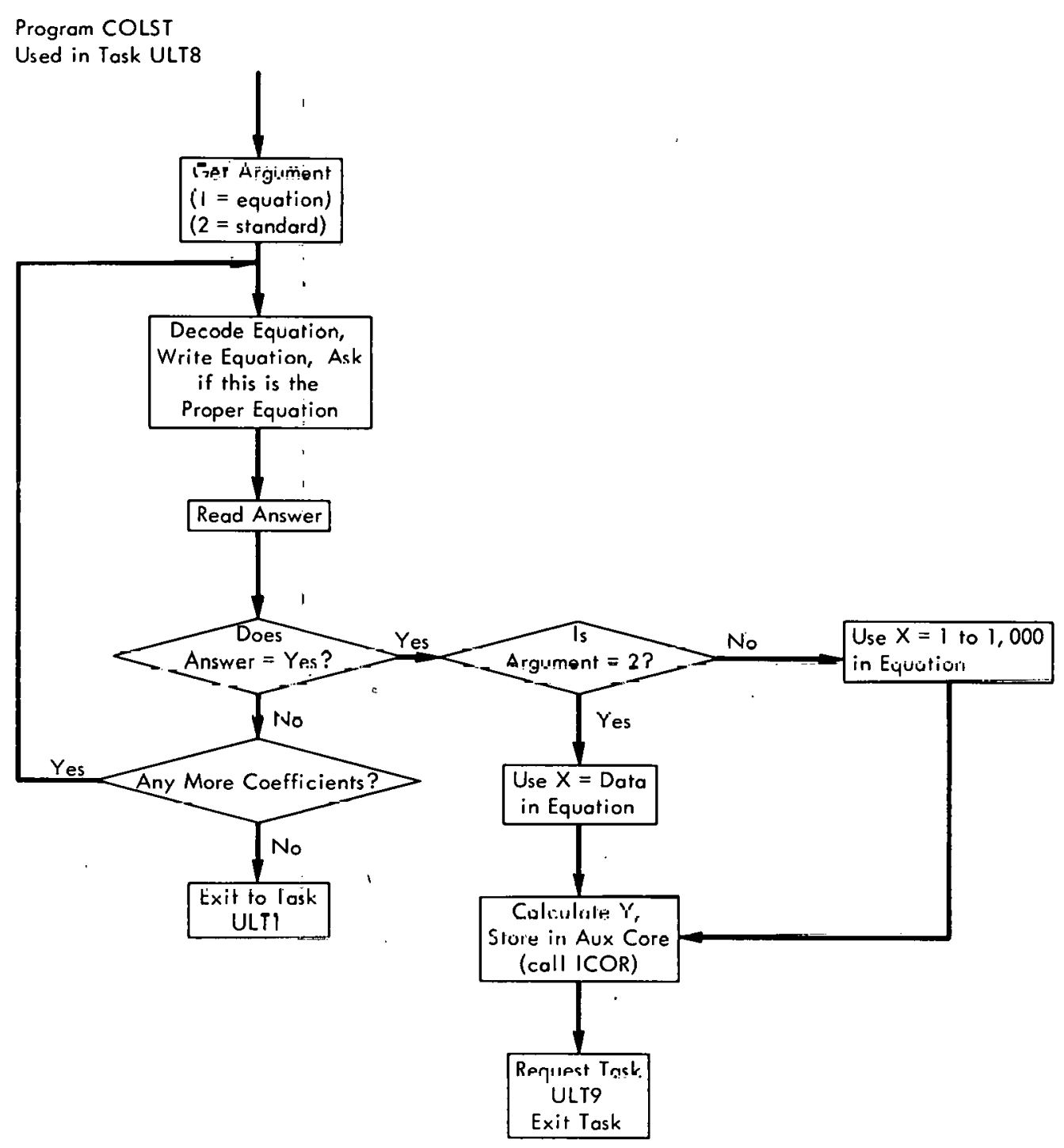


Program MATH 3

Task ULT9

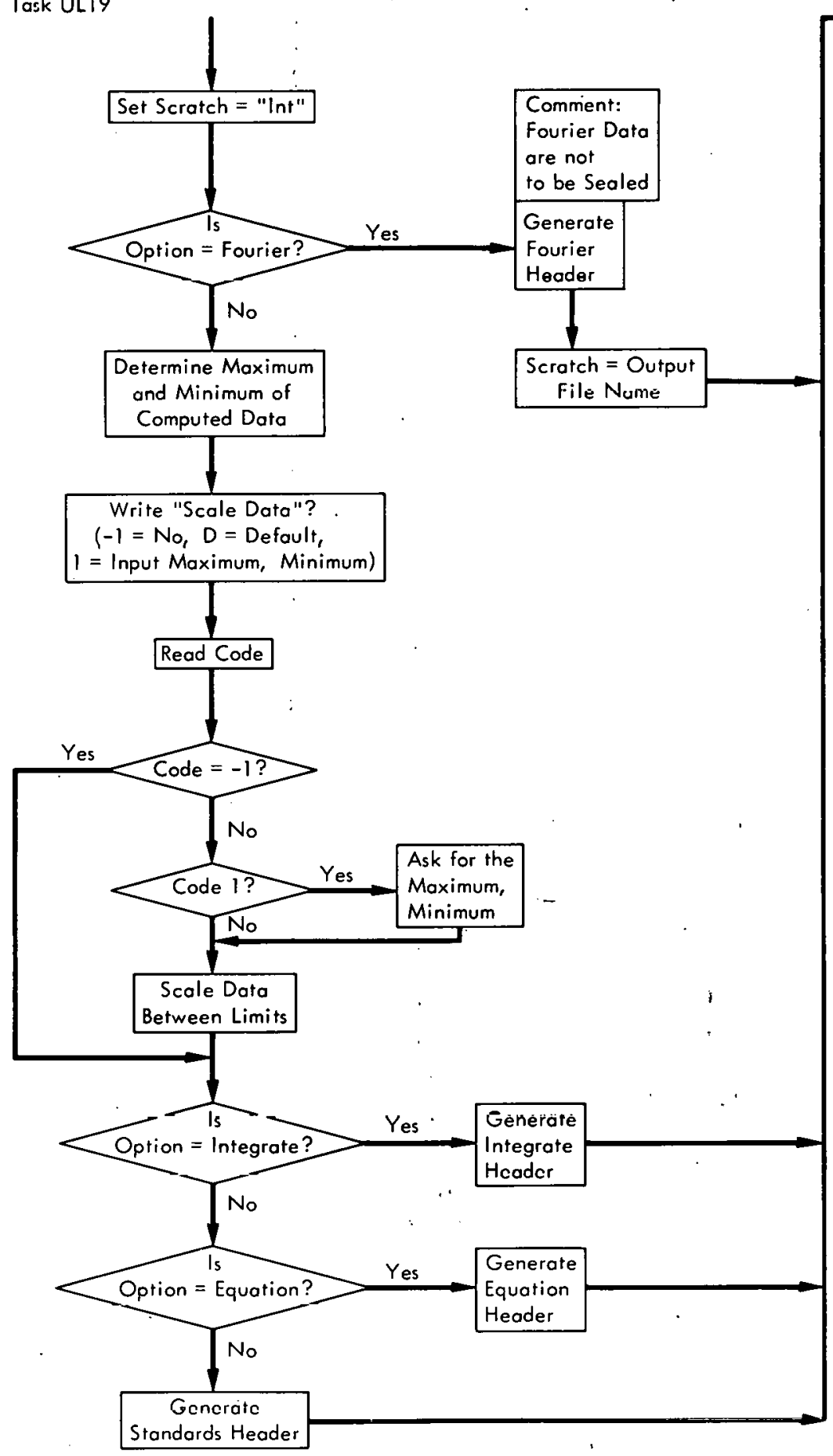

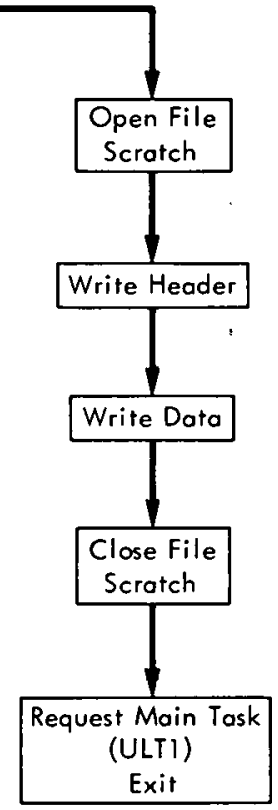




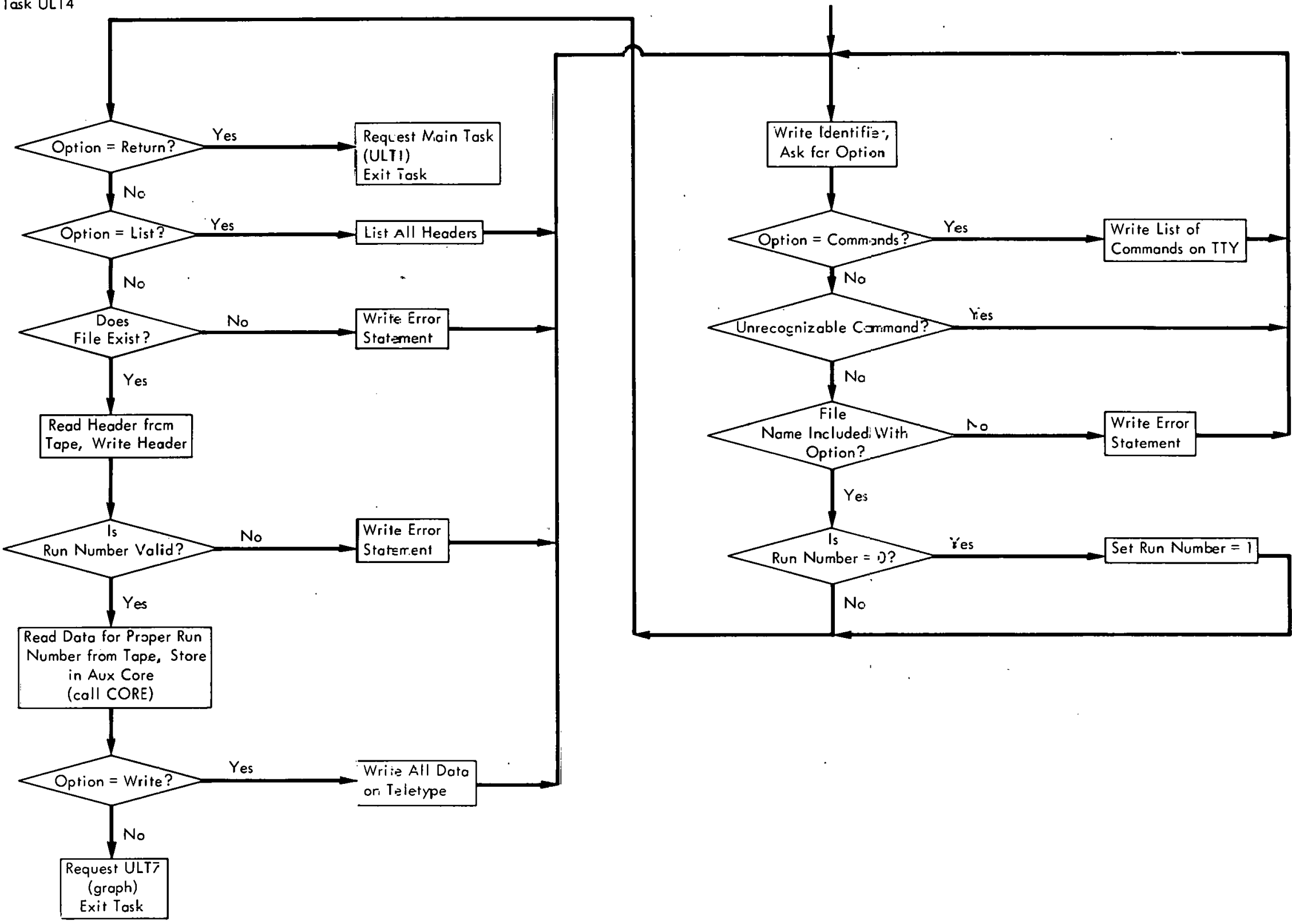




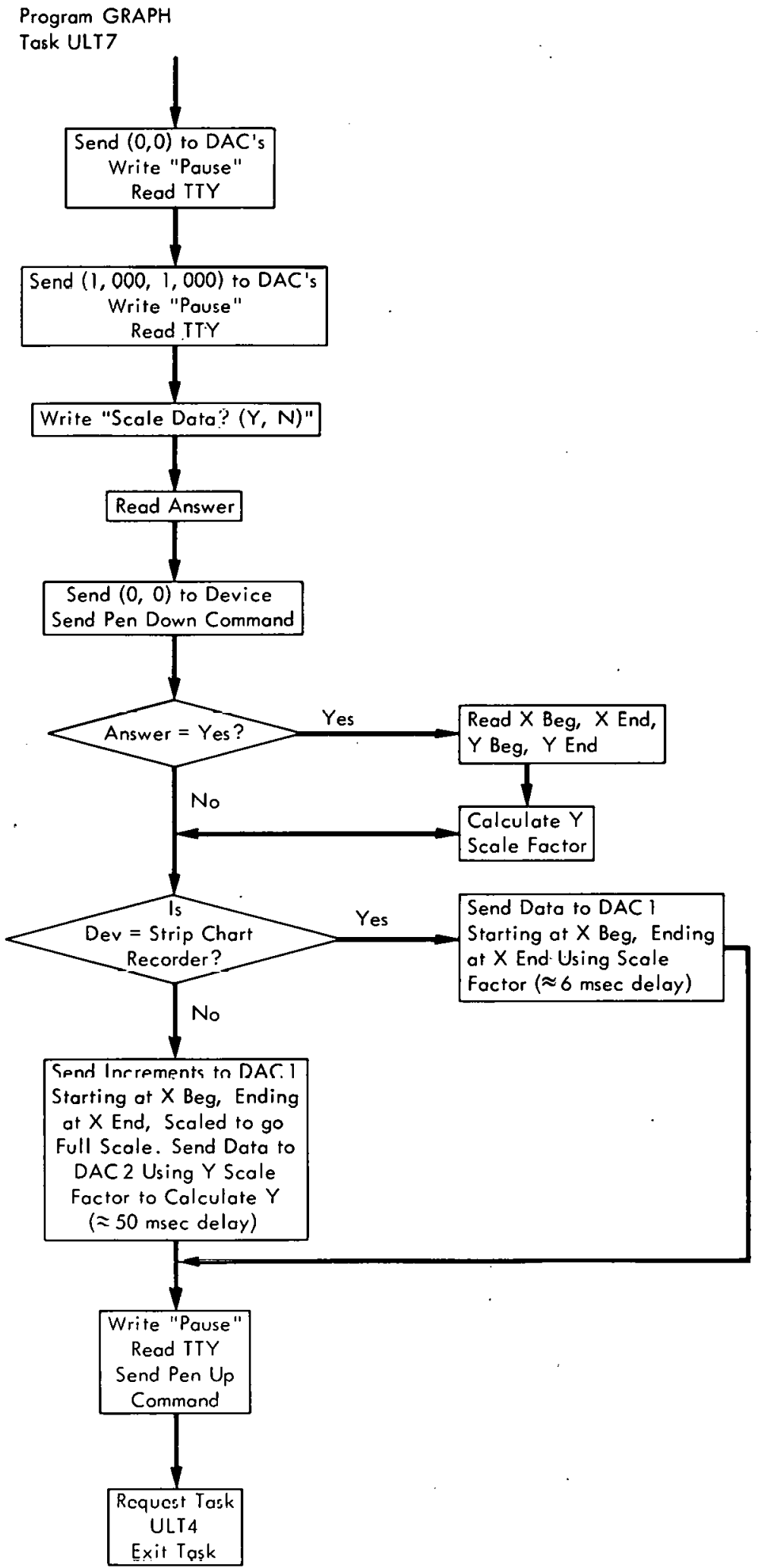




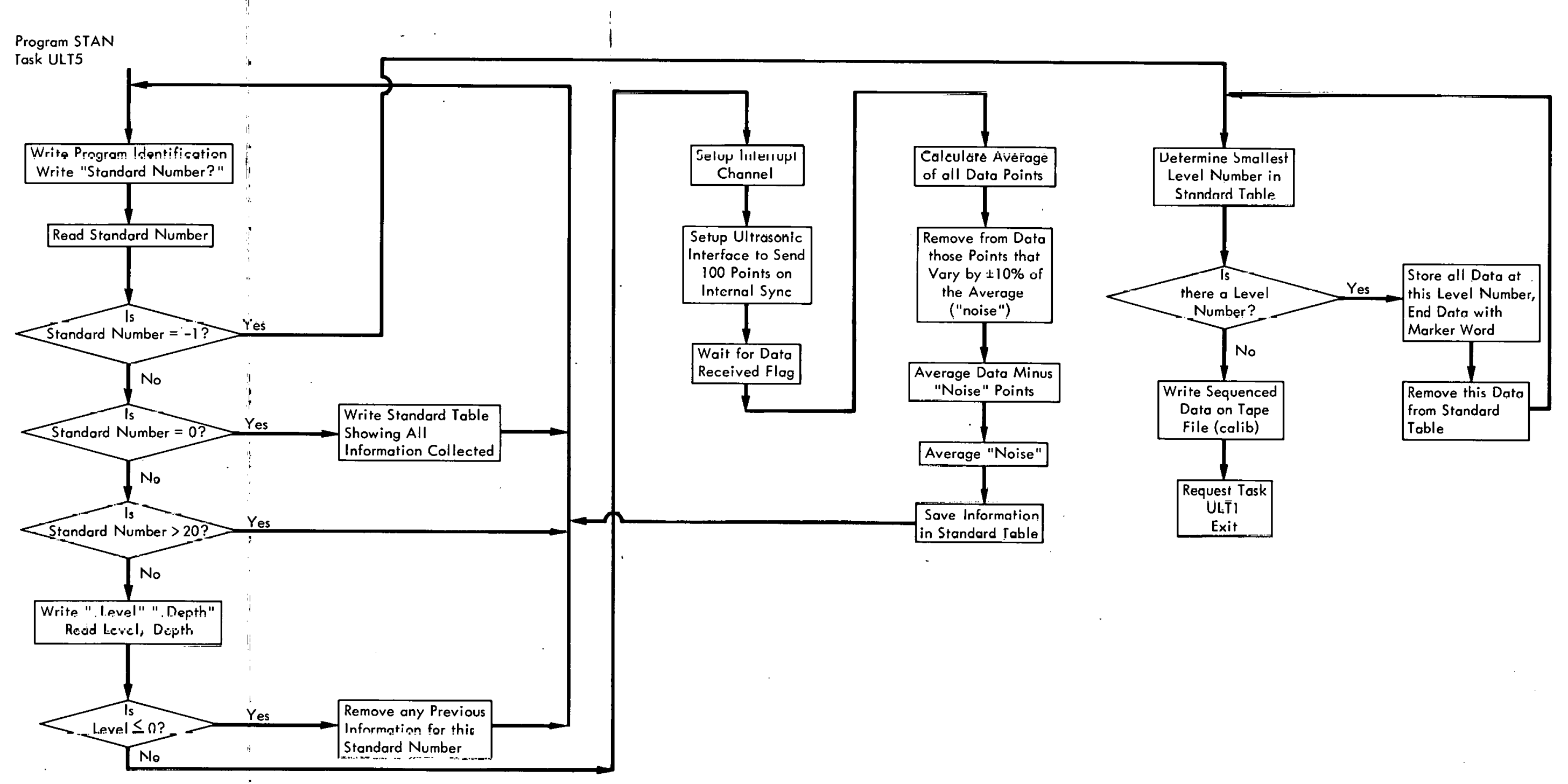


OPERATOR INSTRUCTIONS

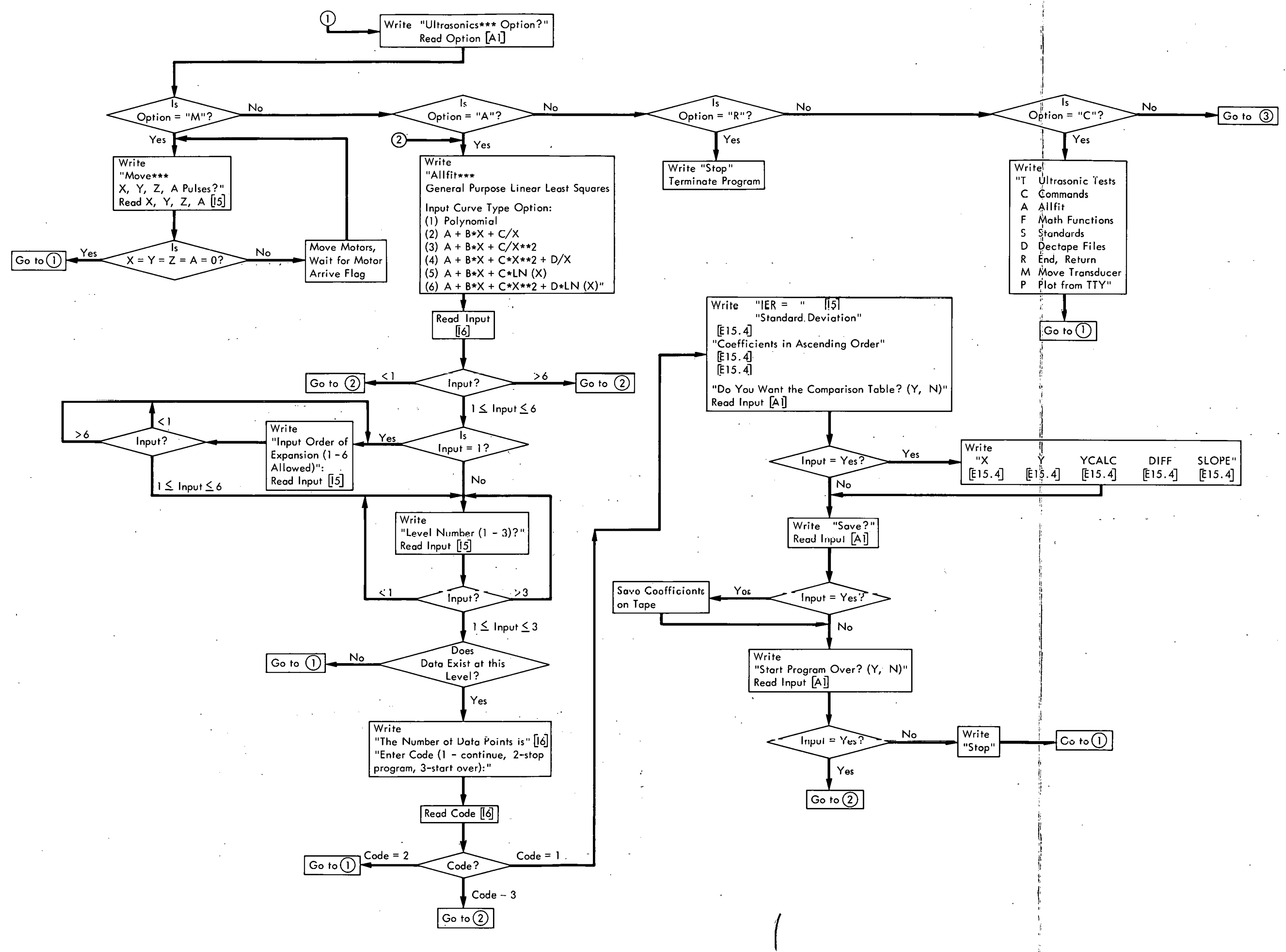




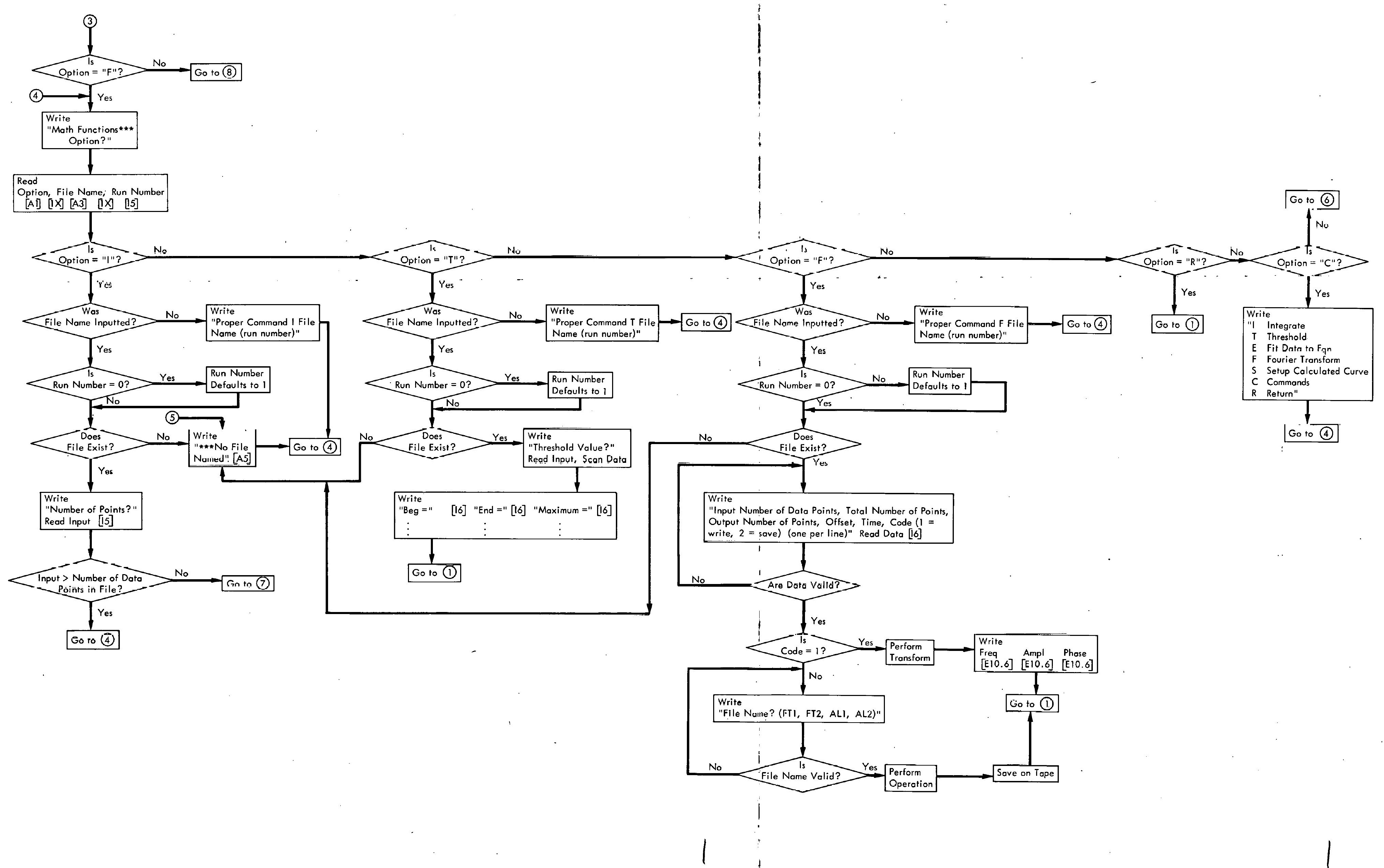



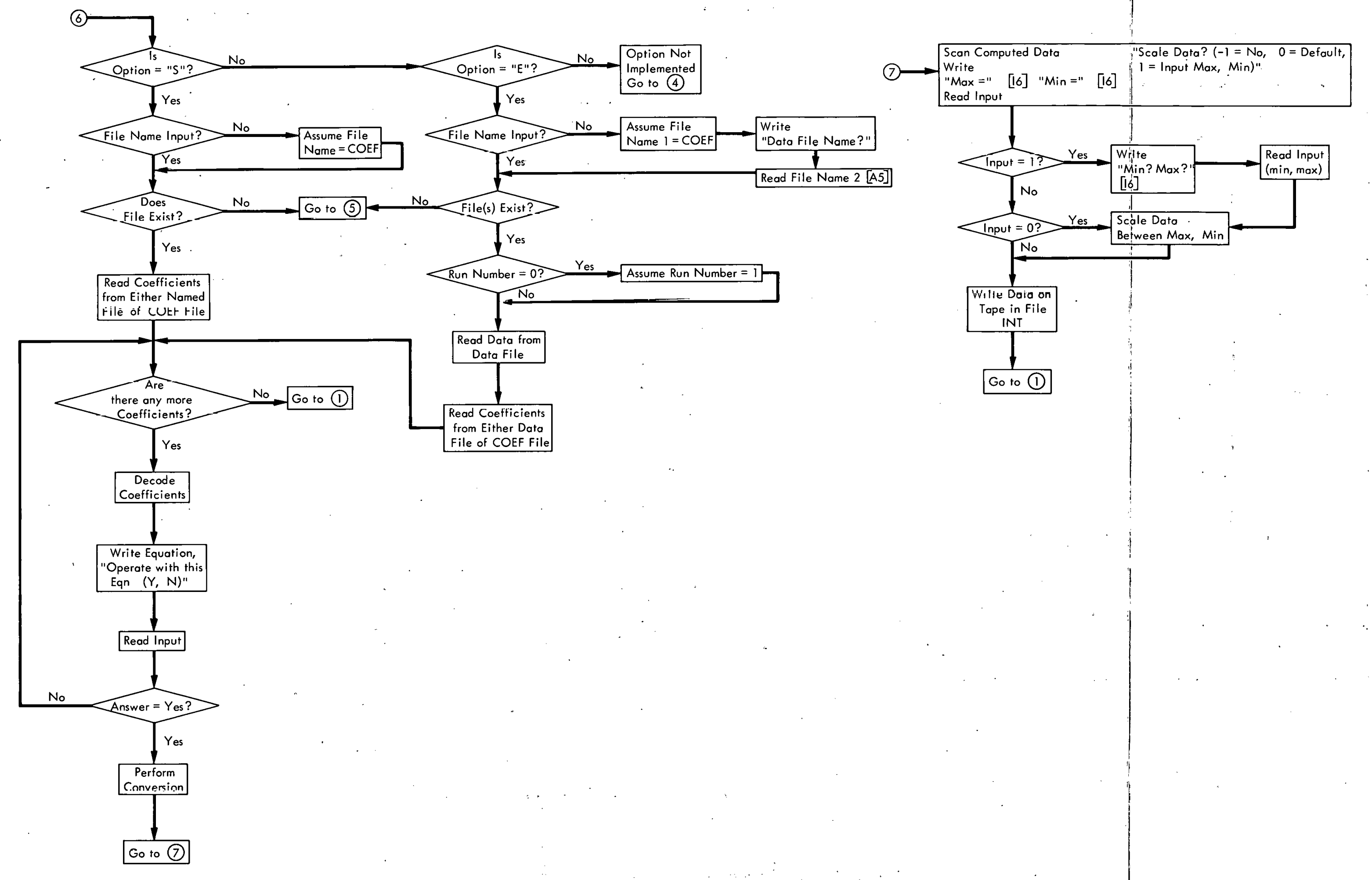


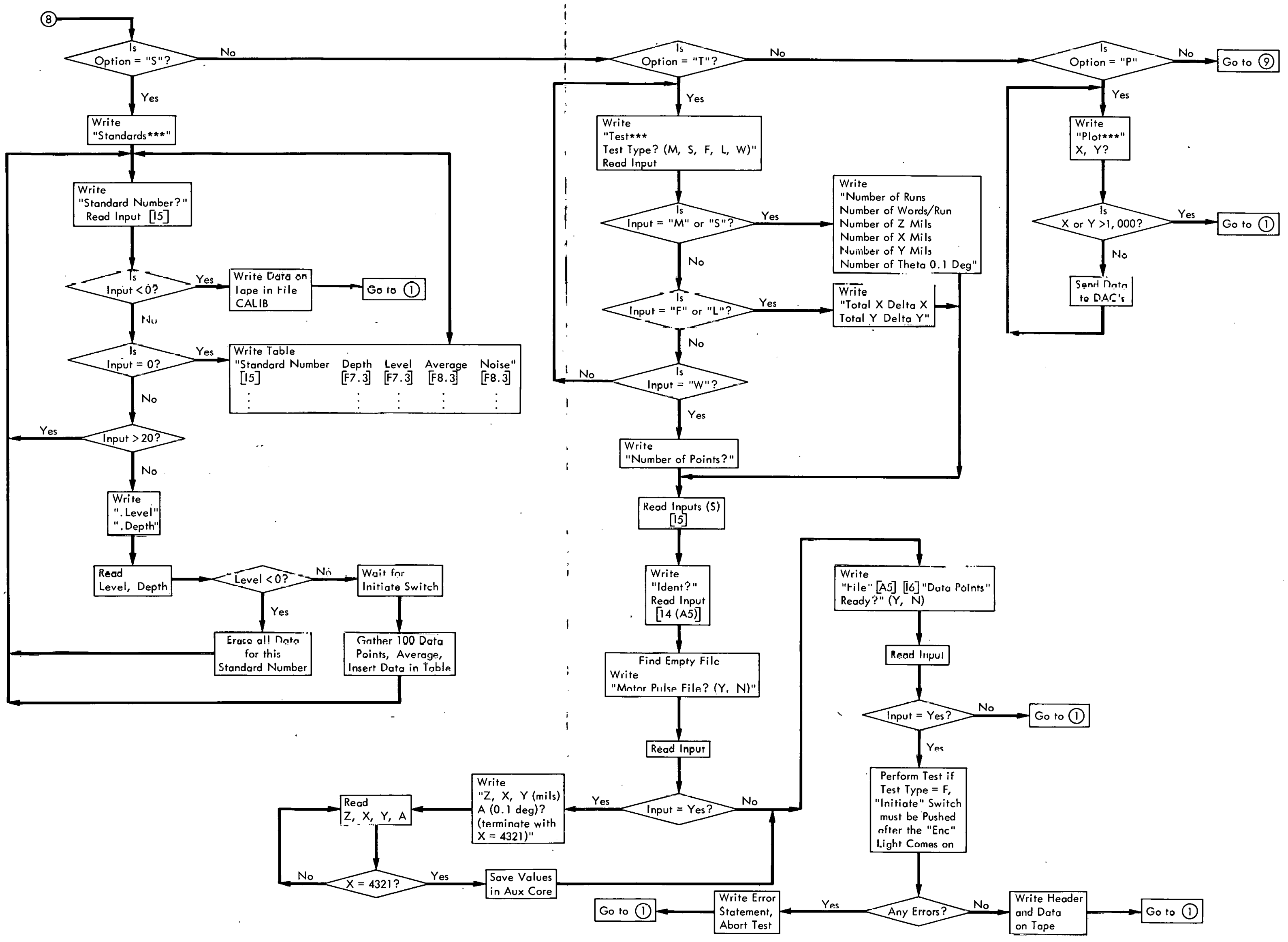




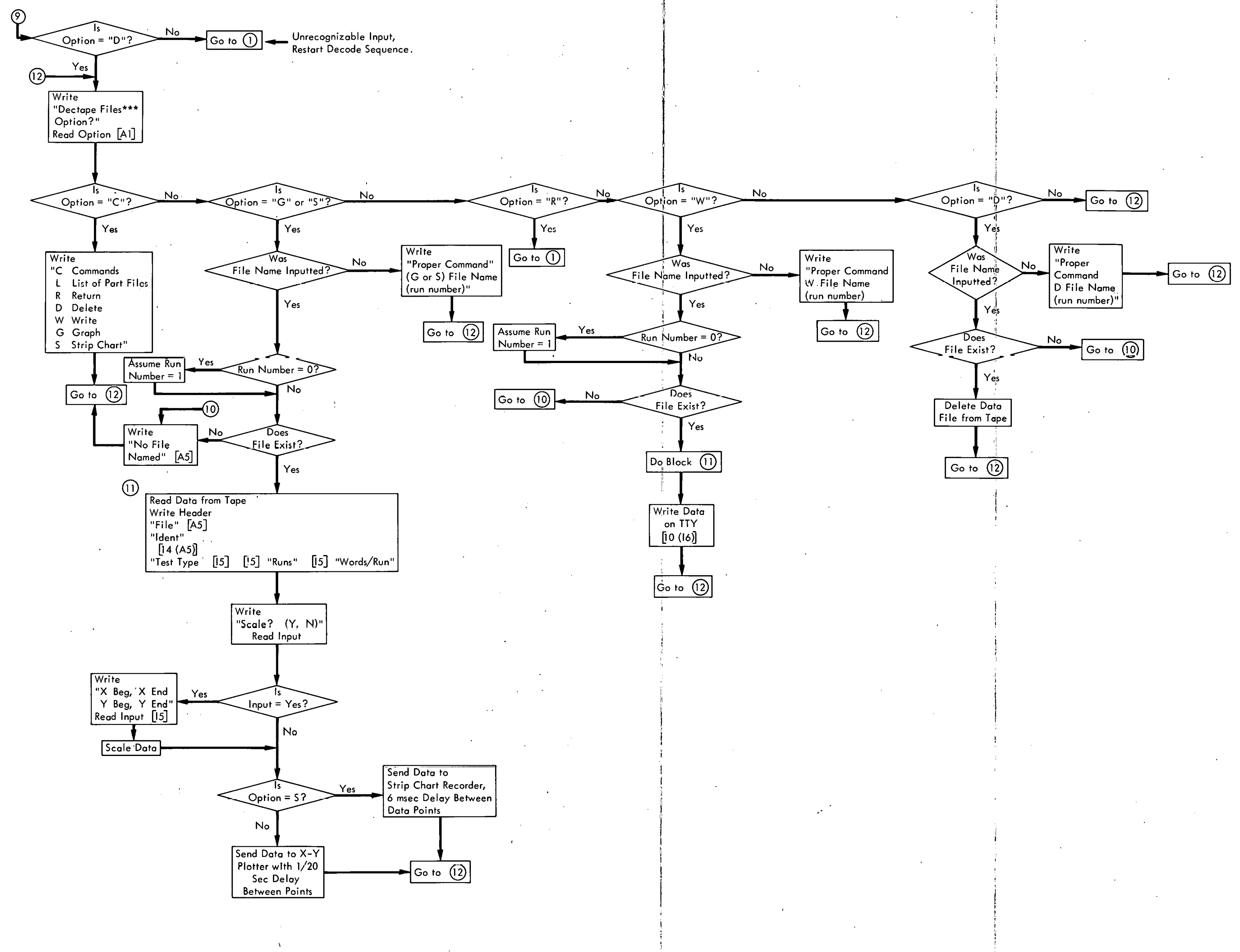




\section{DISTRIBUTION}

Atomic Energy Commission - ALO

Vespe, V. C.

Atomic Energy Commission - ORO

Hickman, H. D.

Zachry, D. S., Jr

Goodyear Atomic Corporation - Portsmouth

Ostroski, A. S.

\section{Lawrence Liverimơờe Làböràtōry}

Liptaı, H. G.

McFarland, G. C.

Technical Information Division

Los Alamos Scientific Laboratory

Baker, R. D.

Briscoe, W. L.

Elliott, D. E.

Oak Ridge Gaseous Diffusion Plant

Barton, J. C.

Blake, H. W.

McLaren, R. A.

Wilcox, W. J., Jr

Winkel, R. A.

Onk Ridge Natinnal Laboratory

Adams, R. K.

Borkowski, C. J.

McClung, R. W.

Oak Ridge Y-12 Plant

Alvey, H. E.

Bernander, N. K.

Briscoe, O.W.

Burditt, R. B.

Burkhart, L. E.
Darby, D. M.

Davenport, C. M. (2)

Denny, A. (2)

Dodson, W. H.

Ellingson, R. D.

Foulk, D. L.

Gray, D. H. (10)

Jackson, V. C.

Jones, F. W.

Kahl, K. G.

Keith, Alvin

Kite, H. T.

Lundin, $M, I$,

Marrow, G. B.

McLendon, J. D.

Mason, D. L.

Miskell, R. V.

Mitchel, G. W.

Moyer, M. W. (2)

Noey, J. L.

Oliphant, G. W.

Schneider, P. G.

Smith, J. H.

Smith, R. D.

Stephens, A. E. (2)

Stoner, H. H.

Weathersby, W. E.

Whitson, W. K.

Wright, C. C.

Yaggi, W. J.

$Y-12$ Central Files (5)

$Y-12$ Central Files (master copy)

$Y-12$ Central Files (rnute)

$Y-12$ Central riles $(Y-12 R C)$

Paducah Gaseous Diffusion Plant

Levin, R. W.

\section{Sandia-Albuquerque}

Ballard, D. W.

Mail Service Section 


\section{Sandia-Livermore}

Baker, A. E.

Library

Murphey, B. F.

In addition, this report is distributed in accordance with the category UC-37, Instruments, as given in the USAEC Standard nistrihution Lists for Unclassified Scientific and Technical Reports, TID-4500. 